\title{
Linguistic Complexity in Firm Disclosures: Obfuscation or Information?
}
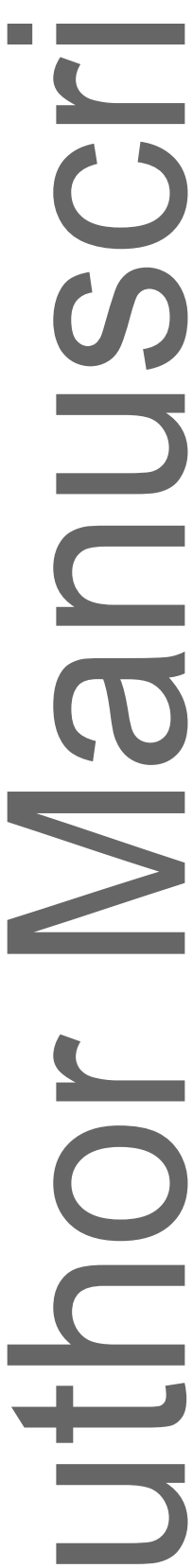

This is the ant manuscript accepted for publication and has undergone full peer review but has not been the wo tl copyediting, typesetting, pagination and proofreading process, which may lead to differences betrm this version and the Version of Record. Please cite this article as doi: 10.1111/1475-679X.12179.

This article is protected by copyright. All rights reserved. 


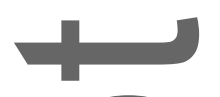

Accepted by Christian Leuz. We thank Lauren Cohen, Mirko Heinle, Feng Li, Tim Loughran, Rabih Moussawi, Luis Palacios, Eddie Riedl, Robert Verrecchia, Yuxing Yan, two anonymous reviewers, and seminar participants at Boston University, Cubist, Florida International, George Washington, UCIrvine, the University of Minnesota Empirical Accounting Conference, University of Toronto, and University of Zurich for useful discussions, comments, and programming advice. We gratefully acknowledge the financial support of the Harvard Business School and of the Wharton School.

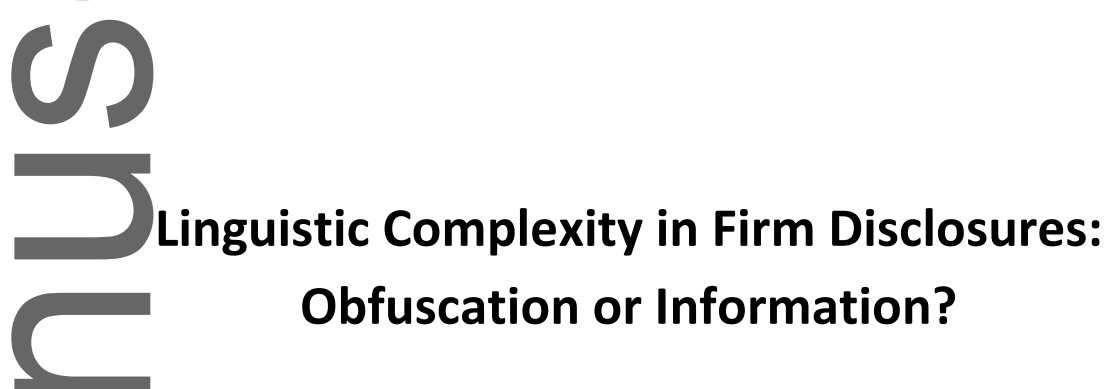

Abstract:

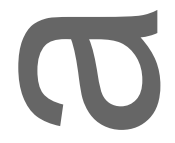

Prior research generally interprets complex language in firms' disclosures as indicative of managerial obfuscation. However, complex language can also reflect the provision of complex information, e.g., informative technical disclosure. As a consequence, linguistic complexity commingles two latent components-obfuscation and information - that are related to information asymmetry in opposite directions. We develop a novel empirical approach to estimate these two latent components within the context of quarterly earnings conference calls. We validate our estimates of these two latent components by examining their relation to information asymmetry. Consistent with our predictions, we find that our estimate of the information component is negatively associated with information asymmetry while our estimate of the obfuscation component is positively associated with information asymmetry. Our findings suggest that future research on linguistic complexity can construct more powerful tests by separately examining these two latent components of linguistic complexity.

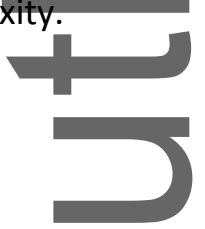

JEL Classification: D82; G14; G18; M41; M45

Keywords: Disclosure; Linguistic complexity; Conference calls; Information asymmetry;

This article is protected by copyright. All rights reserved. 


\section{Introduction}

An extensive prior literature examines the relation between the linguistic complexity of corporate disclosures and various firm outcomes. This literature generally interprets the use of complex language as an intentional choice by managers to obfuscate in order to increase information processing costs and delay the market reaction to news (e.g., Li [2008]). An alternative view is that complex language could be necessary to convey information about the firm's business transactions and operating strategy (e.g., Bloomfield [2008]). In reviewing the literature on linguistic complexity, Loughran and McDonald [2016] conclude, "researchers face the problem of separating the business and the document. These issues are intertwined because the document attempts to describe the economic reality of the business" (p. 1198).

In this paper, we show that linguistic complexity commingles two latent components that have opposite relations to information asymmetry: an "information" component and an "obfuscation" component. The information component represents linguistic complexity attributable to informative technical disclosure about the business. The obfuscation component represents linguistic complexity intended to reduce the informativeness of the disclosure. As a result of this commingling, the relation between overall linguistic complexity and information asymmetry is theoretically ambiguous. In contrast, we show that the relations between the two latent components of linguistic complexity and information asymmetry are theoretically unambiguous; i.e., the information (obfuscation) component is negatively (positively) associated with information asymmetry.

We develop an empirical approach to estimate the latent components of linguistic complexity within the context of quarterly earnings conference calls. The key to our approach is to identify the portion of the linguistic complexity that represents managers' appropriate disclosure 
response to business complexity in the absence of obfuscation. We exploit the fact that conference calls allow us to observe the linguistic complexity of an outside party-security analysts-in the same setting as the manager's linguistic complexity. Prior research finds that analysts have incentives to acquire and convey value-relevant information (Mayew [2008], Twedt and Rees [2012]), suggesting that they are unlikely to have obfuscation incentives during the call. As such, we use analysts' linguistic complexity as a benchmark for estimating the two latent components. We then validate our approach by examining the relation between our estimates of the two latent components and information asymmetry.

We first follow prior work and examine the association between overall managerial linguistic complexity and information asymmetry. Following an extensive prior literature, we measure linguistic complexity using the Gunning [1952] Fog index and information asymmetry using the Amihud [1992] measure of illiquidity. As conference calls include both scripted presentations and more spontaneous responses to questions, we separately examine the presentation and the response portions of the call. Consistent with prior work that suggests the linguistic complexity of 10-Ks reflects obfuscation, we find a positive relation between managerial Fog in the presentation and information asymmetry. However, we find a negative relation between managerial Fog in the response and information asymmetry. While these results suggest the informativeness of linguistic complexity differs between scripted and spontaneous language, our analysis of the latent components suggests a more nuanced conclusion.

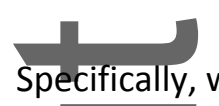
Specifically, when we decompose linguistic complexity into its two latent components, we find a negative (positive) relation between the estimated information (obfuscation) component and information asymmetry. These findings are similar for both the presentation and response. These results illustrate that the relation between overall linguistic complexity and information asymmetry 
is ambiguous because complex language is driven by two components that have opposite relations to information asymmetry. In contrast, our decomposition shows that the relation between the components themselves and information asymmetry is unambiguous.

Finding that the two latent components have opposite relations with information

asymmetry should mitigate concerns that our estimates are biased in any one direction. For

example, if our estimate of the information component contains some obfuscation, it would bias the negative (positive) coefficient on the information (obfuscation) component upward (downward); and hence bias against finding opposite directional effects. While any empirical estimate of an unobserved latent variable will have some amount of noise and bias, our findings suggest that the (a) noise and bias is sufficiently mild that our estimates are empirical descriptive of the underlying theoretical constructs.

Our results are robust to a variety of sensitivity tests. First, the results hold (and in some cases become stronger) when we control for other language attributes, such as number of words, industry jargon, forward-looking statements, and tone. Second, the results are robust to controls for pre-call information asymmetry and to estimating a within-industry, within-firm, and withinmanager analysis, suggesting time-series variation in these components explains time-series variation in information asymmetry. Third, the results hold under three Monte Carlo placebo tests that use randomly selected non-event days, alternative conference call days, and language from another firm's conference call. Fourth, we further validate our measures by showing that the information (obfuscation) component is positively (negatively) associated with the likelihood that managers provide quantitative earnings guidance on the call, as would be expected if managers act consistently in their qualitative and quantitative voluntary disclosure decisions.

This article is protected by copyright. All rights reserved. 
Finally, we examine our decomposition for loss firms. Prior work finds that loss firms exhibit greater linguistic complexity in their 10-Ks and attributes this finding to managerial obfuscation of poor performance (Li [2008]). An alternative interpretation is that managers of loss firms provide more information to explain poor performance (Bloomfield [2008]). While it might be more satisfying to attribute the higher Fog of loss firms to either greater obfuscation or greater information, our results suggest both forces are present. We find that loss firms have significantly greater values of both information and obfuscation components during calls. Thus, controlling for obfuscation, managers of loss firms provide more information. However, managers of loss firms also obfuscate to a greater extent. Collectively, we find that identifying the latent obfuscation and information components of linguistic complexity provides more powerful tests of the relation between linguistic complexity and capital market outcomes.

Our paper contributes to the large stream of literature examines the linguistic complexity of corporate disclosures. Following Li [2008], most of the prior literature focuses on linguistic complexity in 10-K filings and interprets complex language as obfuscation (see Loughran and McDonald [2016] for a review). Recent papers by Guay, Samuels, and Taylor [2016] and Dyer, Lang, and Stice-Lawrence [2017] suggest that the linguistic complexity of 10-Ks could also be the result of accounting standards (e.g., FAS 133 and 157) and assume that regulatory-induced complexity results in less informative disclosures. By decomposing linguistic complexity into its latent information and obfuscation components, we show that complex language can result in more informative disclosure. This finding provides an important contrast to prior literature that assumes complex language necessarily renders disclosures less informative. Moreover, our finding that the latent components have countervailing effects on information asymmetry potentially explains the mixed empirical results that relate measures of overall linguistic complexity to measures of information content (e.g., Loughran and McDonald [2014]) and to fraudulent behavior (e.g., Hoberg and Lewis [2015]).

This article is protected by copyright. All rights reserved. 
We also provide a new empirical approach that future researchers can use to improve construct validity for other linguistic measures. Our conference call setting provides us with several advantages in this regard. First, the language on conference calls is less driven by regulation and accounting standards than that in mandatory SEC filings, which reflects considerable boilerplate language that usually does not vary from period to period. Thus, the language on conference calls is more likely to reflect an intentional disclosure choice by managers. This notion is in the spirit of the reporting incentives literature, which finds managers use discretion both to inform and to obfuscate (e.g., Leuz and Wysocki [2016]). Second, conference calls allow us to observe the linguistic complexity of security analysts, who are outside of the firm's financial reporting system and have little or no incentive to obfuscate in their language. Thus, analysts provide a benchmark level of linguistic complexity that is unique for a specific conference call. This approach is in contrast to prior work, which predominantly uses industry-level benchmarks to estimate firm-level discretionary reporting decisions (e.g., discretionary accruals) and suffers from an inability to cleanly separate reporting decisions from the firm's economic activity (e.g., Leuz and Wysocki [2016]; Loughran and McDonald [2016]). While our approach is also susceptible to the difficulty of separating economics and reporting decisions, finding opposite relations between the latent components and information asymmetry suggest that our estimates of these components are empirically descriptive.

The remainder of the paper proceeds as follows. Section 2 reviews the relevant prior literature. Section 3 describes our research design. Section 4 presents the sample and descriptive statistics. Section 5 presents our findings, and Section 6 concludes.

\section{Prior Literature}

Regulators have often expressed concern that the language in firms' disclosures has become increasingly complex (see Loughran and McDonald [2014]). To the extent that complex language

This article is protected by copyright. All rights reserved. 
increases information processing costs for investors, managers can use complex language to "obfuscate" the true nature of the firms' current and future performance (Li [2008]). Li [2008] uses the Gunning [1952] Fog Index to measure the "linguistic complexity" of firms' $10-\mathrm{K}$ filings. ${ }^{1}$ He finds that firms with higher 10-K Fog have lower current earnings performance and less persistent future earnings performance, consistent with managers using linguistic complexity to obfuscate poor performance.

Since Li [2008], a growing literature uses Fog to examine the relation between linguistic complexity of mandatory disclosures (e.g., 10-Qs or 10-Ks) and a variety of firm outcomes, such as investment efficiency, bid-ask spreads, delayed pricing of accounting information, voluntary disclosure, and short-sale constraints (see Loughran and McDonald [2016] for a review). Prior work also examines the relation between Fog and the decisions of external parties, such as trading of unsophisticated investors (Miller [2010]; Lawrence [2013]), analysts' outputs (Lehavy, Li, and Merkley [2012]; Bozanic and Thevenot [2015]), and disagreement among credit rating agencies (Bonsall and Miller [2017]). ${ }^{2}$

Despite the widespread use of the Fog index, there is an underlying concern about its construct validity because Fog potentially commingles informative text with uninformative text (see, e.g., Lang and Stice-Lawrence [2015]). Loughran and McDonald [2014] find mixed evidence on the relation between the Fog of 10-Ks and the information environment, but stronger evidence using electronic file size of 10-Ks. Bonsall, Leone, Miller, and Rennekamp [2017] suggest that file size

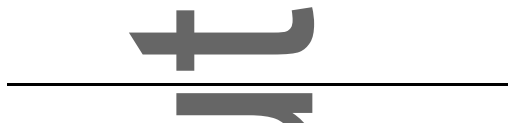

${ }^{1}$ Li [2008] uses "readability" and "linguistic complexity" interchangeably to describe the construct that Fog measures. Throughout the paper, we use the latter term because it applies to both spoken and written words. ${ }^{2}$ While the vast majority of studies focus on the Fog of firms' disclosures, examples of studies examining Fog of disclosures by external parties include De Franco et al. [2012], who examine the Fog of sell-side analyst reports, and Dougal et al. [2012], who examine the Fog of a firm's media coverage.

This article is protected by copyright. All rights reserved. 
results are driven by pictures and other graphical material that are unrelated to linguistic complexity. ${ }^{3}$ In a survey piece, Loughran and McDonald [2016] offer a skeptical view on the (

construct validity of the Fog index. Our goal is to show that the construct validity of linguistic complexity measures like Fog can be substantially improved by decomposing the measure into its latent components.

We focus on the use of complex language in conference calls, rather than in mandatory SEC filings. ${ }^{4}$ Conference calls are informative to market participants and lead to reductions in information asymmetry (e.g., Erankel, Johnson, and Skinner [1999]; Bowen, Davis, and Matsumoto [2002]; Brown, Hillegeist, and Lo [2004]). Recent papers by Brochet, Naranjo, and Yu [2014], Burgoon et al., [2014], Brochet, Loumioti, and Serafeim [2015], and Allee and DeAngelis [2015] use Fog to measure the linguistic complexity of conference calls, but their focus is mainly on Fog as a mechanism to obfuscate information through language barriers, short-termism, or incentives to reduce transparency.

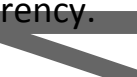

Conference calls also arguably provide stronger managerial incentives to obfuscate than the 10-K setting. Li [2008] argues the benefit of obfuscation is that "by increasing the processing cost of adverse information, managers hope that it is not reflected in stock prices or in prices with a delay" (p. 224). In a conference call, analysts and investors have 30-60 minutes of interactive discussion with managers on the earnings announcement date. The benefits of delaying the processing of adverse information in this setting are substantial: obfuscation could prevent follow-up questions on

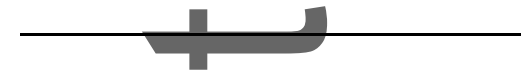

${ }^{3}$ Bonsall, et al. [2017] suggest an alternative proprietary measure developed by StyleWriter: the Bog Index. They note that the Bog Index takes grammatical features of written text into account that are omitted from the Fog index; e.g., passive voice. For this reason, it is less likely to be applicable to spoken language.

${ }^{4}$ Early ressearch suggests that "readability" measures, such as Fog and the Fleisch-Kinkaid index, also capture "listenability" (Allen [1952]; Harwood [1955], Fang [1967]). Notably, Harwood [1955] concludes that more "difficult" text was easier to comprehend when read than when heard.

This article is protected by copyright. All rights reserved. 
bad news and could delay market reaction to bad news until after the call, when there will be less focus on the company. Bushee, Matsumoto, and Miller [2003] report that there is high individual investor attention on the company during the call and that, prior to Reg FD, a commonly expressed reason for restricting individual investor access to calls was managers' concerns that they would overreact to information released during the call. Thus, the higher degree of timeliness and visibility of the conference call compared to the $10-\mathrm{K}$ release provide a powerful setting for examining obfuscation incentives. $^{5}$

\section{Research Design}

\subsection{THEORETICAL INFORMATION STRUCTURE}

We conjecture that a manager's linguistic complexity, denoted $L C$ _Manager, is determined by two forces. First, linguistic complexity is related to the intrinsic amount of informative technical disclosure that would be provided on the conference call by a benevolent manager; i.e., the information content of manager's language in the absence of obfuscation (e.g., Bloomfield [2008]). We denote this component as Info ${ }^{*}$, where ${ }^{*}$ indicates an unobservable variable. Second, complex language can also result from intentional obfuscation, or an intentional reduction in informative language (e.g., Li [2008]), which we denote Obfu ${ }^{*}$. Formally, we represent managerial linguistic complexity as:

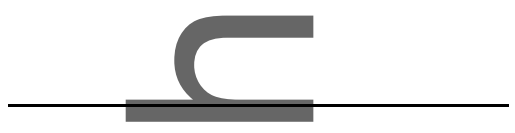

\footnotetext{
${ }^{5}$ The notion that obfuscation incentives are present in conference calls is not unique to our paper. For example, Larcker andiZakolyukina [2012, p. 499] state: "In contrast to prior studies on deception which use the text in written disclosures such as $10-\mathrm{Ks}$, we use arguably more spontaneous disclosures of conference calls. There are a number of limitations to using formal disclosures such as 10-Ks and 10-Qs in deception studies. First, formal disclostres are more scripted and prior research has shown that their content does not change much overtime. Second, the different parts of the reports are written and edited by different individuals and these individuals are unlikely to be executives. Finally, these disclosures lack spontaneity that characterizes conference calls."
}

This article is protected by copyright. All rights reserved. 
$L C \_$Manager $=\varphi_{0}+\varphi_{1} \operatorname{Info}^{*}+\varphi_{2} O b f u^{*}+\varepsilon$

$(1)$

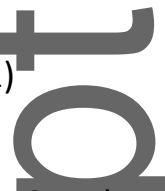

where $\varphi_{1}>0$ and $\varphi_{2}>0$.

(1)

The notion that managerial linguistic complexity is increasing in the intrinsic amount of technical information provided on a conference call (i.e., $\varphi_{1}>0$ ) is supported by prior evidence that long sentences and complex words-two inputs to common measures of linguistic complexity-do not necessarily indicate obfuscation. First, complex words are commonly used in financial contexts to convey informative technical details without any loss of comprehension. As Loughran and McDonald [2014] point out, "One of the longest words occurring with reasonable frequency in 10-Ks is 'telecommunications', a word not likely to force most readers to consult their dictionaries" ( $p$. 1645). Second, longer sentences can convey more information because they better show the relationships among various topics than short sentences (Redish and Selzer [1985]). ${ }^{6}$ Thus, in the absence of obfuscation incentives, it is reasonable to assume that longer sentences or complex words are necessary for better comprehension in certain firms or in certain settings.

We seek to recover empirical estimates of the latent variables, Info ${ }^{*}$ and $O b f u^{*}$. Using conference calls, we can observe the linguistic complexity of an external party-security analysts-in the same disclosure setting as managers' linguistic complexity. Prior research suggests analysts have incentives to acquire and convey value-relevant information during conference calls (Mayew [2008],

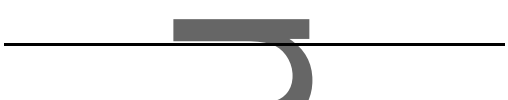

${ }^{6}$ For example, Charrow and Charrow [1979] find that adding more words to highlight the relationships among information items in jury instructions leads to a decrease in readability scores (due to the longer sentences) but an increase in comprehension by jurors. Long sentences also often represent changes in "discourse plans," where something the speaker says triggers related thoughts, causing the speaker to keep going with the sentence to add the additional information (Deese [1978]).

This article is protected by copyright. All rights reserved. 
Mayew, Sharp, and Venkatachalam [2012], Matsumoto, Pronk, and Roelofsen [2011], Twedt and Rees [2012]). While managers may seek to obfuscate information provided on the call, analysts should not seek to do so. Accordingly, we assume that the analyst's linguistic complexity on the call, which we represent as $L C \_$Analyst, reflects only the intrinsic amount of informative technical disclosure on the call. Formally,

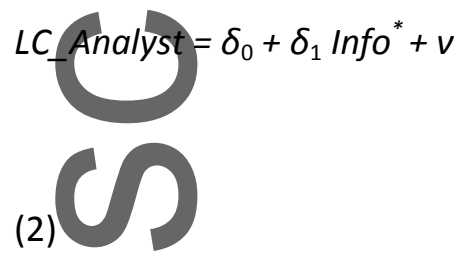

where $\delta_{1}>0$. We expect $\delta_{1}>0$ for the reasons cited earlier: complex words and longer sentences can increase comprehension and information content in a business context (Deese [1978], Charrow and Charrow [1979], Redish and Selzer [1985], Loughran and McDonald [2014]). Under the identifying assumption that analysts' linguistic complexity does not reflect intentional obfuscation, we can use the linguistic complexity of analysts on the call as a benchmark level of complexity that one would expect in the absence of obfuscation.

In particular, Appendix A shows that we can recover estimates of Info ${ }^{*}$ and $O b f u^{*}$ from a regression of LC_Manager on LC_Analyst,

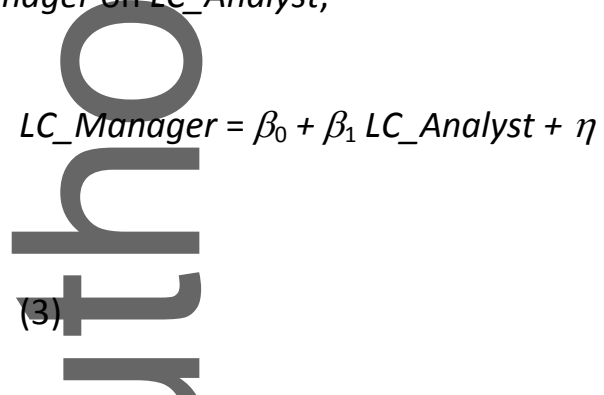

where the fitted value is an estimate of the latent information component (Info) and the residual is an estimate of the latent obfuscation component (Obfu).

This article is protected by copyright. All rights reserved. 
To validate that our estimates of the two latent components measure the respective theoretical constructs, we rely on economic theory that suggests obfuscatory (informative) disclosure is associated with greater (lower) information asymmetry between shareholders and managers, InfoAsym (e.g., Bloomfield [2002]). Formally we assume,

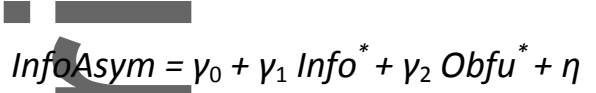

(4)

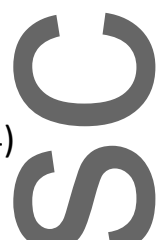

where $\gamma_{2}>0$ and $\gamma_{1}<0$. Note that equation (4) expresses information asymmetry as a function of the unobserved latent components of linguistic complexity. Appendix A shows that we can test for construct validity by replacing the unobservable latent components in (4) with our empirical measures of these components and estimating:

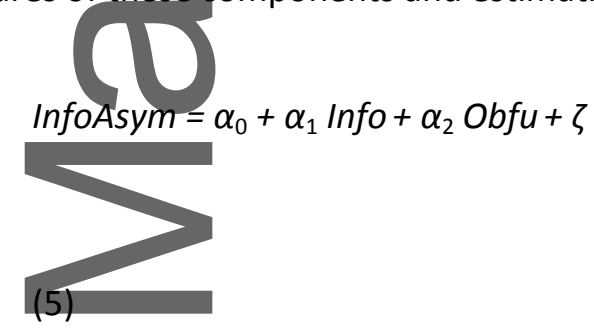

Appendix A solves for the coefficients $\alpha_{1}$ and $\alpha_{2}$ in equation (5) under the assumed information structure and shows: (i) that the coefficient on our measure of the information component, $\alpha_{1}$, is predicted to be negative regardless of the magnitude of measurement error in our empirical measures, and (ii) that the coefficient on our measure of the obfuscation component, $\alpha_{2}$, is predicted to be positive so long as measurement error is not too large.

An important feature of our empirical validation test is that, while $L C$ C Complexity is increasing in both latent components, the two components affect InfoAsym in opposite directions (see Figure 1). Hence, if our decomposition is empirically descriptive, we expect to decompose a 
single variable — whose relation to information asymmetry is ambiguous - into two separate components, one that is positively related to information asymmetry and one that is negatively

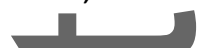

related to information asymmetry. Finding that the two latent components of $L C_{-}$Manager have opposite signs validates our identification strategy.

Appendix A also examines the robustness of our identification strategy to a violation of our key identifying assumption; i.e., the linguistic complexity of analysts does not reflect intentional obfuscation. We show that when the linguistic complexity of analysts is also influenced by obfuscation (i.e., a setting where $L C \_$Analyst is also a function of $O b f u^{*}$ ), the coefficient on Info $(O b f u)$ in equation (5) will be biased upward (downward). The intuition for this result is that the predicted value, Info, would commingle both information and obfuscation, as would the residual value, Obfu. Because information and obfuscation have opposite effects on information asymmetry, the coefficients will be biased toward zero. Hence, this would bias against finding $\alpha_{1}<0$ and $\alpha_{2}>0$. Our empirical results suggest that such effects are not large enough to invalidate our estimates.

\subsection{EMPIRICALESTIMATION OF EQUATION (3)}

We estimate equation (3) using the Gunning [1952] Fog index to measure linguistic complexity. The Fog index is a function of the number of words per sentence and the percent of complex words (i.e., words with more than two syllables):

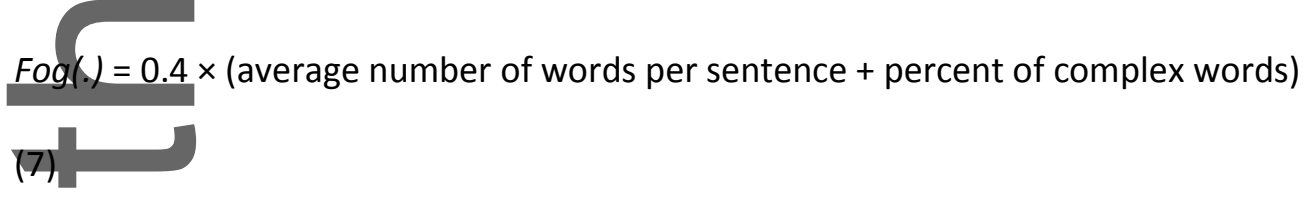

To calculate average words per sentence, we deviate from prior literature that follows Li [2008] and uses the Lingur: EN::Fathom Perl routine to calculate Fog. The Fathom routine can understate the amount of Fog in numerically intensive text because, among other issues, it mistakes decimal points 
for periods. We use the Lingua::EN::Sentence Perl routine that better identifies sentence breaks (see Appendix B for details).

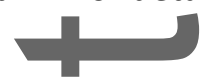

Lower values of Fog(.) correspond to less complex text. Taken literally, the Fog index is intended to measure the hypothetical years of formal education necessary to comprehend the

r

material. For example, a Fog index of 12 indicates formal education at the level of a high school senior (i.e., 12th grade), while a Fog index of 16 indicates college education.

We measure managerial Fog separately for the presentation and Q\&A portions of the call. Fog(Present) represents the Fog index of managers' language during the presentation, and Fog(Response) is the Fog of managers' responses to questions. We measure analyst Fog, Fog(Analyst), using the analysts' questions and statements during the Q\&A portion of the call.

In estimating equation (3), we include a number of variables related to the economic complexity of the firm and its transactions that might not be evident in analysts' language (e.g., Barth, Kasznik, and McNichols [2001]; Chen, Cheng, and Lo [2010]). For example, prior work suggests that managers of complex firms provide more information on conference calls (e.g., Tasker [1998]) and more voluntary disclosure (e.g., Guay, et al., [2016]). Thus, while business complexity on its own should be positively associated with information asymmetry, the appropriate managerial disclosure response to such complexity (i.e., provision of additional information) should be negatively associated with information asymmetry.

One challenge in measuring business complexity is that variables that proxy for business complexity could also reflect reporting incentives (Leuz and Wysocki [2016]). Thus, we attempt to choose variables that would explain cross-sectional variation in business complexity in the absence of reporting or obfuscation incentives. Moreover, any obfuscation incentives captured by this set of variables would likely be conditional on firm performance (e.g., earnings surprise), which we control 
for in our information asymmetry tests. ${ }^{7}$ The complexity variables we use are firm size (Size); firm leverage (Leverage); book-to-market ratio (BM); historical stock performance (Returns); acquisitions (Acquisitions), capital intensity (Caplntensity), capital expenditures (Capex), research and development (R\&D); debt and equity issuance (Financing); cash flow volatility ( $\sigma C F O)$; goodwill impairments (Goodwill) and restructuring charges (Restructuring) (see, e.g., Barth, Kasznik, and McNichols [2001]; Chen, Cheng, and Lo [2010]).

While no firm characteristic will perfectly capture only complexity or only reporting incentives, our information asymmetry validation tests will indicate whether measurement error or bias in these variables is large enough to invalidate the decomposition. Regardless, in subsequent analyses, we show that these controls are not necessary to obtain valid estimates of the two latent components.

3.3 EMPIRICAL ESTIMATION OF EQUATION (5)

We measure of information asymmetry using the Amihud [2002] illiquidity construct (see, e.g., Lang and Maffett [2011]). Following Amihud [2002], Illiquidity, is defined as

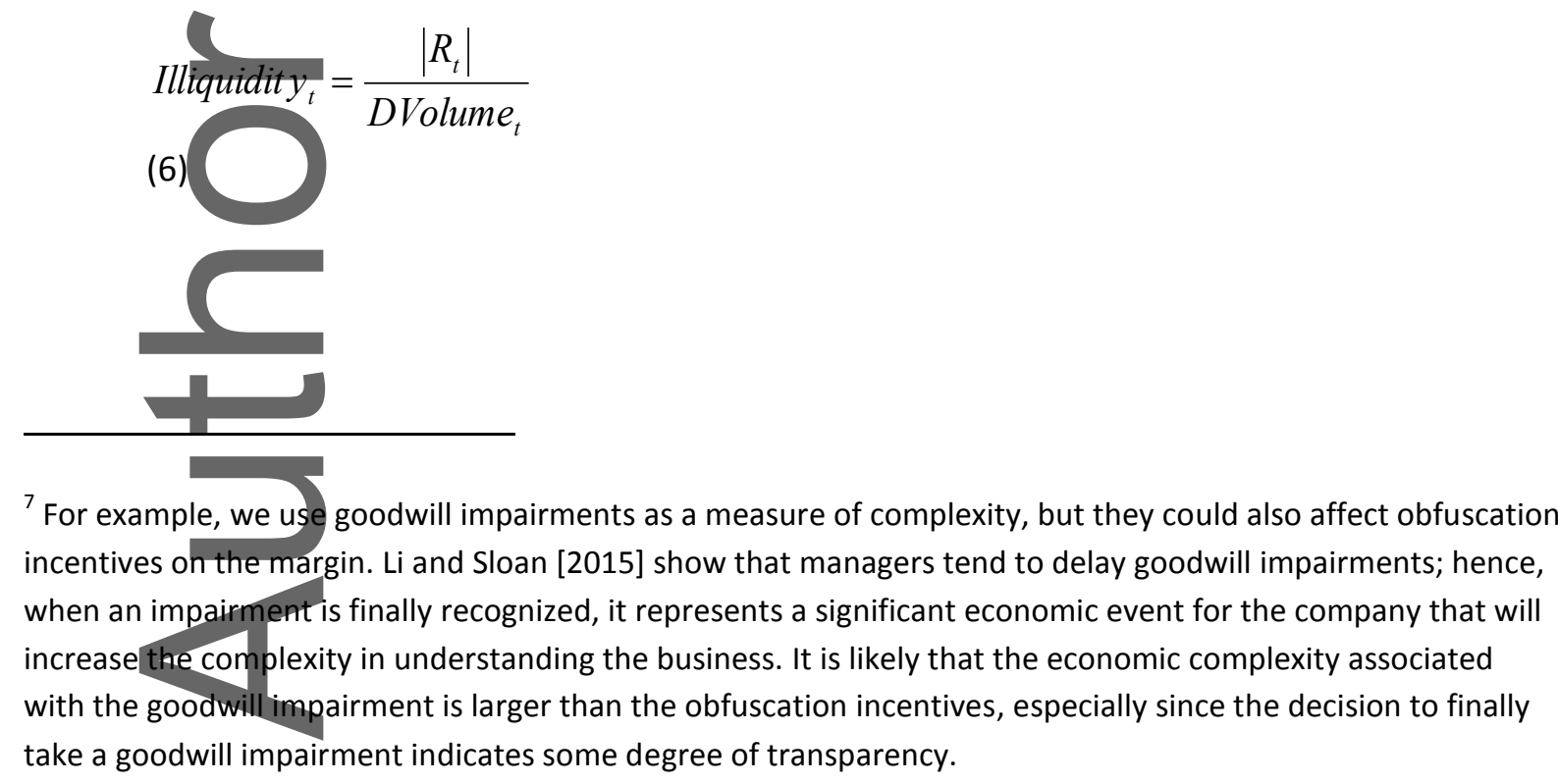

This article is protected by copyright. All rights reserved. 
where $R_{t}$ is the daily return and $D$ Volume $e_{t}$ is the daily dollar volume (in millions). The primary advantage of this variable is that it is easily calculated using CRSP data and is available for all firms in our sample. ${ }^{8}$ We calculate this measure at the daily level, winsorizing at the 1 st and 99th percentile, and then take the average value over the period starting the day of the call and ending twenty-five trading days subsequent to the call. To mitigate any effects of measurement error, we use the percentile ranks of Illiquidity in our tests (Balakrishnan, Core, and Verdi [2014]). ${ }^{9}$

We control for a number of determinants of information asymmetry in our validation tests. These controls, which we label as Base Model Controls, include: firm size (Size), book-to-market ratio $(B M)$, returns over the quarter (Returns), idiosyncratic volatility over the quarter, (IdioVol), analyst coverage and dispersion (Coverage and Dispersion), an indicator for whether the firm provided a quantitative earnings forecast the day of the conference call (MgmtForecast), the firm's quarterly earnings surprise (Surprise), an indicator for whether firm had a loss that quarter (Loss), special items for the quarter (Specltems), and an indicator for whether the firm meet or beat analyst forecasts by $\$ 0.01$ or less (SmallBeat). ${ }^{10}$ Some of these variables are presumably also related to

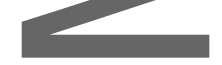

\footnotetext{
${ }^{8}$ In Table IA-1 of the Internet Appendix, we estimate our tests with an alternative measure of information asymmetry: the information asymmetry component of the bid-ask spread, or $\lambda$. We compute $\lambda$ using the estimation procedure of Madhavan, Richardson, and Roomans [1997] and Armstrong, Core, Taylor, and Verrecchia [2011]. Because this measure requires intra-day data from TAQ, it is available for only approximately $75 \%$ of our sample. Our results hold when we use this alternative measure.

${ }^{9}$ We use percentile ranks because Illiquidity has extreme values and a skewed distribution. However, percentile ranks could lead to loss of information. To address this, we estimate equation (5) using the log of Illiquidity as the dependent variable and using robust regression rather than OLS. Table IA-9 of the Internet Appendix shows that these alternative approaches do not affect our inferences.

${ }^{10}$ We also considered controlling for share turnover, but it is highly correlated with other controls. When we include it as a control, its VIF is above 3 and it affects the significance of some of the other controls; e.g., analyst dispersion. Because analyst Fog is an important variable in our study, we decided to include analyst dispersion rather than turnover. In Table IA- 6 of the Internet Appendix, we present results that include turnover, 1/price, earnings smoothness, and NYSE/NASDAQ listing indicators as additional controls. The
}

This article is protected by copyright. All rights reserved. 
obfuscation incentives and outcomes (e.g., Loss and SmallBeat). Thus, by controlling for such variables in our information asymmetry validation tests, we focus on estimating the incremental relation between the obfuscation (information) component and information asymmetry. ${ }^{11}$

\section{Sample and Descriptive Statistics}

(1)

We construct our sample using conference call transcripts from Thomson Reuters StreetEvents, analyst and management forecasts from I/B/E/S, and stock returns and accounting items from CRSP and Compustat. We begin the sample in 2002, when conference call transcripts are first available from StreetEvents, and conclude in 2011. The sample consists of 60,172 firm-quarters with conference call transcripts and the necessary CRSP, Compustat, and I/B/E/S data.

Table 1 presents descriptive statistics for variables used in our analysis; see Appendix C for variable definitions. Panel A shows that sample firms tend to be large (mean Size $=7.168$ ) with high analyst coverage (mean $=9.240$ ) and with PP\&E (Caplntensity) accounting for $25 \%$ of the average rossetbas

firm's asset base. The average firm has Acquisitions of $0.6 \%$ of total assets, capital expenditures (Capex) of $1.2 \%$ of assets, $R \& D$ expense $(R \& D)$ of $1.1 \%$ of assets, and debt and equity issuances (Financing) that amounted to $3.6 \%$ of total assets during the quarter. The average (median) earnings surprise (Surprise) is $0.0 \%(0.1 \%)$ of market value at the beginning of the quarter, with $15 \%$ of the coefficients on our estimates of the latent components remain significant at conventional levels after including these additional controls.

${ }^{11}$ Chen, Hribar, and Melessa [2017] raise the concern that coefficients can be biased when using the residual from one regression as a dependent variable in a second regression. In our study, we use the residual from one regression as an independent variable in a second regression (and also include the predicted value). Figure 1 of Chen et al. [2017] makes clear that our setting is outside the scope of their paper. Nevertheless, to ensure that a similar concern does not apply to our setting, we re-estimate information asymmetry regressions using raw values of linguistic complexity of managers and analysts, and the union of control variables from equations (3) and (5). In this single-stage estimation, the linguistic complexity of managers represents obfuscation because it is incremental to the analysts' linguistic complexity, which captures the information component. We tabulate the results in Table IA-10 and confirm that our findings are robust to a single-stage estimation.

This article is protected by copyright. All rights reserved. 
sample meeting or beating analyst forecasts by a penny or less (SmallBeat) and $16.7 \%$ of the sample reporting losses (Loss). Also, $2.8 \%$ of the sample took a goodwill impairment (Goodwill), $22.8 \%$ had a restructuring charge (Restructuring), and the average firm had income-reducing special items (mean Specltems $=-0.003$

Panel B reports descriptive statistics for the measures of linguistic complexity and information asymmetry. Analysts tend to use less complex language (mean Fog (Analyst) $=8.851$ ) than managers, who use much more complex language in the presentation part of the call (mean Fog $($ Present $)=15.861)$ than in response (mean Fog(Response) $=11.956)$. The differences in means and medians between Fog(Analyst), Fog(Present), and Fog(Response) are statistically significant ( $p$ values $<0.01$, two-tailed). The lower complexity of the response compared to the presentation suggests that the vetting of the presentation by IR personnel and legal counsel creates more complexity than the spontaneous responses of managers. Also, Deese [1978] finds that simple sentences (i.e., fewer words) are more common in conversational exchanges than in monologues. Moreover, relative to prior work that focuses on 10-Ks, the language used on conference calls appears relatively less complex. For example, Li [2008] finds the MD\&A section of the average 10-K from 1993 to 2003 has a Fog of $18.23 .^{12}$

5. Results

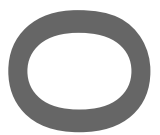

5.1 IDENTIFYING THE LATENT COMPONENTS IN COMPLEX LANGUAGE

Table 2 reports results from regressions of managerial linguistic complexity on analysts' linguistic complexity and business complexity variables (eq. (3)). We estimate regressions separately

\footnotetext{
${ }^{12}$ This difference is even more pronounced when one considers that prior work likely had artificially low Fog due to the technicalerror in the Perl routine discussed in Appendix B. For example, using a method without this error, Loughran and McDonald [2014] find the average 10-K from 2003 to 2011 has a Fog of 18.94
}

This article is protected by copyright. All rights reserved. 
for the presentation and response portions of the call. We present results for three different models: a model based solely on the linguistic complexity of analysts (columns (1) and (4)), a model based<smiles>C1CCCC1</smiles>

solely on business complexity variables (columns (2) and (5)), and a model based on both (columns (3) and (6)). We rank all of the independent variables into deciles and scale them to range from 0 to 1, which allows us to easily compare the relative economic significance of each variable; each coefficient represents the difference in the dependent variable between the top and bottom decile of the respective independent variable. This specification has the added advantage of being robust to outliers and nonlinearities.

Columns (1) and (4) report a positive and highly statistically significant coefficient on analysts' linguistic complexity (Fog(Analyst)) for both the presentation and response portions of the call. Columns (3) and (6) indicate that the coefficient on Fog(Analyst) is generally unaffected by the inclusion of business complexity variables. In the Fog(Present) regression, the magnitude of the coefficient on Fog(Analyst) is comparable to the effect of Goodwill impairments, but much smaller than the effect of Size, $R \& D$, and Leverage. This relatively low magnitude for Fog(Analyst) makes sense for the presentation part of the call, as it is prepared and delivered before the analysts ask questions. However, the coefficient on Fog(Analyst) is much larger in the Fog(Response) regression (0.22 vs. 0.09 , and its magnitude is comparable to Size, book-to-market (BM), and cash flow volatility ( $\sigma C F O)$. Thus, Fog(Analyst) is an important determinant of managers' linguistic complexity in the response part of the call, with a coefficient that is comparable in magnitude to many of the well-established determinants of Fog.

For the business complexity variables, results in column (2) suggest managers use more complex language in the presentation when their firms are smaller, have greater leverage, lower historical stock returns, lower capital intensity, greater R\&D, greater cash flow volatility, and take a 
goodwill impairment. Results in column (5) suggest managers use more complex language in the response when their firms are larger, have lower book-to-market, lower capital intensity, greater $R \& D$, greater cash flow volatility, and take a goodwill impairment or restructuring charge. In the combined model for the presentation (column (3)), there is no change in the significant of the business complexity variables, whereas in the combined model for the response (column (6)), the coefficient on prior stock returns becomes significant and the coefficient on Goodwill loses significance. ${ }^{13}$

Column (7) reports two-tailed $p$-values for a test of the difference in coefficients between columns (3) and (6). Firm size, leverage, and historical stock performance have a significantly stronger relation with the linguistic complexity of the presentation ( $p$-values all $\leq 0.10$ ), whereas book-to-market, capital intensity, restructuring charges, and the linguistic complexity of analysts have a significantly stronger relation with the linguistic complexity of the response ( $p$-values all $\leq$ 0.10). The coefficients in columns (3) and (6) are generally of the same sign, with the exception of Size and Restructuring. These significant sign differences indicate that the model is identifying the managerial disclosure response to complexity in each part of the call, rather than just a consistent linear combination of business complexity variables.

Notably, the analyst-only model for the response (column (4)) has a substantially higher adjusted R-squared (11.7\%) than the analyst-only model for the presentation (2.2\%) and both business-complexity-only models (5.0\% and 3.7\%). Moreover, the adjusted R-squared of the r combined model for the response (14.3\%) is substantially larger than for the presentation (7.1\%), ${ }^{13}$ We also considered adding the number of segments as a measure of business complexity. However, Berger
and Hann [2007] find that the number of segments a firm discloses is likely to be a strategic disclosure. In Table
IA-3 of the thternet Appendix, we add number of business segments and number of geographic segments to
the Table 2 model. The number of geographic segments is negatively related to Fog. However, including
number of segments in the decomposition model does not change our findings.

This article is protected by copyright. All rights reserved. 
consistent with analyst Fog better reflecting managerial Fog in the Q\&A part of the call. While these adjusted R-squareds are fairly low, they are comparable to other textual analysis work. For example, Li [2008] reports adjusted R-squareds of $6 \%$ to $8 \%$ in explaining $10-\mathrm{K}$ Fog after including year and industry fixed effects (p. 232). Thus, our R-squareds are comparable to Li [2008] for the Fog(Present) model and much larger for the Fog(Response) model, where Fog(Analyst) provides the strongest identification of managerial Fog.

We use these regression models to provide the basis for estimating the latent information and obfuscation components. The fitted values of columns (3) and (6) are our estimates of the latent information components Info(Present) and Info(Response), respectively. The residual values of columns (3) and (6) are our estimates of the latent obfuscation components, Obfu(Present) and Obfu(Response), respectively.

Panel A of Jable 3 reports descriptive statistics for our estimates of the latent components. Because the obfuscation components are regression residuals, the means are zero by construction; this does not suggest that the average level of obfuscation is zero. Similarly, the information component seems relatively large because we include the intercept in that component. Including the intercept from Table 2 in the calculation of the obfuscation components would increase (decrease) the mean of the obfuscation (information) components by 15.15 and 9.93, respectively, but would not affect any of our tests, which focus on the variation in the latent components.

Panel B of Table 3 reports correlations among Fog(Present), Fog(Response), and their respective latent components. Spearman (Pearson) correlations appear above (below) the diagonal. The correlation between $\mathrm{Obfu(.)}$ and $\mathrm{Fog}($.$) is 0.96$ for the presentation and 0.93 for the response; whereas the correlation between Info(.) and Fog(.) is 0.27 for the presentation and 0.38 for the response. These correlations indicate that the obfuscation component explains much of the 
variation in managerial Fog, as would be expected given the fairly low R-squareds of the decomposition model. The correlation between Obfu(Present) and Obfu(Response) is 0.35, suggesting that obfuscation manifests slightly differently in the presentation and the response. In contrast, the correlation between Info(Present) and Info(Response) of 0.70 , which is consistent with the information components stemming from discussions of the firm's business, which in the absence of obfuscation, should be similar across the two portions of the call.

\subsection{LINGUISTIC COMPLEXITY AND INFORMATION ASYMMETRY}

\section{(}

We validate our measures of the latent components by testing whether they exhibit the expected associations with information asymmetry. Table 4 reports results from estimating regressions of information asymmetry on the measures of linguistic complexity and controls. As before, we rank all of the independent variables into deciles and scale them to range from 0 to 1 .

Before we assess the latent components, we estimate equation (5) using Fog(Present) and Fog(Response), which is the approach followed by the prior literature that examines total Fog. Column (1) shows that the coefficient on Fog(Present) is positive and statistically significant, which is consistent with prior research that finds linguistic complexity is negatively associated with the information environment (e.g., Miller [2010]; Lang and Stice-Lawrence [2015]). In contrast, the coefficient on Fog(Response) is negative and statistically significant, suggesting linguistic complexity is conveying information in the Q\&A. Taken together, these results could be interpreted as showing that managers use linguistic complexity to obfuscate in the presentation and provide information in 1. the response. However, our decomposition will show that this conclusion is biased by the commingling of the two latent components.

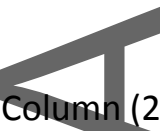

(2) presents results after decomposing Fog(Present) and Fog(Response) into their respective latent components: Obfu(Present), Info(Present), Obfu(Response), and Info(Response). 
Recall from Table 3 that the correlation between Info(Present) and Info(Response) is 0.70 , consistent with the two components being estimated as different linear combinations of the same set of variables (see Table 2). However, the correlation is sufficiently high that it induces multicolinearity in our regression when we include all four components together. ${ }^{14}$ Thus, for the remainder of our analysis, we combine Info(Present) and Info(Response) into a single variable, Info(Both), using the first principal component of the two variables.

In column (2), the coefficient on the information component, Info(Both), is negative and highly significant - n contrast, the coefficients on the obfuscation components are both positive: the coefficient on Obfu(Present) is statistically significant at the 0.01 level and the coefficient on Obfu(Response) is insignificant (but with a $p$-value of 0.11 ). Thus, consistent with our predictions, the two components of the linguistic complexity are related to information asymmetry in opposite directions. 15

In terms of economic magnitudes, the coefficients on the obfuscation components are similar in magnitude to the coefficient on meet-or-beat (SmallBeat), which proxies for potential earnings management. The coefficients indicate that moving from the bottom to the top decile of Obfu(.) leads to a 0.01-0.02 percentile increase in Illiquidity. Based on the median raw value (0.00166) and the $51^{\text {st }}$ and $52^{\text {nd }}$ percentile values $(0.00176$ and 0.00186$)$, this implies a $6 \%-12 \%$

${ }^{14}$ Whenever Info(Present) and Info(Response) are included together in a regression, the variance inflation factors are always above 7, whereas whenever Obfu(Present) and Obfu(Response) are included together in a regression, the variance inflation factors are always below 2 .

${ }^{15}$ To examine whether our results are monotonic and not driven by extreme values, we report portfolio sorts in Table IA-2 of the Internet Appendix. We sort firms into quintiles based on the linguistic complexity measures and calculate the average abnormal information asymmetry for firms in each portfolio, where the abnormal information asymmetry is the residual from a regression of Illiquidity on the Base Model Controls. For both the presentation and response, we find that abnormal information asymmetry is monotonically increasing (decreasing) across quintiles of the obfuscation (information) component. Moreover, information asymmetry is significantly different between the top and bottom quintiles in each case.

This article is protected by copyright. All rights reserved. 
increase in Illiquidity due to the obfuscation component. The coefficient on the information component indicates that moving from the bottom to the top decile of Info(Both) leads to a 0.04 T percentile decrease in Illiquidity. Based on the median raw value and the 46th percentile value (0.00166 and 0.00133 ), this implies a $19.9 \%$ decrease in Illiquidity due to the information component. Thus, the coefficients on the latent components of linguistic complexity have a reasonable economic magnitude. ${ }^{16}$

In column (3), we control for other characteristics of the language in the presentation and response. For each part of the call, we include the number of words in the portion of the call (Length), the number of words that are industry jargon (Jargon), the proportion of sentences containing forward-looking statements (ForwardLook), the number of positive tone words (PositiveTone), and the number of negative tone words (NegativeTone). ${ }^{17}$ Consistent with our earlier tests, each variable is measured separately for the presentation and response, ranked into deciles, and scaled to range between 0 and $1 .{ }^{18}$ For these attributes, we find length and forward-looking

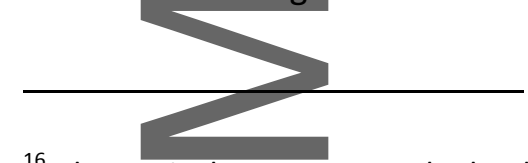

${ }^{16}$ Alternatively, we can use the log-level specification tabulated in Table IA-9 of the Internet Appendix to assess economic magnitudes. The coefficient on the independent variables in a log-level specification represents the growth rate in Illiquidity when moving from the bottom to the top decile of the respective variable (recall that our independent variables are scaled decile ranks). The coefficient on Obfu(Present) in this specification is 0.07 , the coefficient on $O b f u$ (Response) is 0.12 , and the coefficient on Info(Both) is -0.27 . These findings suggest moving from bottom to top decile is associated with a $7 \%$ increase, $12 \%$ increase, and $27 \%$ decrease in Illiquidity.

${ }^{17}$ Industry jargon words are the 100 most common words with more than two syllables used by firms in the same two-digit SIC code; the measure of forward-looking sentences is from Li [2010] and Brochet, Loumioti, and Serafeim [2015]; and positive tone words and negative tone words are from Loughran and McDonald [2011]. In untabulated analysis, we find the number of words in the presentation and response is correlated 0.92 with the file size of the transcript. This should not be surprising given that conference call transcripts are exclusively comprised of text, unlike 10-K filings, which include pictures and advanced graphics. Thus, the inclusion of the number of words in the respective sections serves as a control for file size (e.g., Loughran and McDonald [2014]).

${ }^{18}$ In Table IA-4 of the Internet Appendix, we report correlations among these additional language attributes. Length, Jargon, PositiveTone, and NegativeTone are all highly correlated with each other (correlations in excess of 0.70 ). However, these measures have much lower correlations with Fog and its latent components (all

This article is protected by copyright. All rights reserved. 
sentences are negatively associated with information asymmetry and the number of negative (positive) tone words is positively (negatively) associated with information asymmetry. However, including these additional language attributes does not affect the signs or significance levels of the latent components of linguistic complexity, with the exception that the coefficient on Obfu(Response) is now significant at the 0.01 level. Thus, our results are not only robust to controls for additional measures of linguistic attributes, but become stronger.

Overall, the results from Table 4 show that our empirical decomposition of linguistic complexity into latent information and obfuscation components is sufficiently powerful to detect their opposite relations with information asymmetry. Moreover, our estimates of the latent components appear distinct from other attributes of language in the call. A research design using only overalt linguistic complexity (column (1)) would have led to a conclusion that the relation between linguistic complexity and information asymmetry is ambiguous or differs based on the part of the call. However, our decomposition approach in columns (2) and (3) shows that the relation between the latent components of linguistic complexity and information asymmetry is unambiguous and does not differ between the presentation and response parts of the call. ${ }^{19}$

\subsection{ALTERNATIVE SPECIFICATIONS}

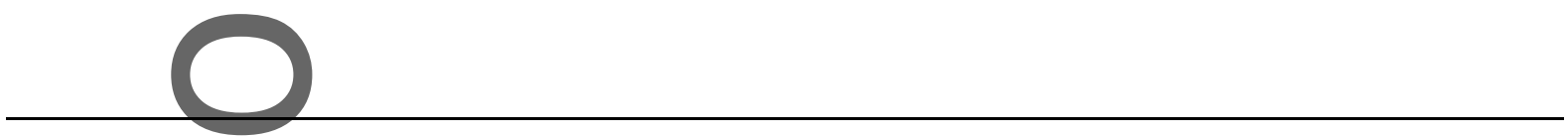

correlations $<0.38$ ). While multicolinearity among the additional language attributes does not affect the coefficients on the latent components, caution is needed when interpreting the coefficients on the additional language attributes.

${ }^{19}$ In Table IA-5 of the Internet Appendix, we repeat our analyses using the two components of Fog included separately-average number of words per sentence and the percent of complex words-and find generally similar results. However, the results are stronger when the two components are combined into the Fog index, supporting the finding of Gunning [1952] that both components together provide a more powerful measure of linguistic complexity. In Table IA-6, we also estimate the results in Table 4 with information asymmetry measured only on the day of the call, and only on the day of the call and the day after. The signs and significance levels of our coefficients are unaffected.

This article is protected by copyright. All rights reserved. 
We provide a number of additional analyses in Table 5. All regressions specifications follow Table 4 and include both Base Model Controls and controls for additional linguistic attributes. For parsimony, coefficients on controls are not tabulated.

First, it is possible that more complex businesses have permanently higher information<smiles>[CH]=C</smiles>

asymmetry, and that our latent components simply proxy for business complexity that is independent of the disclosure response to complexity. In column (1) of Table 5, we include the average value of information asymmetry immediately prior to the call to control for any crosssectional differences in the benchmark level of information asymmetry, as well as any time-varying economic complexity present prior to the call. The obfuscation (information) component remains positively (negatively) associated with post-call information asymmetry.

Next, we examine whether our results are robust to including industry fixed effects (column (2)), firm fixed effects (column (3)), and both firm and manager fixed effects (column (4)). The inclusion of both firm and manager fixed effects controls for differences in managerial "style" with respect to the language of the conference call (e.g., Davis et al. [2015]). ${ }^{20}$ The results for the information and obfuscation components are the same as in Table 4 with one exception. The coefficient on Obfu(Present) is positive but insignificant when firm fixed effects are included. This result suggest that within-firm variation in obfuscation in the presentation is likely limited due to the use of similar language, or scripting, across quarters (Lee [2015]). Despite this one exception, the results consistently indicate that within-industry, within-firm, and within-manager variation in the

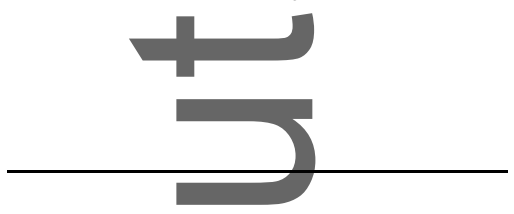

\footnotetext{
${ }^{20}$ We estimate manager fixed effects following Davis et al. [2015]. We obtain the identity of the CEO on Execucomp and require that the firm has changed CEOs during our sample period (2002-2011). These requirements allow us to distinguish a manager effect from a firm effect, but reduce our sample to 24,787 firm-quarters.
}

This article is protected by copyright. All rights reserved. 
information (obfuscation) component of linguistic complexity is negatively (positively) associated with information asymmetry.

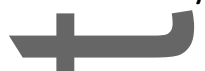

Finally, we assess the relative importance of analyst linguistic complexity and the business complexity variables to our empirical estimation strategy by estimating the latent components

separately using only analyst complexity and only business complexity. In column (5) of Table 5, we report the results using latent components derived only from the linguistic complexity of analysts (see columns (1) and (4) of Table 2). The results mirror Table 4; the latent components are significantly associated with information asymmetry in the predicted directions.

In column (6) of Table 5, we report the results using latent components derived only from the business complexity variables (see columns (2) and (5) of Table 2). The results hold for the Obfu(Present) and Info(Both) components, but are the wrong sign and no longer significant for the Obfu(Response) component. Thus, not surprisingly, the business complexity variables do a poor job of explaining managerial Fog during the Q\&A part of the call. Overall, these results suggest that the strength of our empirical identification is derived from the linguistic complexity of analysts, which is the unique feature of our study. ${ }^{21}$

\subsection{MONTE CARLO PLACEBO TESTS}
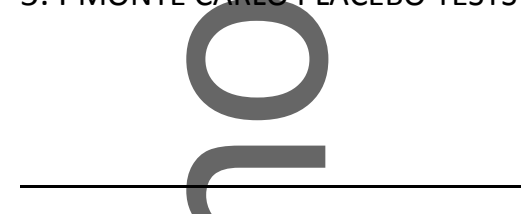

${ }^{21}$ This finding should also allay concerns that analyst Fog may reflect analyst incentives to obfuscate, thereby weakening the identification. As an additional test of this conjecture, we build on Mayew [2008], which finds that managers allow favorable analysts to ask questions early in the call. If favorable analysts help managers to obfuscate, then our results should be weaker for analyst Fog from the first half of the call. In Table IA-7 of the Internet Appendix, we estimate the model separately for Fog(Analyst) from the first half of the call ("early") and second half ("late"). We find that early and late Fog(Analyst) has similar explanatory power in the Table 2 model and that the latent components have almost identical relations with information asymmetry in the Table 4 regression. Thus, we do not find evidence consistent with favorable analysts facilitating managerial obfuscation. 
In Table 6, we report the results using three Monte Carlo placebo tests. In the first two panels, we randomly select a different date for each conference call. In Panel A, we randomly select a non-conference call date within a 250-day window of the original conference call date, excluding dates within 25 trading days of the call. In Panel B, we randomly select another conference call date for the same firm between 2002 and 2011. We measure information asymmetry based on this random event date and re-estimate the regression in column (3) of Table 4. We repeat this step 1000 times, retaining coefficient estimates for each iteration. Then, rather than testing whether the coefficients in Table 4 are different from zero, we test whether they are different from the coefficients on the randomly selected day. This comparison allows us to rule out the possibility that we are documenting a general phenomenon that is not specific to the market's reaction to the conference call (e.g., Larcker, Ormazabal, and Taylor [2011]). In both placebo tests, we find that the relation between information asymmetry and the information (obfuscation) component of linguistic complexity is significantly more negative (positive) on the actual conference call date than on the random event dates (even though the sign pattern of the coefficients is similar in one of the two placebo tests).

In Panel C, we randomly select a value of Fog(Present) and Fog(Response) from our sample and replace the actual value with the randomly selected value. Then, we estimate the decomposition model (Table 2) using the randomly selected value and test whether the resulting estimates of the two latent components are related to information asymmetry (Table 4). If our model is simply picking up a linear combination of the independent variables, then we should find the same results in the placebo test. However, if our model is capturing managers' specific disclosure responses to business complexity, the results will not hold in the placebo test. We find that the Table 4 results are significantly different than the placebo results, suggesting that our model captures the disclosure response to complexity, and not business complexity per se. 
We also validate our decomposition approach by examining the relation between the latent components of linguistic complexity and the decision to provide quantitative earnings guidance during the call. Guay et al., [2016] find a positive relation between linguistic complexity of the 10-K and voluntary disclosure, which they interpret as inconsistent with the linguistic complexity of the average 10-K resulting from an intentional choice to obfuscate. While Guay et al. [2016] make no attempt to separate and measure the two components of linguistic complexity, and study linguistic complexity in a mandatory disclosure setting that is heavily influenced by regulation (e.g., Dyer et al., [2017]), we can use a similar test in our setting to validate our estimates of the components of linguistic complexity.

In the conference call setting, managers are able to choose both the complexity of their language and whether to provide earnings guidance. If managers act consistently in their voluntary disclosure practices (i.e., managers who choose to be transparent, do so consistently), then managers that use complex language to provide information to shareholders are more likely to provide earnings guidance, whereas managers that use complex language to obfuscate are less likely to provide guidance. Thus, if our estimates of the two latent components of linguistic complexity are empirically descriptive, we expect that the information component is positively associated with the likelihood of providing earnings guidance during the call, whereas the obfuscation components are negatively associated with the likelihood of providing guidance.

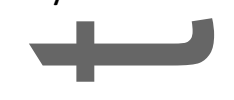

In Table 7, we present results of the relation between the provision of quantitative earnings guidance and the latent components of linguistic complexity. The dependent variable is an indicator

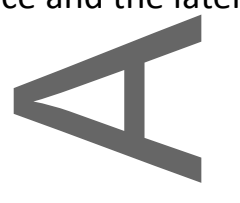

This article is protected by copyright. All rights reserved. 
variable for whether the firm provides an earnings forecast during the conference call. ${ }^{22}$ In column (1), we report results using the total Fog measures, Fog(Present) and Fog(Response). We find that (r) Fog(Present) is negatively associated with guidance, which suggests that linguistic complexity in the presentation is associated with a lower probability of guidance. There is no significant relation between $F o g($ Response) and guidance.

In column (2), we include our estimates of the two latent components and the results provide a much clearer picture of managerial behavior. Both obfuscation components, Obfu(Present) and Obfu(Response), are negatively associated with guidance, whereas the information component Info(Both) is positively associated with guidance. These results indicate that managers are acting consistently in their use of guidance and linguistic complexity. In column (3), we control for stickiness in guidance decisions by using guidance in the prior period (Billings, Jennings, and Lev [2014]). Our results hold for the Obfu(Present) and Info(Both) components, but are weaker for the Obfu(Response) component ( $p$-value $=0.11)$. Overall, these results further validate that our decomposition is empirically descriptive of two latent components of linguistic complexity.

\subsection{LATENT COMPONENTS OF LINGUISTIC COMPLEXITY AND EARNINGS}

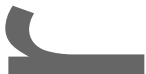

Finally, as an application of our approach to prior work, we examine how the latent components of linguistic complexity vary with a firm's earnings. While Li [2008] reports that loss firms have higher 10-K Fog and attributes this finding to managers obfuscating poor performance, Bloomfield [2008] notes that this result could be driven by loss firms providing investors with more information to explain the poor performance.

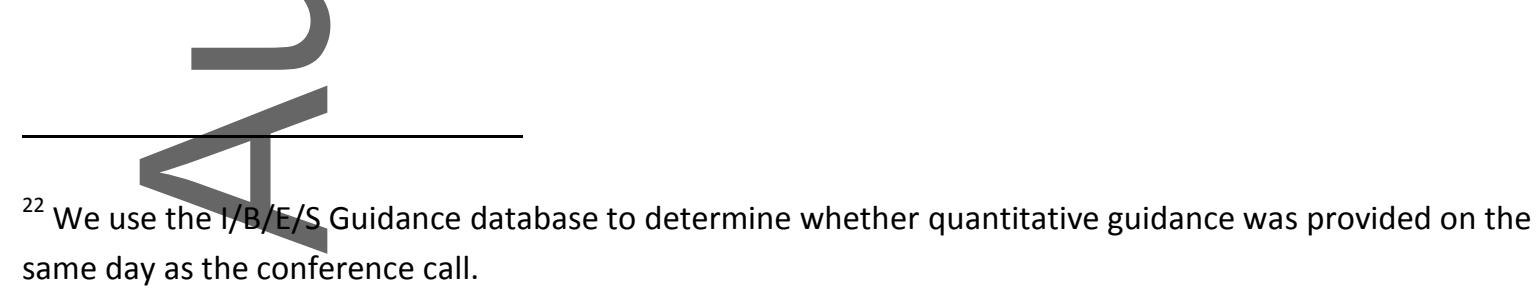

This article is protected by copyright. All rights reserved. 
Panel A of Table 8 presents mean and median values of the information and obfuscation components separately for profit and loss firms. First, consistent with Li [2008], we find loss firms have significantly higher Fog during both the presentation and response. Second, we find that loss firms have significantly greater values of both information and obfuscation components during both parts of the call. Thus, instead of finding that higher Fog in loss firms is due only to greater obfuscation or to greater information, our results suggest both forces are present.

Importantly, if our measures of the latent components of linguistic complexity are empirically descriptive, then an increase in obfuscation (or information) should be reflected in the level of the respective latent component, not the marginal effect of that component on information asymmetry. That is, the notion that managers in loss firms obfuscate more than profit firms implies the level of obfuscation differs between profit and loss firms while the marginal effect of obfuscation on information asymmetry should be the same.

To investigate whether the marginal effects of obfuscation and information components vary between profit and loss firms, we re-estimate the regressions in Table 4 partitioning the sample into profit and loss firms. Panel B of Table 8 presents results. Note that estimating the regression within sample partitions leads to a reduction in power, especially for the loss firms, which constitute less than $1 / 6$ th of our sample $(10,074$ firms-quarters). Nevertheless, regardless of whether the firm is profitable or not, we continue to find a strong positive (negative) relation between the obfuscation (information) component and information asymmetry.

6. Conclusion

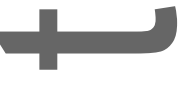

Prior research generally interprets complex language in a firm's disclosures as indicative of managerial obfuscation. However, complex language can also reflect the provision of informative technical disclosure. As a consequence, linguistic complexity commingles two latent components- 
obfuscation and information - that are related to information asymmetry in opposite directions. In this paper, we develop an empirical approach to estimate these two latent components within the context of quarterly earnings conference calls. Specifically, we use the linguistic complexity of security analysts to identify the portion of managerial linguistic complexity related to obfuscation and the portion related to the provision of information.

Consistent with our estimates measuring the underlying latent components of linguistic complexity, we find a predicted negative (positive) relation between the estimated information (obfuscation) component of linguistic complexity and information asymmetry. These relations hold across both the presentation and response parts of the conference call. The results are robust to controlling for other linguistic attributes of the call; to using within-industry, within-firm, and withinmanager designs; and to several placebo tests. We also validate our decomposition by showing that the information (obfuscation) component is positively (negatively) associated with the provision of quantitative earnings guidance on the call, as would be expected if managers act consistently in their qualitative and quantitative voluntary disclosure decisions. Finally, we show that our decomposition produces more nuanced conclusions for loss firms than existing work that suggests managers of loss firms use Fog to obfuscate poor performance. We show that some managers of loss firms use complex language to provide more informative disclosures.

The conference call setting provides internal validity by allowing us to identify informative managerial linguistic complexity using analyst linguistic complexity in the same disclosure venue. Our findings suggest that researchers can improve the power of their tests by controlling for the level of linguistic complexity expected in the absence of obfuscation. One important caveat to our decomposition approach is that we cannot speak to the generalizability of the approach outside of the conference call setting; e.g., 10-K or 10-Q disclosures. We encourage future work to explore 
whether the decomposition needs to be modified or updated to be setting-specific. Regardless, our findings suggest that regulators and researchers should exercise caution when assuming that complex language is necessarily less informative than simple language.

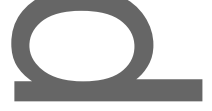

-

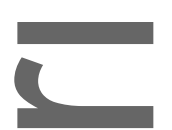

REFERENCES

ALLEE, K., ANDM. DEANGELIS. "The structure of voluntary disclosure narratives: Evidence from tone dispersion." Journal of Accounting Research 53 (2015): 241-274.

ALLEN, W. "Readability of instructional film commentary." Journal of Applied Psychology 36 (1952): $164-168$

AMIHUD, Y. "Illiquidity and stock returns: Cross-section and time-series effects." Journal of Financial Markets 5 (2002): 31-56.

ARMstrong, C.; J. Core; D. TAYLoR; AND R. VerreCCHiA. "When does information asymmetry affect the cost of icapital?" Journal of Accounting Research 49 (2011): 1-40.

BALAKRISHNAN, K; J. CORE; AND R. VERDI. "The relation between reporting quality and financing and investment: Evidence from changes in financing capacity." Journal of Accounting Research 52 (2014): 1-36.

BARTH, M.; R. KASZNHK; AND M. MCNICHOLS. "Analyst coverage and intangible assets." Journal of Accounting Research 39 (2001): 1-34.

BERGER, P., AND R. HANN. "Segment profitability and the proprietary and agency costs of disclosure." The Accounting Review 82 (2007): 869-906.

BILLINGS, M, R. JENNINGS, AND B. LEV. “On guidance and volatility." Journal of Accounting and Economics 60(2015): 161-180.

BLOOMFIELD, R. "Incomplete revelation hypothesis and financial reporting." Accounting Horizons 16 (2002): 233-243.

BLOOMFIELD, $R$. "Discussion of 'Annual report readability, current earnings, and earnings persistence.'”' Journal of Accounting and Economics 45 (2008): 248-252.

BonsalL, S.);A. LEONE; B. MilleR; AND K. RenNeKAMP. "A plain English measure of financial reporting readability." Journal of Accounting and Economics 63 (2017): 329-357.

BONSALL, S., AND B. MILLER. "The impact of narrative disclosure readability on bond ratings and the cost of debt capital." Review of Accounting Studies (2017): forthcoming.

This article is protected by copyright. All rights reserved. 
BOWEN, R.; A. DAVIS; AND D. MATSUMOTO. "Do conference calls affect analysts' forecasts." The Accounting Review 77 (2002): 285-316.

BOZANIC, Z. AND M.THEVENOT. "Qualitative disclosure and changes in sell-side financial analysts' information environment." Contemporary Accounting Research 32 (2015): 1595-1616.

BROCHET, F.,P.NARANJO; AND G. YU. "The Capital Market Consequences of Language Barriers in the Conference Calls of Non-U.S. Firms." The Accounting Review 91 (2015):1023-1049.

BROCHET, F., M. LOUMIOTI; AND G. SERAFEIM, "Speaking of the short-term: Disclosure horizon and managerial myopia." Review of Accounting Studies (2015): 1122-1163.

BROWN, S.; S. HILLEGEIST; AND K. LO. "Conference calls and information asymmetry." Journal of Accounting and Economics 37 (2004): 343-366.

Burgoon, J.;W. MAyeW; J. Giboney; A. Elkins; K. Moffit; B. Dorn; M. Byrd; And L. SPItZley. "Which spoken language markers identify deception in high-stakes settings? Evidence from earnings conference calls." Journal of Language and Social Psychology (2015): 1-35.

BusheE, B.; D. MATSUMOto; AND G. MilleR. "Open versus closed conference calls: The determinants and effects of broadening access to disclosure" Journal of Accounting and Economics 34 (2003): $149-180$

Charrow, R, AND V. Charrow. "A psycholinguistic study of jury instructions." Columbia Law Review 79 (1979): 1306-1374.

CHEN, W.; P. HRIBAR; AND S. MELESSA. "Coefficient bias when using residuals as the dependent variable" Working Paper, University of lowa, 2017.

CHEN, X.; Q. CHENG; AND K. LO. "On the relationship between analyst reports and corporate disclosures: Exploring the roles of information discovery and interpretation." Journal of Accounting and Economics 49 (2010): 206-226.

DAVIS, A.; W. GE; D. MATSUMOTO; AND J. ZhANG. "The effect of manager-specific optimism on the tone of earnings conference calls." Review of Accounting Studies 20 (2015): 639-673.

De FrAnCO, G.; O. HOPE; D. VYAS; AND Y. ZHOU. "Analyst report readability." Contemporary Accounting Research 32 (2015): 76-104.

DEESE, J. "Thought into speech: Linguistic rules and psychological limitations in processing information determine how we put our ideas into words." American Scientist 66 (1978): 314321

Dougal, C.;. ENGELBERG; D. GARCIA; AND C. PARSONS. "Journalists and the stock market." Review of Financial Studies 25 (2012): 639-679.

This article is protected by copyright. All rights reserved. 
Dyer, T.; M. LANG; AND L. SticE-LAWRENCE. "The evolution of 10-K textual disclosure: Evidence from Latent Dirichlet Allocation." Journal of Accounting and Economics (2017): forthcoming.

FANG, I., “The 'easy listening' formula." Journal of Broadcasting 11 (1966-1967): 63-68.

FRANKEL, R.; M. JOHNSON; AND D. SKINNER. "An empirical examination of conference calls as a voluntary disclosure medium." Journal of Accounting Research 37 (1999): 133-150.

GUAY, W.; D. SAMUELS; AND D. TAYLOR. "Guiding through the fog: Financial statement complexity and voluntary disclosure." Journal of Accounting and Economics 62 (2016): 234-269.

GUNNING, R. 1952. "The technique of clear writing." New York, NY: McGraw-Hill International Book Co.

HARWOOD, K. "Listenability and readability." Speech Monographs 22 (1955): 53-57.

HOBERG, G.,AND C. LEWIS. “Do fraudulent firms produce abnormal disclosure?” Working Paper, Vanderbilt Owen Graduate School of Management, 2015.

LANG, M., ANDM, MAFFETT. "Transparency and liquidity uncertainty in crisis periods." Journal of Accounting and Economics 52 (2011): 101-125.

LANG, M., AND L. STICE-LAWRENCE. "Textual analysis and international financial reporting: Large sample evidence." Journal of Accounting and Economics 60 (2015):110-135.

LARCKER, D.; G., ORMAZABAL; AND D. TAYLOR. "The market reaction to corporate governance regulation." Journal of Financial Economics 101 (2011): 431-448.

LARCKER, D., AND A. ZAKOLYUKINA. "Detecting deceptive discussions in conference calls." Journal of Accounting Research 50 (2012): 495-540.

LAWRENCE, A. "Individual investors and financial disclosure." Journal of Accounting and Economics 56 (2013): 130-147.

LEE, J. "Can investors detect managers' lack of spontaneity? Adherence to pre-determined scripts during earnings conference calls." The Accounting Review (2015): 229-250.

LEHAVY, R.; F. LI; ANDK. MERKLEY. "The effect of annual report readability on analyst following and the properties of their earnings forecasts." The Accounting Review 86 (2012): 1087-1115.

LI, F. "Annual report readability, current earnings, and earnings persistence." Journal of Accounting and Economics 45 (2008): 221-247.

LI, F. "The information content of forward-looking statements in corporate filings: A naive Bayesian machine learning approach." Journal of Accounting Research 48 (2010): 1049-1102.

This article is protected by copyright. All rights reserved. 
LOUGHRAN, T., AND B. MCDONALD. "Measuring readability in financial disclosures." The Journal of Finance 69 (2014): 1643-1671.

LOUGHRAN, T., AND B. MCDONALD. "Textual analysis in accounting and finance: A survey" Journal of Accounting Research 54 (2016): 1187-1230.

MADHAVAN, A.; M. RichARDSON; AND M. RoOMANS. "Why do security prices change? A transaction-level analysis of NYSE stocks." Review of Financial Studies 10 (1997): 1035-1064.

MATSUMOTO, D.; M.PRONK; AND E. RoElofSEN. "The information content of managers' presentations and analysts discussion sessions." The Accounting Review 86 (2011): 1383-1414.

MAYEW, W. "Evidence of management discrimination among analysts during earnings conference calls." Journak of Accounting Research 46 (2008): 627-659.

MAYEW, W.; N. SHARP; AND M. VENKATACHALAM. "Using earnings conference calls to identify analysts with superion private information." Review of Accounting Studies 18 (2012): 386-413.

MILLER, B. "The effects of reporting complexity on small and large investor trading." The Accounting Review 85 (2010): 2107-2143.

REDISH, J. C., AND J. SELZER. "The place of readability formulas in technical communication." Technical Communication 32 (1985): 46-52.

TASKER, S. "Bridging the information gap: Quarterly conference calls as a medium for voluntary disclosure." Review of Accounting Studies 3 (1998): 137-167

TWEDT, B. ANDL. REES. "Reading between the lines: An empirical examination of qualitative attributes of financial analysts' reports." Journal of Accounting and Public Policy 31 (2012): 1-21.

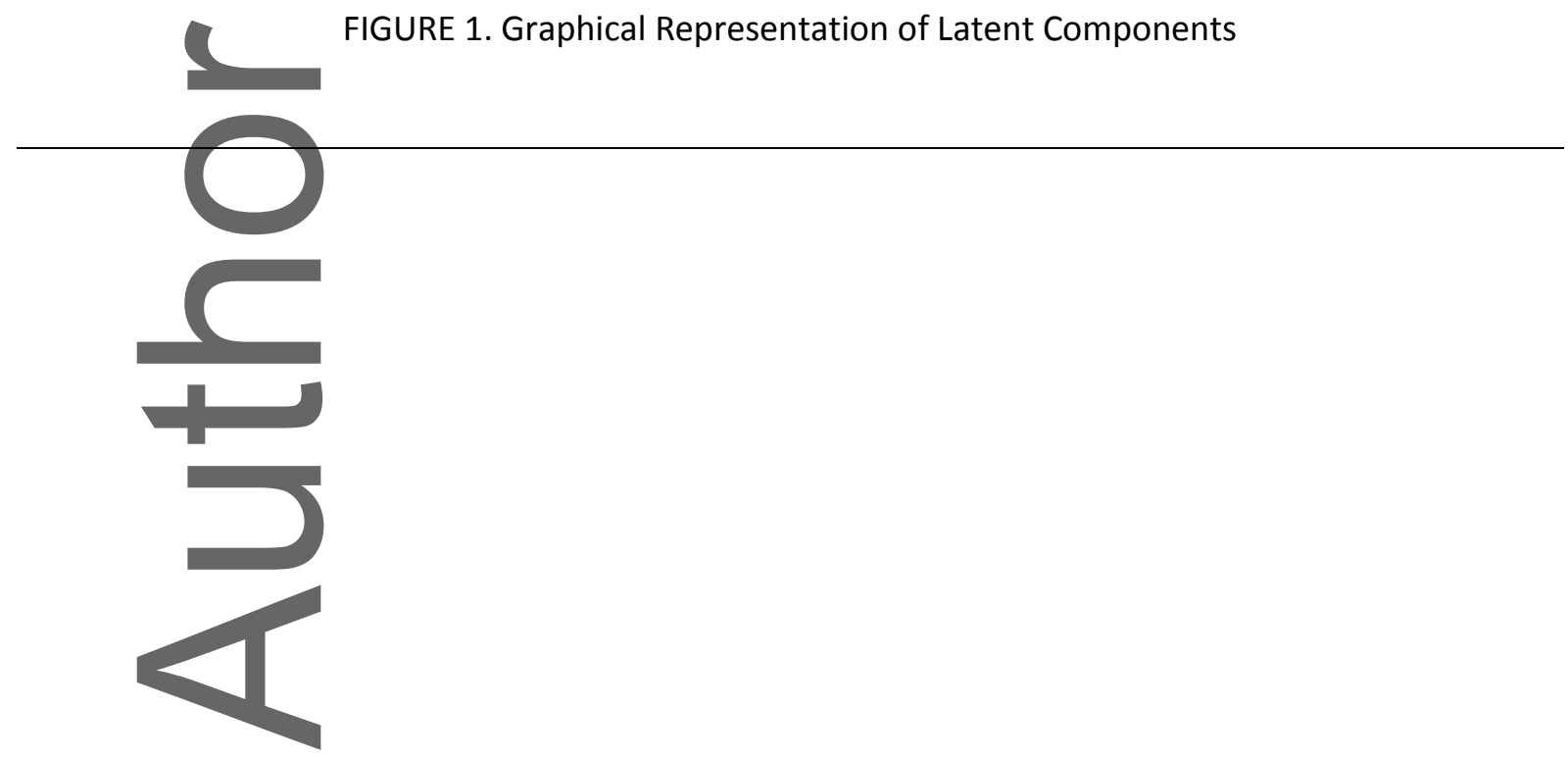

This article is protected by copyright. All rights reserved. 


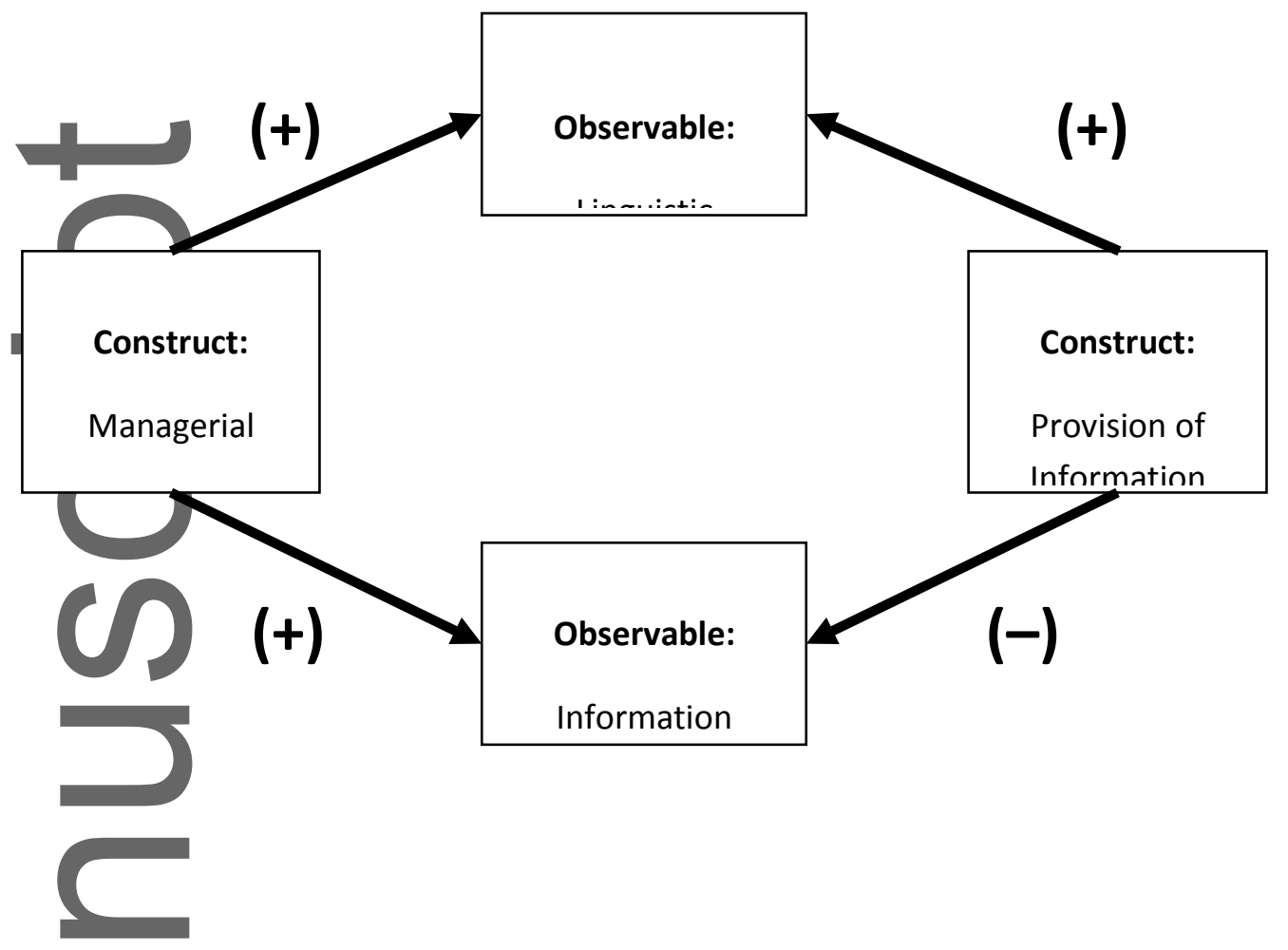

This figure presents a graphics representation of the latent components of managerial linguistic complexity. Predicted signs appear in parentheses.

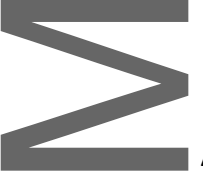

APPENDIX A. Derivation of regression coefficients in eqn (5).

This appendix separately analyzes the effect of measurement error (A.1) and violation of the assumption that the linguistic complexity of analysts does not reflect obfuscation (A.2) on the estimated regression coefficients $\alpha_{1}$ and $\alpha_{2}$ in equation (5).

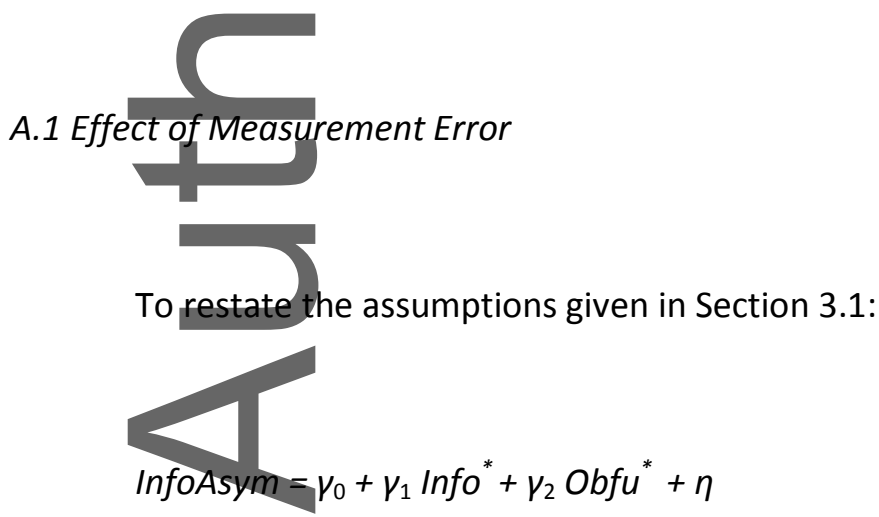

This article is protected by copyright. All rights reserved. 


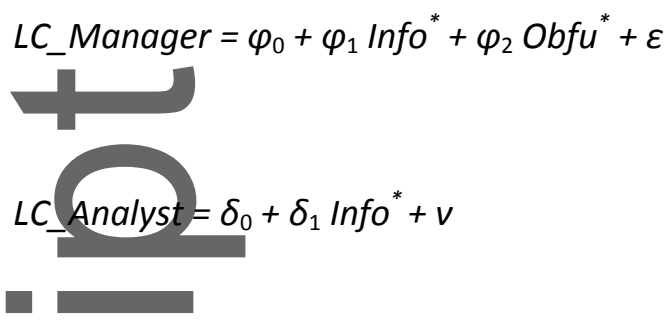

where ${ }^{*}$ indicates unobserved variables; $\eta, \varepsilon$, and $v$, represent measurement error; and $\gamma_{1}<0, \gamma_{2}>0$, $\phi_{1}>0, \varphi_{2}>0$, and $\delta_{1}>0$. For tractability, we additionally assume Info ${ }^{*}, O b f u^{*}, \eta, \varepsilon$, and $v$ are all independently distributed with mean zero and variances $\sigma_{I}^{2}, \sigma_{O}^{2}, \sigma_{\eta}^{2}, \sigma_{\varepsilon}^{2}$, and $\sigma_{v}^{2}$ respectively, and set $\varphi_{0}=\delta_{0}=0, V_{1}=-1$ and $\gamma_{2}=1$. We also assume that we have a sufficiently large sample, so that our estimated regression coefficients converge to their probability limits.

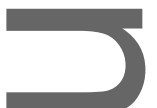

Our empirical estimate of $I n f o^{*}\left(O b f u^{*}\right)$, denoted Info (Obfu), is the fitted (residual) value from a regression of $L C \_$Manager on LC_Analyst:
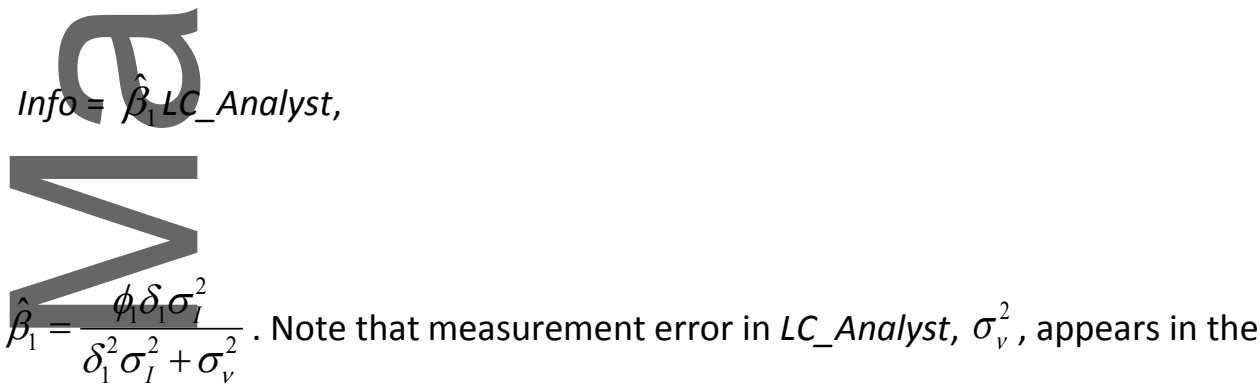

denominator and attenuates this coefficient. The fitted value, Info, is given by
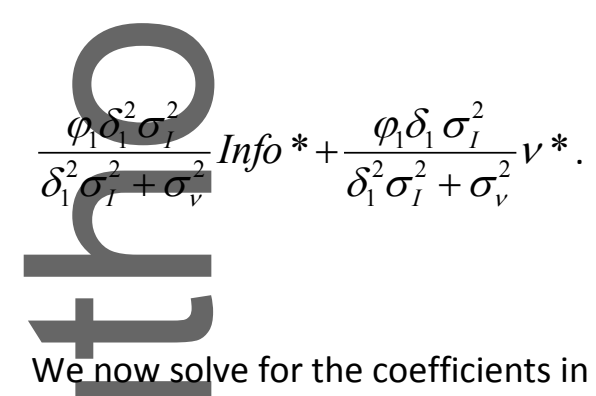

where $\hat{\beta}_{1}=\frac{\phi_{1} \delta_{1} \sigma_{I}^{2}}{\delta_{1}^{2} \sigma_{I}^{2}+\sigma_{v}^{2}}$. Note that measurement error in $L C_{-}$Analyst, $\sigma_{v}^{2}$, appears in the

We now solve for the coefficients in equation (5) in the presence of measurement error. The standard formulas for the slope coefficients from a regression of $y$ on $x_{1}$ and $x_{2}$ are given by

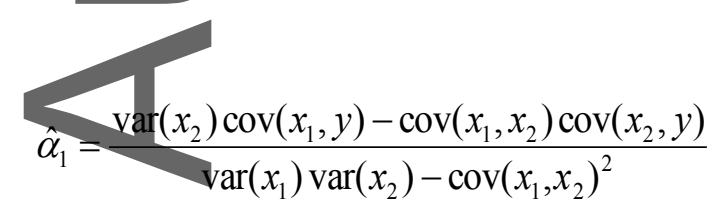

This article is protected by copyright. All rights reserved. 


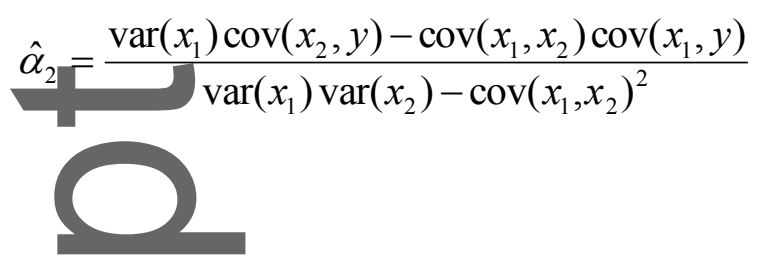

From the above information structure, we have that

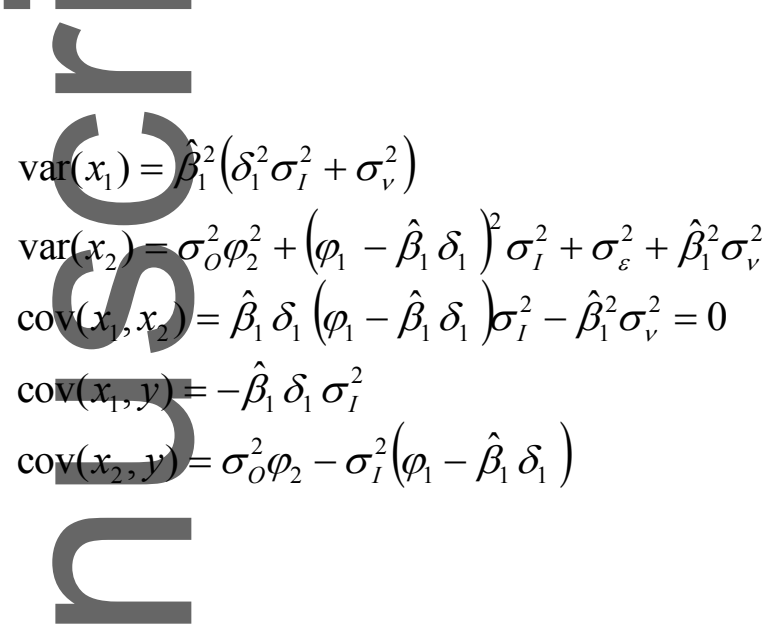

Substituting in the respective variances and covariances and using some algebra yields

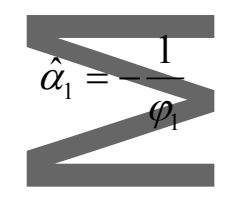

and

$$
\hat{\alpha}_{2}=\frac{\varphi_{2} \delta_{1}^{2} \sigma_{I}^{2} \sigma_{O}^{2}+\sigma_{v}^{2}\left(\varphi_{2} \sigma_{O}^{2}-\varphi_{1} \sigma_{I}^{2}\right)}{\delta_{1}^{2} \sigma_{I}^{2}\left(\varphi_{2}^{2} \sigma_{O}^{2}+\sigma_{\varepsilon}^{2}\right)+\sigma_{v}^{2}\left(\varphi_{1}^{2} \sigma_{I}^{2}+\varphi_{2}^{2} \sigma_{O}^{2}+\sigma_{\varepsilon}^{2}\right)} .
$$

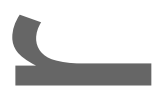

These results demonstrate that the sign of the coefficient on our estimate of the information component, $\hat{\alpha}_{1}$, is unambiguously negative and its magnitude is not affected by measurement error. In contrast, the presence of measurement error does affect the sign of the coefficient on our estimate of the obfuscation component, $\hat{\alpha}_{2}$. The denominator of $\hat{\alpha}_{2}$ is unambiguously positive, so we need only consider the sign of the numerator. The first term in the numerator is also unambiguously positive, so we need only consider the sign and magnitude of the second term.

Define $\Delta_{\text {Manager }}=\left(\varphi_{2} \sigma_{O}^{2}-\varphi_{1} \sigma_{I}^{2}\right)$, where $\Delta_{\text {Manager }}$ is the difference between the variation in LC_Manager attributable to obfuscation and the variation in LC_Manager attributable to information. For $\triangle_{\text {Manager }} \geq 0$, the variation in $L C$ _Manager attributable to obfuscation exceeds the 
variation attributable to information and $\hat{\alpha}_{2}$ is unambiguously positive. For $\Delta_{\text {Manager }}<0$, the variation in $L C_{-}$Manager attributable to obfuscation is less than the variation attributable to information and $\hat{\alpha}_{2}$ is positive so long as measurement error in LC_Analyst $\left(\sigma_{v}^{2}\right)$ is not too large.

To summarize, measurement error does not affect the sign of the coefficient on our estimate of the information component $\left(\hat{\alpha}_{1}\right)$, but does impart a negative bias on the coefficient on our estimate of the obfuscation component $\left(\hat{\alpha}_{2}\right)$. For sufficiently large values of measurement error $\left(\sigma_{v}^{2}\right), \hat{\alpha}_{2}$ will be negative. This is the opposite of our predicted sign, and illustrates that measurement error biases against finding $\hat{\alpha}_{2}>0$.

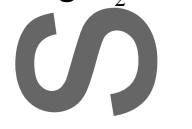

A.2 Effect of Obfuscation in Linguistic Complexity of Analysts

We begin by reformulating the expression for $L C_{-}$Analyst to include an intentional obfuscation component:
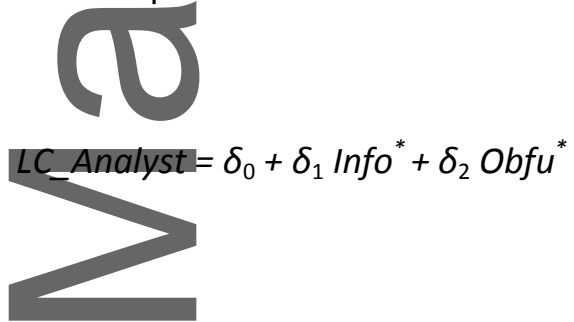

where $\delta_{2}>0$. Note that expression is more general than the prior expression in which we assumed $\delta_{2}=0$. We employ the same assumptions as in A.1., except that for tractability, we do not additionally consider measurement error (i.e., $\sigma_{v}^{2}=\sigma_{\varepsilon}^{2}=0$ ).

Our empirical estimate of $\operatorname{Info} o^{*}\left(O b f u^{*}\right)$, denoted Info (Obfu), is the fitted (residual) value from a regression of $L C \_$Manager on $L C \_$Analyst:

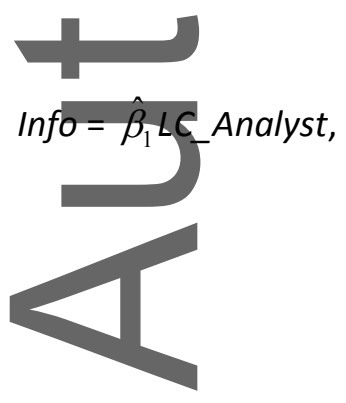

This article is protected by copyright. All rights reserved. 
where $\hat{\beta}_{1}=\frac{\phi_{1} \delta_{1} \sigma_{I}^{2}+\phi_{2} \delta_{2} \sigma_{O}^{2}}{\delta_{1}^{2} \sigma_{I}^{2}+\delta_{2}^{2} \sigma_{O}^{2}}$. Note that as a result of $\delta_{2}>0$, the variance of the obfuscation component, $\sigma_{O}^{2}$, now appears in both the numerator and denominator. As a result, the fitted value, Info, is now given by

$$
\frac{\varphi_{1} \delta_{1} \sigma_{I}^{2}+\varphi_{2} \delta_{2} \sigma_{O}^{2}}{\delta_{1}^{2} \sigma_{I}^{2}+\delta_{2}^{2} \sigma_{O}^{2}} \operatorname{Info} *+\frac{\varphi_{1} \delta_{1} \sigma_{I}^{2}+\varphi_{2} \delta_{2} \sigma_{O}^{2}}{\delta_{1}^{2} \sigma_{I}^{2}+\delta_{2}^{2} \sigma_{O}^{2}} v^{*}
$$

We now solve for the coefficients in equation (5) in the presence of $\delta_{2}>0$. Substituting in the respectivevariances and covariances into the standard formulas for the slope coefficients and using some algebralyields:

$$
\begin{aligned}
& \hat{\alpha}_{1}=\frac{\delta_{2} \sigma_{O}^{2}-\delta_{1} \sigma_{I}^{2}}{\hat{\beta}_{1}\left(\delta_{2}^{2} \sigma_{O}^{2}+\delta_{1}^{2} \sigma_{I}^{2}\right)} \\
& \hat{\alpha}_{2}=\frac{\sigma_{O}^{2}\left(\phi_{2}-\hat{\beta}_{1} \delta_{2}\right)-\sigma_{I}^{2}\left(\phi_{1}-\hat{\beta}_{1} \delta_{1}\right)}{\sigma_{O}^{2}\left(\phi_{2}-\hat{\beta}_{1} \delta_{2}\right)^{2}+\sigma_{I}^{2}\left(\phi_{1}-\hat{\beta}_{1} \delta_{1}\right)^{2}}
\end{aligned}
$$

First, consider the sign of $\hat{\alpha}_{1}$, the coefficient on our estimate of the information component. The denominator is unambiguously positive, and we need only consider the sign of the numerator. Define $\Delta_{\text {Analyst }}=\left(\delta_{2} \sigma_{O}^{2}-\delta_{1} \sigma_{I}^{2}\right)$, where $\Delta_{\text {Analyst }}$ is the difference between the variation in LC_Analyst attributable to obfuscation and the variation in LC_Analyst attributable to information. For $\Delta_{\text {Analyst }}<$ 0 , the variation in $L C$ _ Analyst attributable to information exceeds the variation attributable to obfuscation and $\hat{\alpha}_{1}<0$, as predicted. However, for $\Delta_{\text {Analyst }}>0$, the variation in LC_Analyst attributable to obfuscation exceeds the variation attributable to information and $\hat{\alpha}_{1}>0$, counter to our prediction. This illustrates that our identification strategy relies on whether the linguistic complexity of analysts predominantly reflects the information component or predominantly reflects the obfuscation component, not that $\delta_{2}=0$ per se. If the analyst linguistic complexity predominantly reflects the information component, our prediction, $\hat{\alpha}_{1}<0$, holds.

This article is protected by copyright. All rights reserved. 
Next, consider the sign of $\hat{\alpha}_{2}$, the coefficient on our estimate of the obfuscation component. The denominator is unambiguously positive, and we need only consider the sign of the numerator. Note that the numerator simplifies to $\Delta_{\text {Manager }}-\hat{\beta}_{1} \Delta_{\text {Analyst }}$. As such, we are left with a similar condition for $\hat{\alpha}_{2}$ to be positive as in A.1, except that now the condition also depends on $\Delta_{\text {Analyst }}$.If both (1) the variation in $L C$ _Manager attributable to obfuscation exceeds the variation attributable to information; i.e., $\Delta_{\text {Manager }}>0$, and (2) the variation in LC_Analyst attributable to information exceeds the variation attributable to obfuscation, $\Delta_{\text {Analyst }}<0$, then $\hat{\alpha}_{2}$ will be unambiguously positive, and our prediction holds. If either (1) or (2) is violated it is possible that $\hat{\alpha}_{2}$ would be negative, counter to are predictions, depending on the precise values of $\Delta_{\text {Manager }}$ and $\Delta_{\text {Analyst }}$.

To summarize, if $L C$ _Analyst also contains an obfuscation component, it biases against finding the coefficient on the information (obfuscation) component is negative (positive).

APPENDIX B. Technical Note on the Perl Routine used to Compute the Fog Index

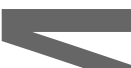

Prior research has generally followed Li [2008] in using the Perl routine Lingua::EN::Fathom to calculate the Fog index. ${ }^{23}$ However, this routine uses a simple regular expression (namely, $\Lambda b\left|s^{*}[. ! ?]\right| s^{*}|b /|$ to identify sentence breaks; i.e., the routine simply looks for punctuation marks (“.!?”) when calculating the number of sentences. ${ }^{24}$ Consequently, the routine is confounded by punctuation used in numbers and abbreviations. For example, consider the following text:

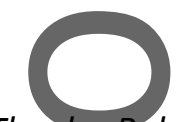

Thanks, Bob. Good morning everyone. Yesterday we reported second quarter revenues of 619 million. We reported net earnings of 24.3 million or 0.78 per diluted share for the quarter compared with net earnings of 15.5 million or 0.50 per diluted share for the same period last year. Our U.S. business has been particularly robust.

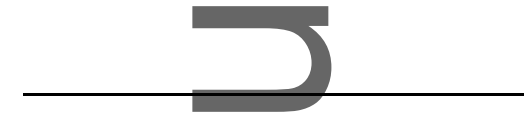

\footnotetext{
${ }^{23}$ Many of the papers cited in Section 2 either explicitly acknowledge their data comes from Li [2008] or state that they use the Lingua::EN::Fathom routine to calculate the Fog index.

${ }^{24}$ Source: http://cpansearch.perl.org/src/KIMRYAN/Lingua-EN-Fathom-1.18/lib/Lingua/EN/Fathom.pm
}

This article is protected by copyright. All rights reserved. 
The passage has 49 words, 11 complex words (i.e., more than two syllables), and five sentences. However, Lingua::EN::Fathom counts extra sentences due to "24.3," “0.78," "15.5," "0.50," "U." and "S." This issue affects the calculation of Fog, which is 10.76 with 11 sentences, compared to the correct value of 12.90 with five sentences.

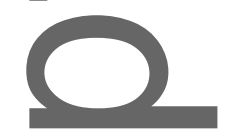

Note that this measurement error is not random. Text passages with more numbers will tend to have erroneously low words per sentence and, thus, an erroneously low Fog index when using the Lingua::EN::Fathom routine. This technical issue could potentially affect prior literature that uses the Fog index. To correct for this issue, we use the Lingua::EN::Sentence routine, which correctly identifies five sentences in the example above, to calculate the number of sentences. Also, we note that the function sent_tokenize in the Python NLTK (Natural Language Toolkit) package and the Fog index provided on the WRDS SEC Analytics Suite are not affected by this issue.

In Table IA-8 of the Internet Appendix, we estimate our results using the Lingua::EN::Fathom Perl routine (Li [2008]), which we call "FathomFog." Panel A shows that one interesting difference from using FathomFog is that the coefficient on Size is positive and significant in explaining FathomFog(Present), whereas as it is negative and significant for the correct Fog(Present). In Panel B, we find that the results for FathomFog are similar to correct Fog for the Obfu(Response) and Info(Both) components, but do not hold for the Obfu(Present) component. Thus, FathomFog provides weaker identification of managerial Fog in the presentation part of the call, which is also the part of the call that is more likely to contain numerical test.

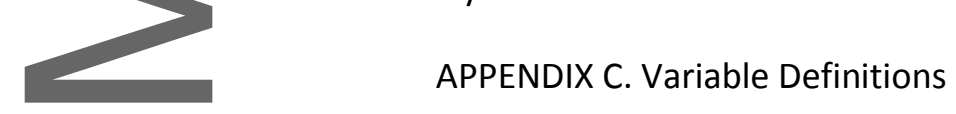

\footnotetext{
Measures of linguistic complexity and information asymmetry

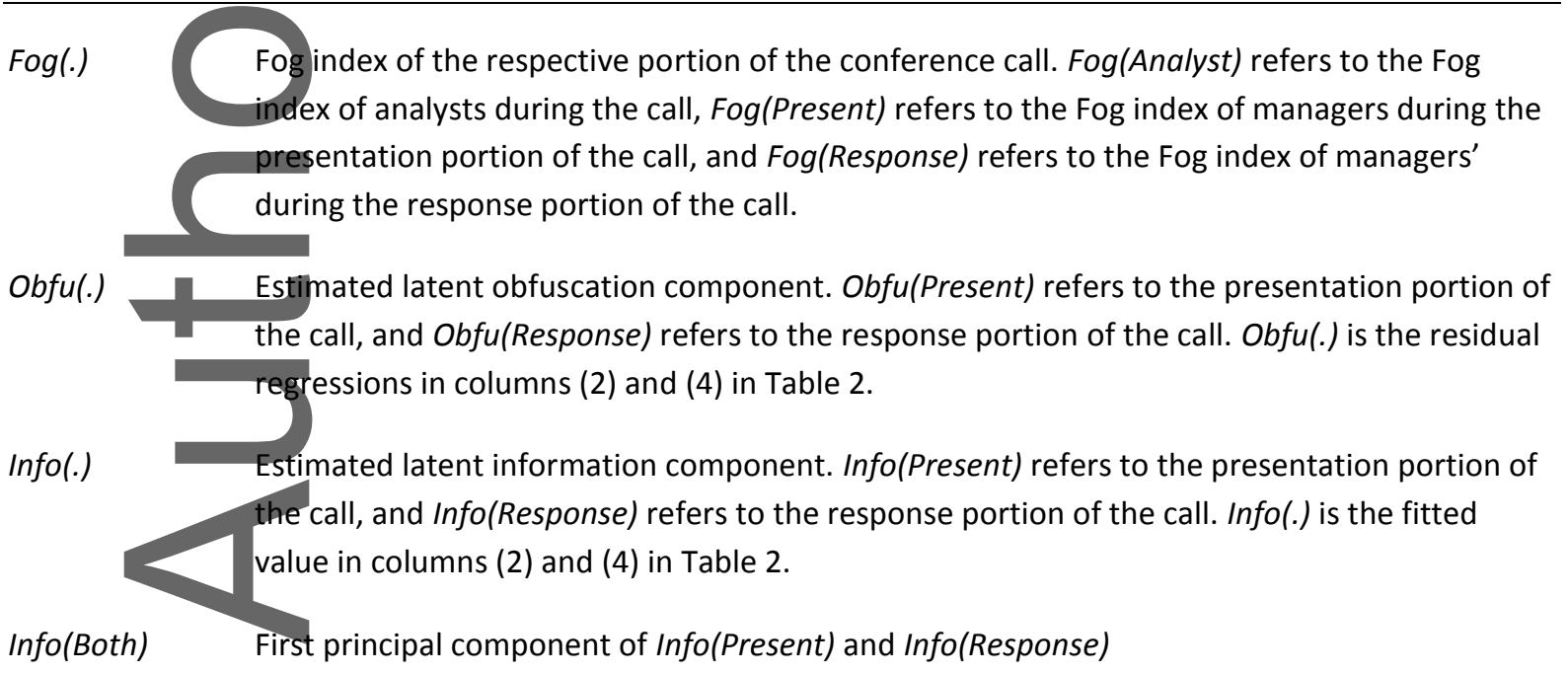

This article is protected by copyright. All rights reserved. 
Illiquidity The average value of the Amihud [2002] measure of illiquidity over the period starting the day of the call and ending twenty-five trading days subsequent to the call. Firm days with zero volume are excluded. This restriction only affects $0.05 \%$ of the 2.1 million daily observations used to compute this measure.

Firm characteristics

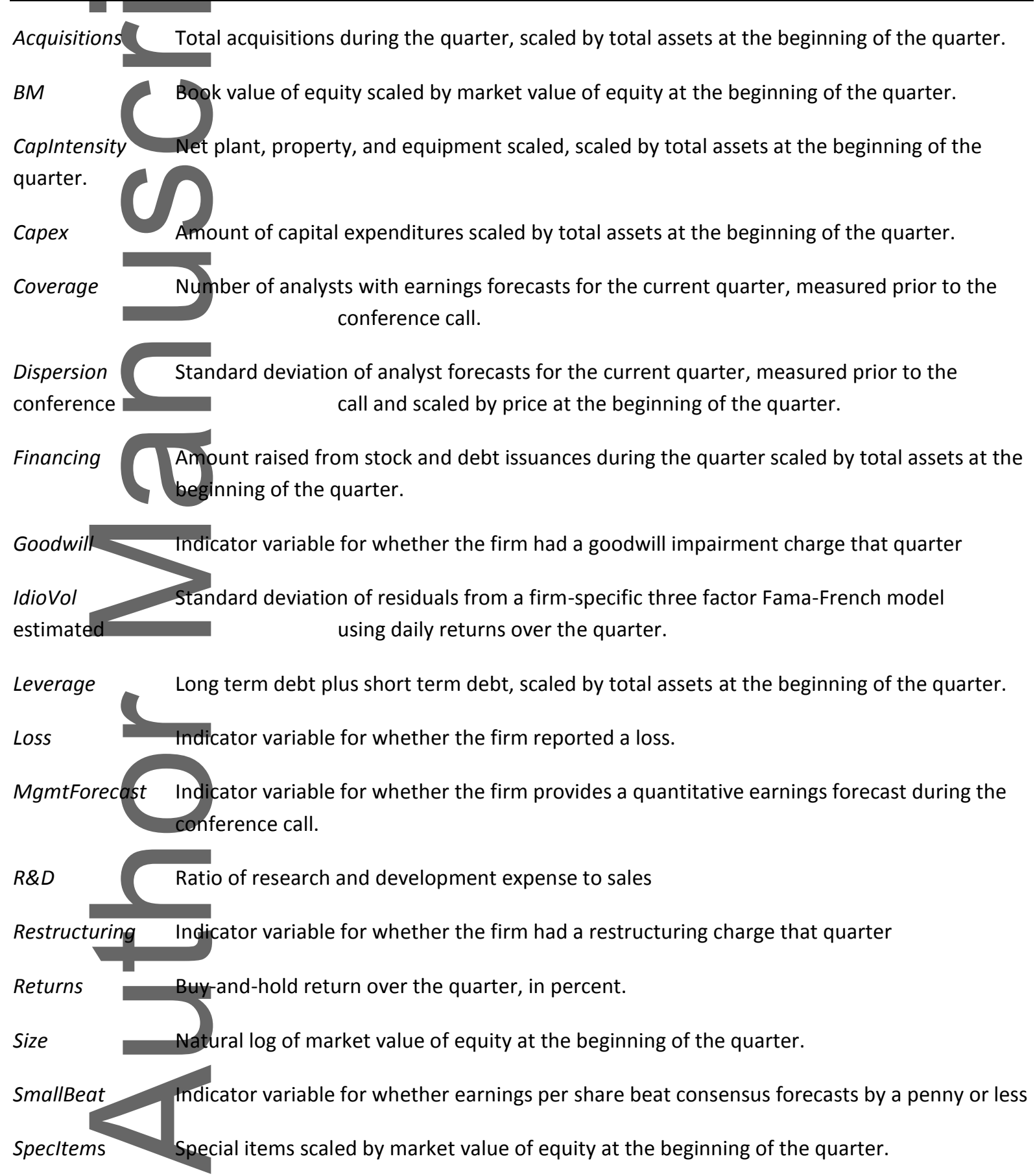

This article is protected by copyright. All rights reserved. 
to the conference call.

oCFO Standard deviation of cash flows from operations scaled by total assets at over the prior five years.

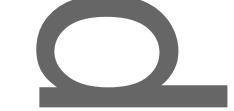

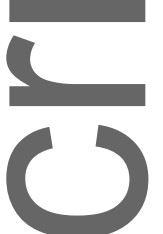

TABLE 1. Descriptive Statistics

PANEL A. Firm Characteristics

\begin{tabular}{|c|c|c|c|c|}
\hline Variable & Std. Dev. & $\mathrm{P} 25$ & Median & P75 \\
\hline Acquisitions & 0.025 & 0.000 & 0.000 & 0.000 \\
\hline 0.509 & 0.382 & 0.257 & 0.431 & 0.670 \\
\hline Caplnten & 0.242 & 0.059 & 0.159 & 0.367 \\
\hline Capex & 0.016 & 0.003 & 0.007 & 0.015 \\
\hline Coverag & 6.318 & 4.000 & 7.000 & 13.000 \\
\hline Dispersi & 0.004 & 0.000 & 0.001 & 0.002 \\
\hline Financing & 0.096 & 0.000 & 0.003 & 0.021 \\
\hline Goodwill & 0.165 & 0.000 & 0.000 & 0.000 \\
\hline Idiovol & 0.013 & 0.014 & 0.019 & 0.028 \\
\hline Leverage & 0.200 & 0.028 & 0.176 & 0.328 \\
\hline Loss & 0.373 & 0.000 & 0.000 & 0.000 \\
\hline MgmtFo & 0.500 & 0.000 & 1.000 & 1.000 \\
\hline$R \& D$ & 0.023 & 0.000 & 0.000 & 0.013 \\
\hline Restructurir & 0.419 & 0.000 & 0.000 & 0.000 \\
\hline Returns & 23.284 & -11.012 & 1.826 & 14.209 \\
\hline Size & 1.599 & 6.033 & 6.998 & 8.154 \\
\hline SmallBeat & 0.357 & 0.000 & 0.000 & 0.000 \\
\hline
\end{tabular}

This article is protected by copyright. All rights reserved. 


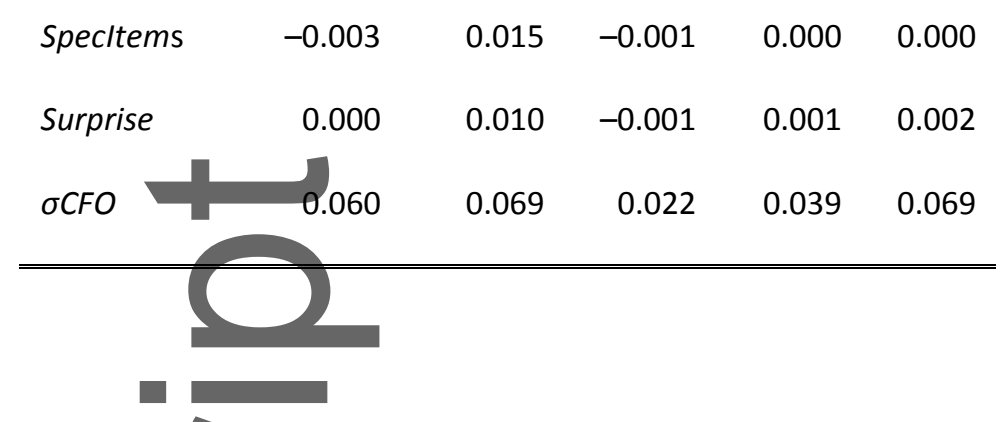

PANEL B. Measures of Linguistic Complexity and Information Asymmetry

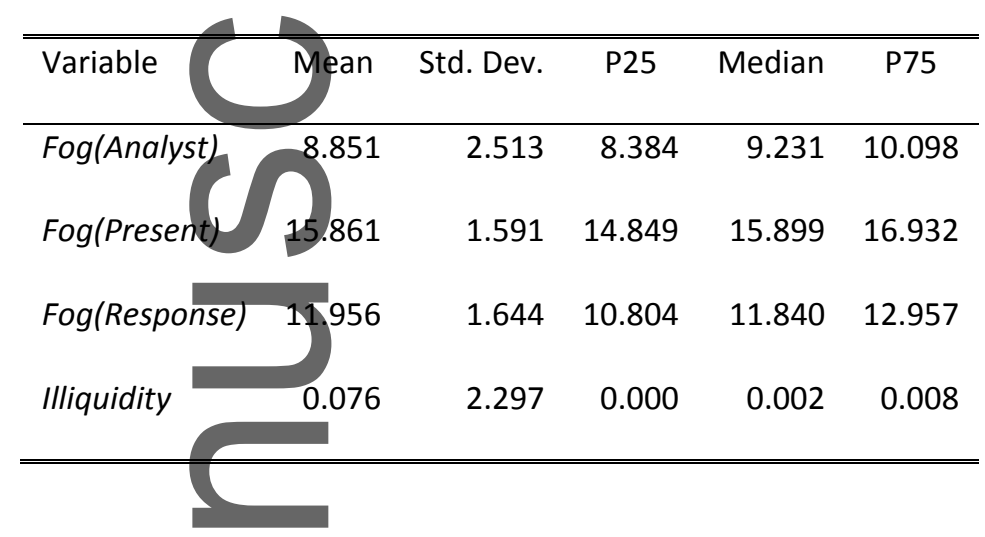

This table presents descriptive statistics for firms in our sample. Our sample is constructed from the intersection of Thomson Reuters StreetEvents, I/B/E/S, and CRSP/Compustat. The sample spans the time period January 2002 to December 2011 and covers a total of 60,172 firm-quarter observations. Panel A reports the distribution of various firm characteristics used in our analysis, Panel B reports the distribution of measures of linguistic complexity and information asymmetry. All variables are winsorized at the $1^{\text {st }}$ and $99^{\text {th }}$ percentiles. See Appendix C for variable definitions.

TABLE 2. Estimating the Latent Components of Managers' Linguistic Complexity

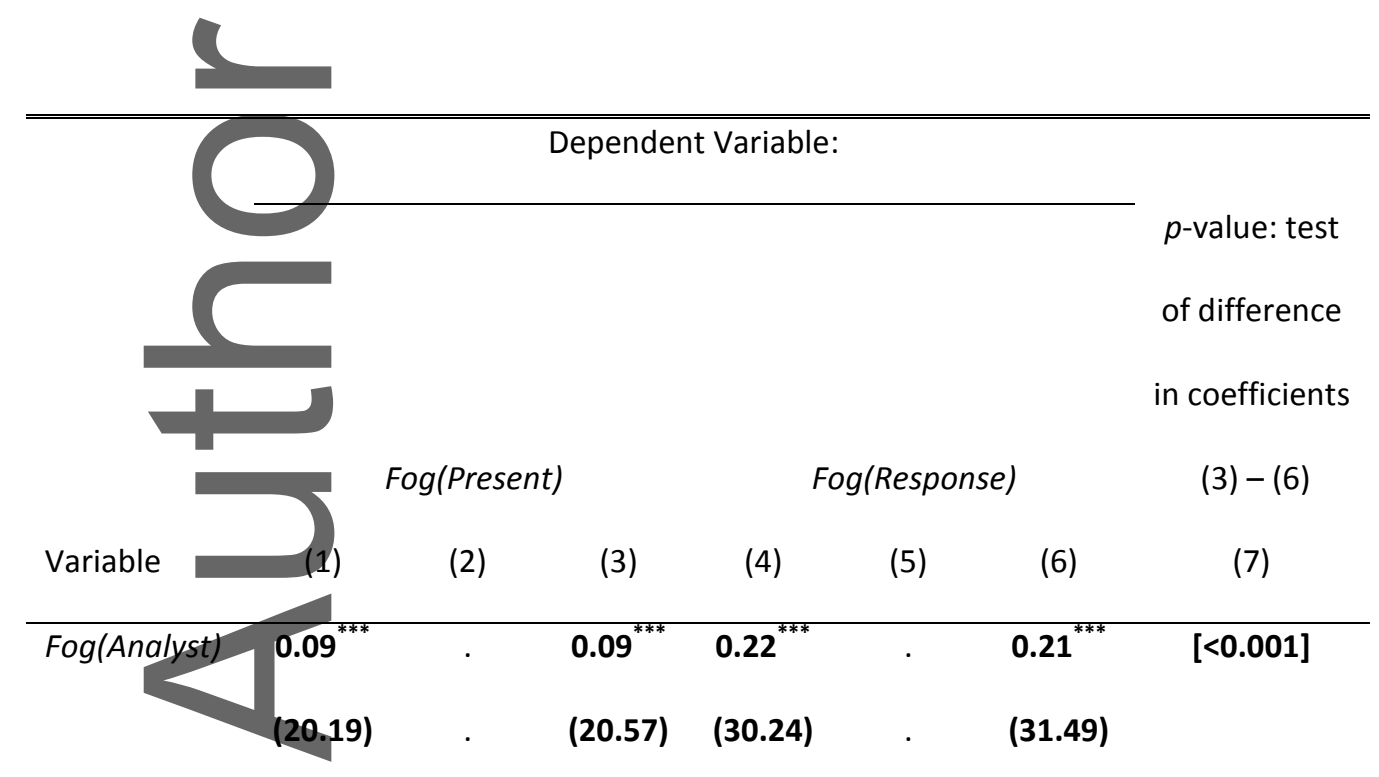

This article is protected by copyright. All rights reserved. 


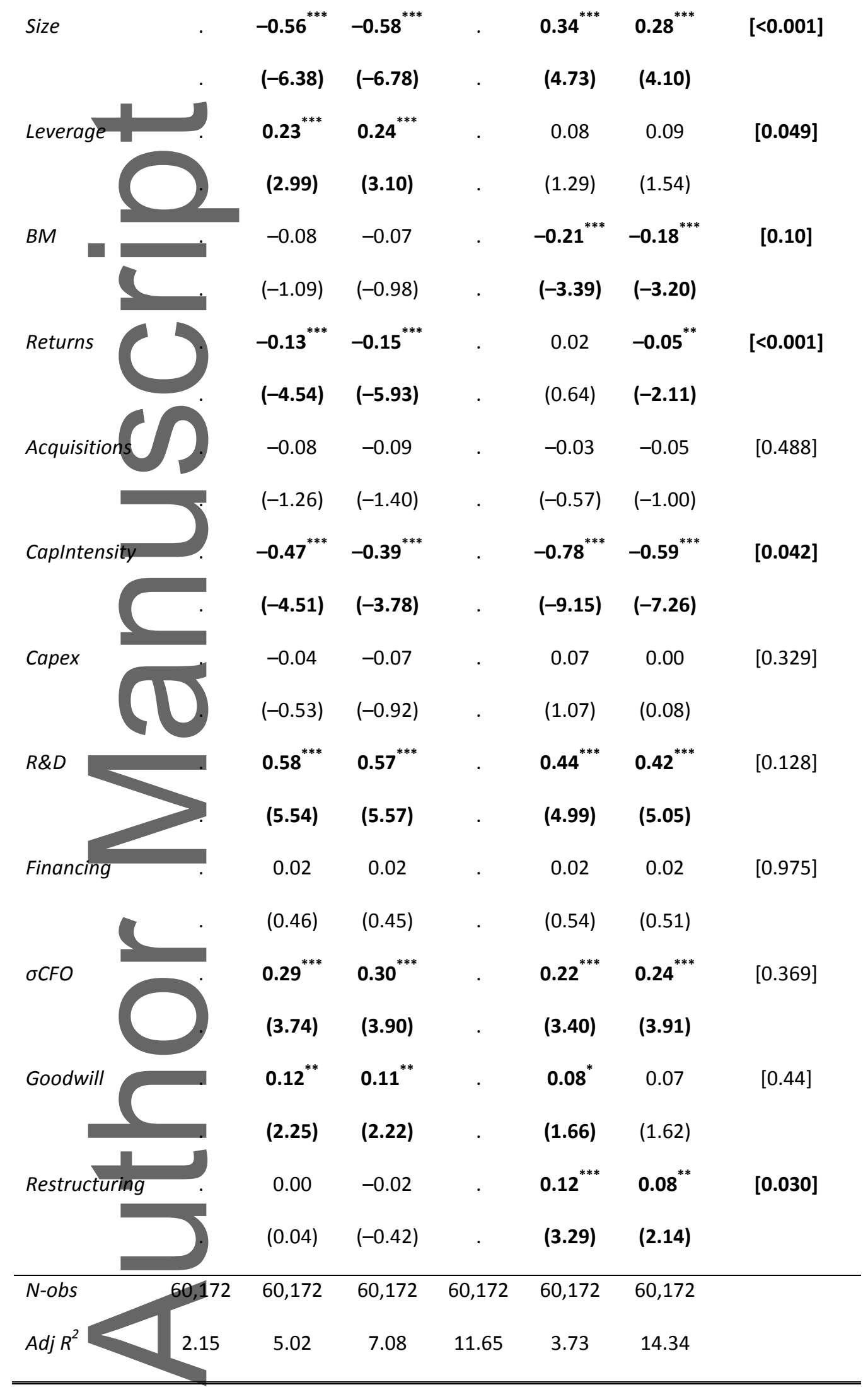

This article is protected by copyright. All rights reserved. 
This table presents results from estimating the linguistic complexity of managers during the respective portion of the conference call, Fog(Present) and Fog(Response), as a function of linguistic complexity of analysts, Fog(Analyst), and variables related to business complexity. We use the following variables to measure business complexity: firm size (Size); firm leverage (Leverage); book-to-market ratio (BM); historical stock performance (Returns); acquisitions (Acquisitions), capital intensity (Caplntensity), capital expenditures (Capex), research and development $(R \& D)$; debt and equity issuance (Financing); cash flow volatility ( $\sigma C F O)$; goodwill impairments (Goodwill) and restructuring charges (Restructuring). See Appendix C for variable definitions. For ease of interpretation, each of these variables is ranked into deciles and scaled to range from 0 to 1 . $t$-statistics appear in parentheses (two-tailed $p$-values appear in brackets) and are based on standard errors clustered by firm and date. ${ }^{* * *}$, and ${ }^{*}$ denote statistical significance at the $0.01,0.05$, and 0.10 levels (two-tail), respectively

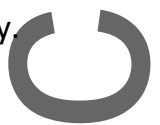

TABLE 3. Distribution of Estimated Latent Components of Linguistic Complexity

PANEL A. Descriptive Statistics

\begin{tabular}{|c|c|c|c|c|c|}
\hline Variable & Mean & Std. Dev. & P25 & Median & P75 \\
\hline Obfu(Pre & 0.000 & 1.533 & -0.978 & 0.028 & 1.026 \\
\hline Info(Pr & 5.861 & 0.423 & 15.599 & 15.855 & 16.132 \\
\hline Obfu(Re & 0.000 & 1.521 & -1.061 & -0.122 & 0.913 \\
\hline Info(Res) & 11.956 & 0.623 & 11.724 & 12.038 & 12.332 \\
\hline
\end{tabular}

PANEL B. Correlation Matrix of Estimated Latent Components of Linguistic Complexity
Variable
(1)
(2)
(3)
(4)
(5) (6)

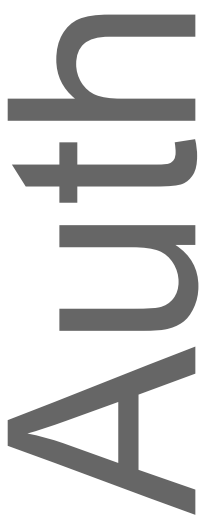

Presentation Portion

$\begin{array}{lllllll}\text { (1) Fog(Present) } & 1.00 & \mathbf{0 . 9 6} & 0.25 & 0.37 & 0.32 & 0.19 \\ \text { (2) Obfu(Present) } & \mathbf{0 . 9 6} & 1.00 & 0.00 & 0.31 & 0.34 & 0.02 \\ & & & & & & \\ \text { (3) Info(Present) } & 0.27 & 0.00 & 1.00 & 0.25 & 0.02 & \mathbf{0 . 6 2}\end{array}$

$\underline{\text { Response Portion }}$

(4) Fog(Response)

$\begin{array}{llllll}0.38 & 0.32 & 0.26 & 1.00 & \mathbf{0 . 9 1} & 0.42\end{array}$

This article is protected by copyright. All rights reserved. 

(5) Obfu(Response)
0.34
0.35
0.00
$0.93 \quad 1.00 \quad 0.09$
(6) Info(Response)
$0.19 \quad 0.00$
$\begin{array}{llll}0.70 & 0.38 & 0.00 & 1.00\end{array}$

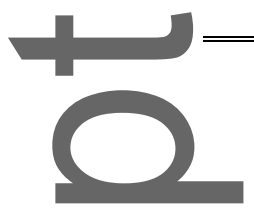

This table presents descriptive statistics and correlations among the latent components of linguistic complexity. Panel A reports the distribution of our empirical estimates of the latent components of managers' linguistic complexity. Panel B reports the correlations among the latent components of linguistic complexity. Fog(.) is the Fog index of the respective portion of the conference call. Obfu(.) is the latent obfuscation component during the respective section of the call and Info(.) is the latent information component during the respective section of the call. Spearman (Pearson) correlations appear above (below) the diagonal and bold denotes correlations in excess of 0.5 .

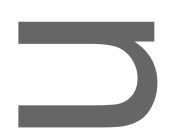

TABLE 4. Linguistic Complexity and Information Asymmetry

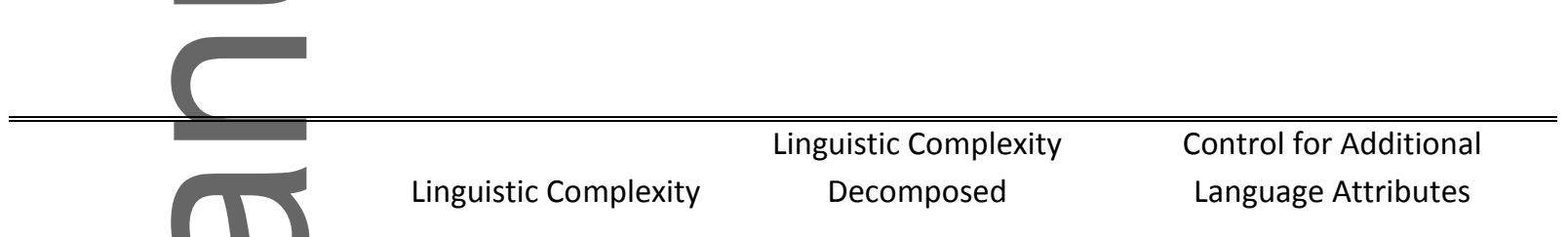

(1)

(2)

(3)

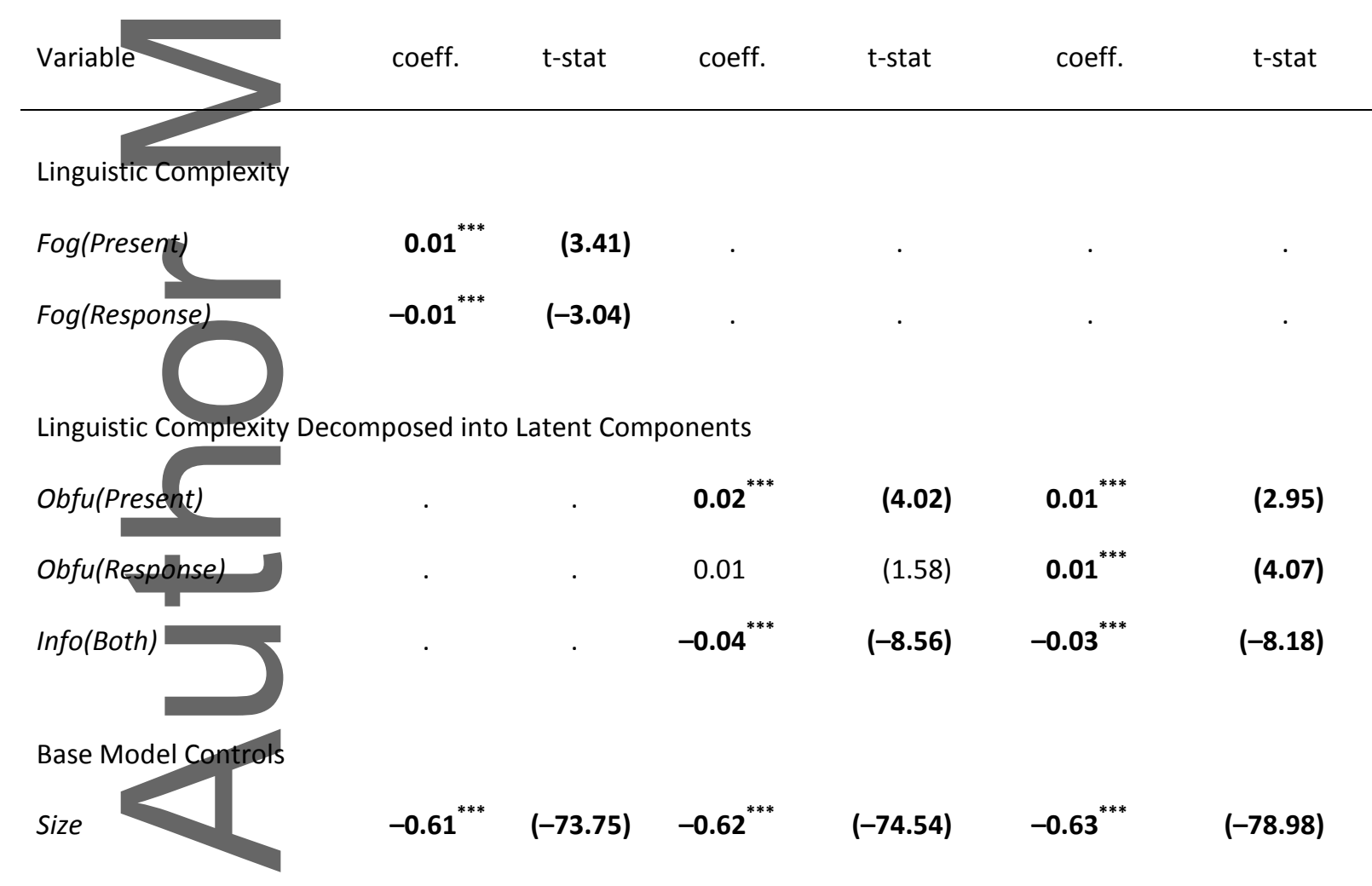

This article is protected by copyright. All rights reserved. 


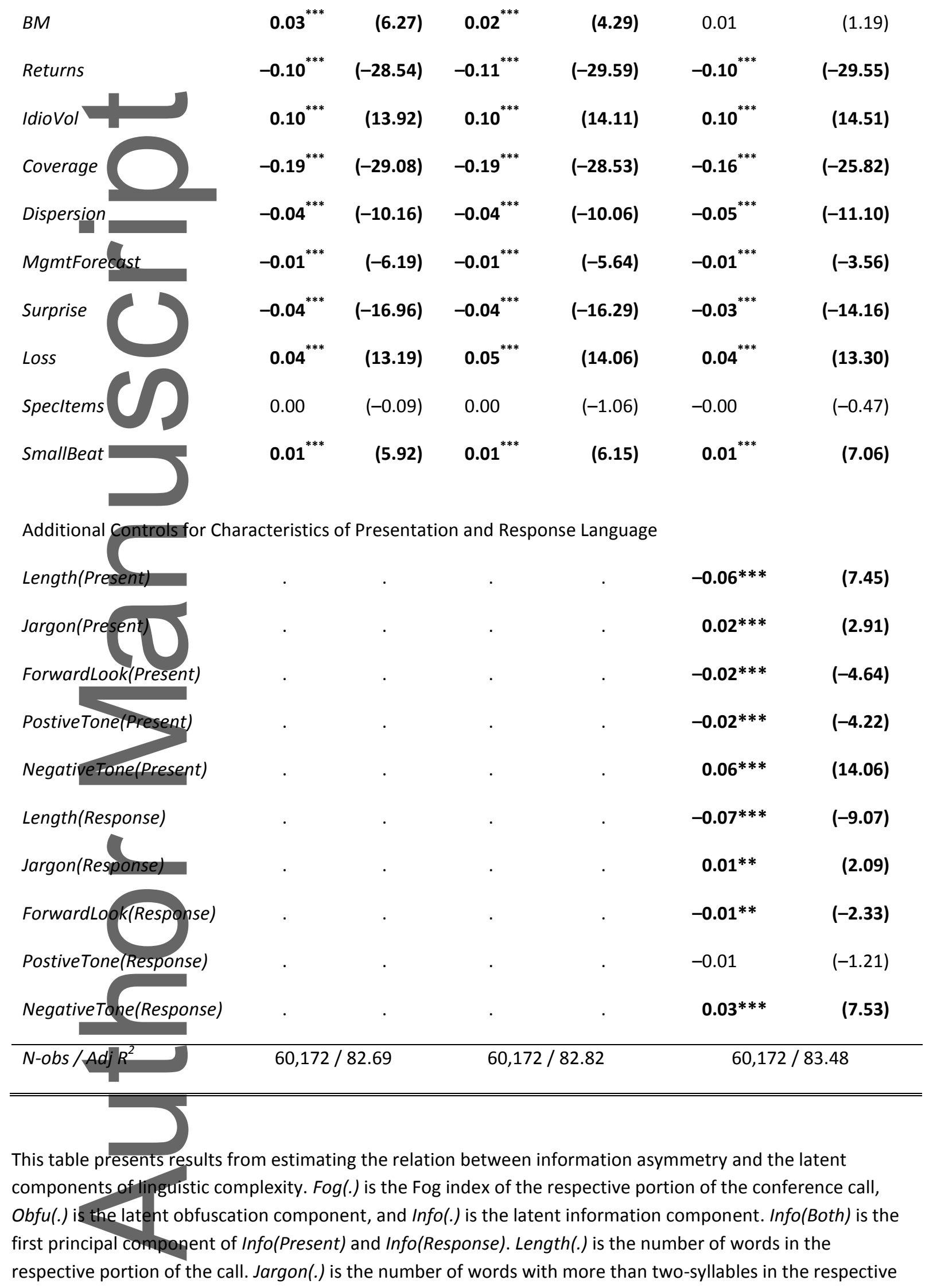

This article is protected by copyright. All rights reserved. 
portion of the call that are industry jargon, where industry jargon is defined as the 100 most common words with more than two-syllables among firms in the same two-digit SIC code. ForwardLook(.) is the proportion of sentences containing forward-looking statements during the respective portion of the call (Li [2010]).

PositiveTone(.) (NegativeTone(.)) is the number of positive (negative) tone words in the respective portion of the call (Loughran and McDonald [2011]). All other variables are as defined in Appendix C. For ease of interpretation, all independent variables are ranked into deciles and scaled to range from 0 to 1 . $t$-statistics appear in parentheses and are based on standard errors clustered by firm and date. ${ }^{* * *},{ }^{* *}$, and ${ }^{*}$ denote statistical significance at the $0.01,0.05$, and 0.10 levels (two-tail), respectively.

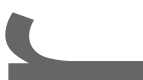

TABLE 5. Linguistic Complexity and Information Asymmetry: Alternative Specifications

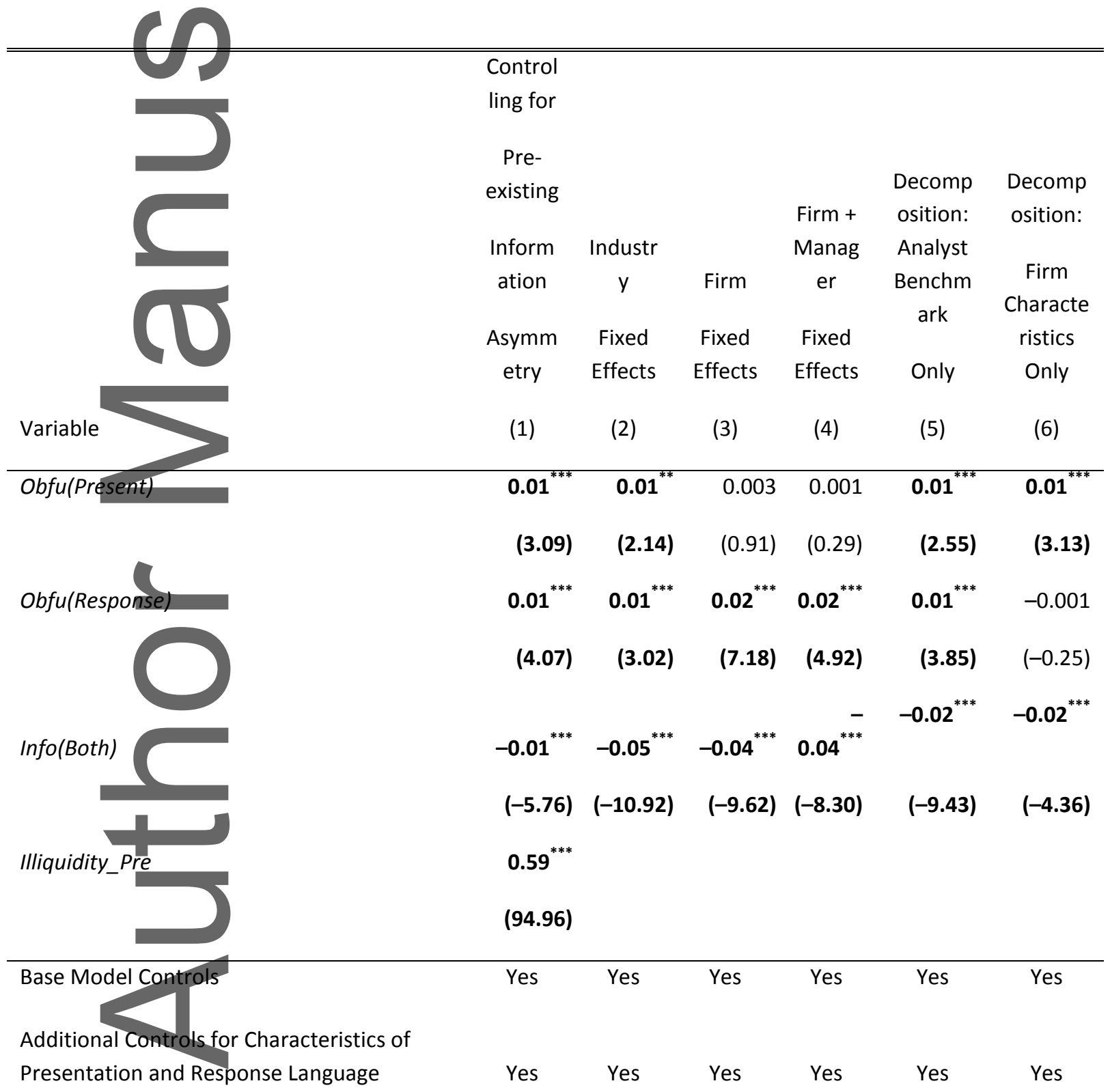

This article is protected by copyright. All rights reserved. 
Firm +

\begin{tabular}{|c|c|c|c|c|c|c|}
\hline \multirow[b]{2}{*}{ Fixed Effects } & & \multicolumn{5}{|c|}{$\begin{array}{l}\text { Firm + } \\
\text { Manag }\end{array}$} \\
\hline & None & y & Firm & er & None & None \\
\hline & 60,172 & 60,172 & 60,172 & 24,787 & $60,172 /$ & $60,172 /$ \\
\hline$N$-obs / Adj & / 91.41 & / 84.10 & / 89.88 & / 89.67 & 83.42 & 83.39 \\
\hline
\end{tabular}

This table presents results from estimating the relation between the latent components of linguistic complexity and information asymmetry using four alternative regression specifications. Specification (1) presents results after control for the average value of the Amihud (2002) measure of illiquidity over the fiscal quarter ended_immediately prior to the conference call (Illiquidity_Pre). Specification (2) presents results from a within-industry design that includes industry fixed effects, where industries are defined based on two-digit SIC codes. Specification (3) presents results from a within-firm design that includes firm fixed effects. Specification (4) presents results from a within-manager design that includes both firm and manager fixed effects. This specification requires both the identity of the CEO (from Execucomp) and that the firm has multiple CEOs during our sample period. Specification (5) estimates the latent information and obfuscation components using only linguistic complexity of analysts as the benchmark, see specifications (1) and (4) of Table 2. Specification (6) estimates the latent information and obfuscation components using only firm characteristics as the benchmark, see specifications (2) and (5) of Table 2. All other variables are as defined in Appendix C. Regression specification follow column 3 of Table 4. For parsimony, coefficients on control variables are not tabulated. $t$-statistics appear in parentheses and are based on standard errors clustered by firm and date ${ }^{* * *},{ }^{* *}$ and ${ }^{*}$ denote statistical significance at the $0.01,0.05$, and 0.10 levels (two-tail), respectively.

TABLE 6. Linguistic Complexity and Information Asymmetry: Monte Carlo Placebo Tests

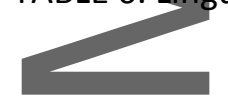

Avg. coeff
Cable 4

This article is protected by copyright. All rights reserved. 


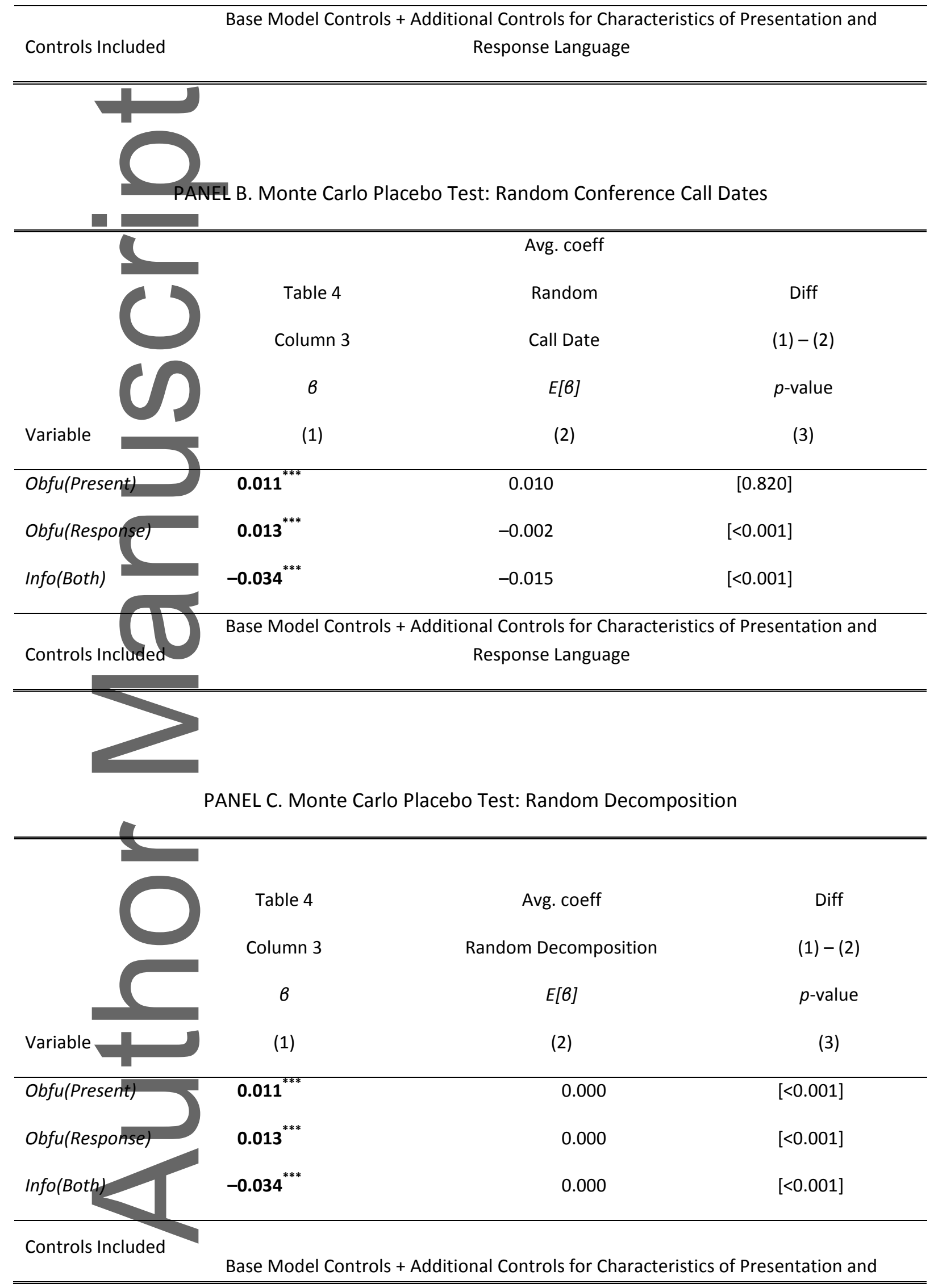

This article is protected by copyright. All rights reserved. 

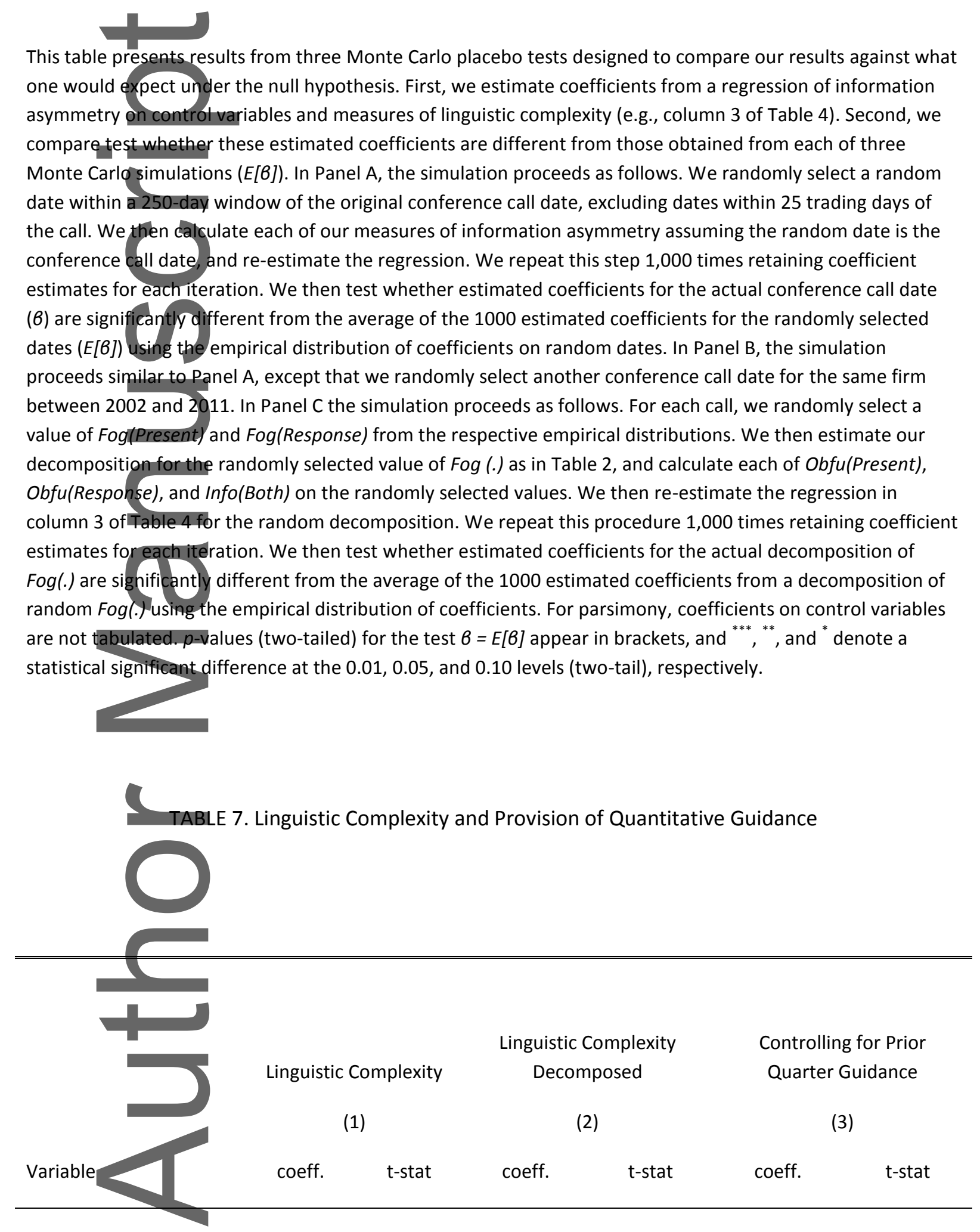

This article is protected by copyright. All rights reserved. 
Linguistic Complexity

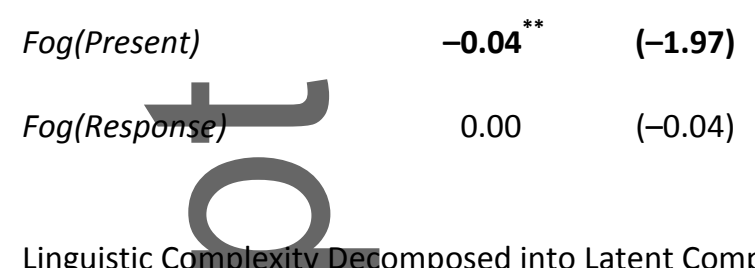

Linguistic Complexity Decomposed into Latent Components

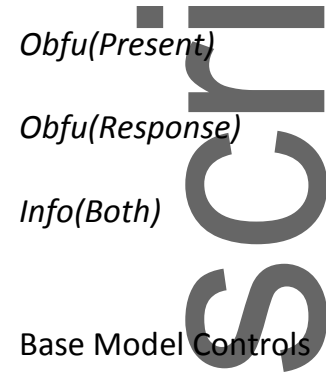

$$
\begin{array}{lll}
-0.06^{* * *} & (-3.06) & -0.03^{* * *} \\
-0.04^{* * *} & (-2.79) & -0.01 \\
0.08^{* * *} & (4.34) & 0.02^{* *}
\end{array}
$$

\begin{tabular}{|c|c|c|c|c|c|c|}
\hline Size & 0.02 & $(0.70)$ & $0.05^{*}$ & (1.91) & 0.01 & $(0.87)$ \\
\hline$B M$ & -0.01 & $(-0.59)$ & 0.01 & $(0.50)$ & 0.00 & $(-0.39)$ \\
\hline Returns & -0.01 & $(-1.58)$ & 0.00 & $(-0.55)$ & 0.00 & (0.23) \\
\hline IdioVol & $0.05^{* * *}$ & (2.96) & $0.05^{* * *}$ & (2.81) & $0.02^{* *}$ & (2.56) \\
\hline Coverage & $0.15^{* * *}$ & (5.74) & $0.14^{* * *}$ & (5.24) & $0.04^{* * *}$ & (3.99) \\
\hline Dispersion & $-0.19^{* * *}$ & $(-11.39)$ & $-0.20^{* * *}$ & $(-11.55)$ & $-0.07^{* * *}$ & $(-10.08)$ \\
\hline Surprise & $0.09^{* * *}$ & (9.74) & $0.09^{* * *}$ & (9.31) & $0.03^{* * *}$ & (6.18) \\
\hline Loss & $-0.08^{* * *}$ & $(-6.48)$ & $-0.09^{* * *}$ & $(-6.94)$ & $-0.03^{* * *}$ & $(-5.12)$ \\
\hline Specltems & $-0.13^{* * *}$ & $(-11.27)$ & $-0.12^{* * *}$ & $(-10.64)$ & $-0.05^{* * *}$ & $(-8.58)$ \\
\hline SmallBeat & 0.00 & $(0.46)$ & 0.00 & $(0.37)$ & 0.00 & (0.96) \\
\hline
\end{tabular}

\begin{tabular}{|c|c|c|c|c|c|}
\hline Length(Present) & $-0.13^{* * *}$ & $(-3.81)$ & $-0.14^{* * *}$ & $(-4.08)$ & $-0.04^{* * *}$ \\
\hline Jargon, & $0.22^{* * *}$ & (6.37) & $0.23^{* * *}$ & (6.74) & $0.09^{* * *}$ \\
\hline ForwardLo & $0.17^{* * *}$ & (10.70) & $0.18^{* * *}$ & (11.23) & $0.07^{* * *}$ \\
\hline PostiveTo & $0.12^{* * *}$ & (5.09) & $0.12^{* * *}$ & (4.95) & $0.04^{* * *}$ \\
\hline gativet & $-0.05^{* * *}$ & $(-2.58)$ & $-0.05^{* *}$ & $(-2.50)$ & $-0.03^{* * *}$ \\
\hline Length(Response) & 0.02 & $(0.51)$ & 0.01 & $(0.31)$ & 0.01 \\
\hline
\end{tabular}

Additional Controls for Characteristics of Presentation and Response Language

This article is protected by copyright. All rights reserved. 


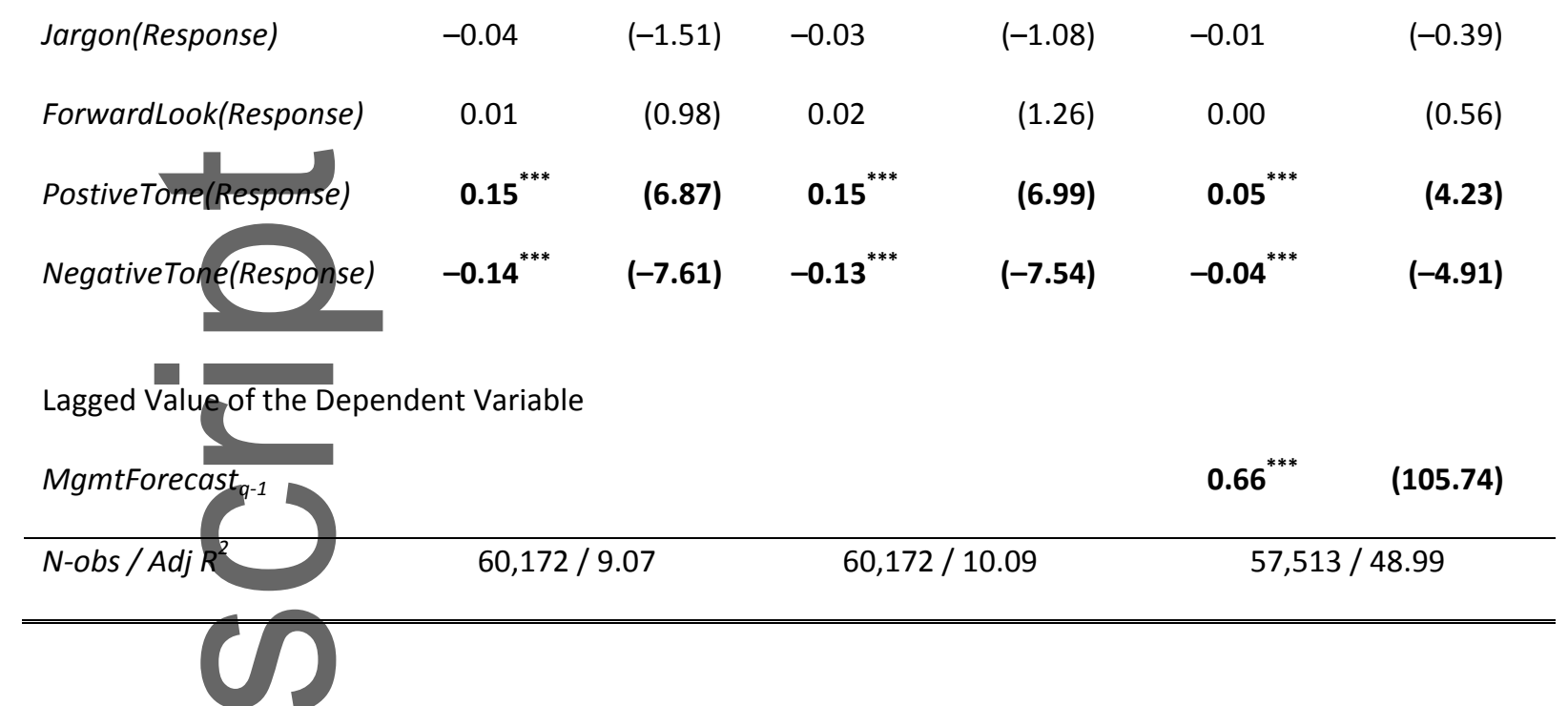

This table presents results from estimating the relation between the provision of quantitative guidance on the call and the latent components of linguistic complexity. The dependent variable is an indicator variable for whether the firm provides an earnings forecast during the conference call $\left(\right.$ MgmtForecast $\left._{q}\right)$. All other variables are as defined in Table 4. For ease of interpretation, all independent variables are ranked into deciles and scaled to range from 0 to 1 . $t$-statistics appear in parentheses and are based on standard errors clustered by firm and date. ${ }^{* * *}$, and ${ }^{*}$ denote statistical significance at the $0.01,0.05$, and 0.10 levels (two-tail), respectively.

BLE 8. Latent Components of Linguistic Complexity in Loss Firms

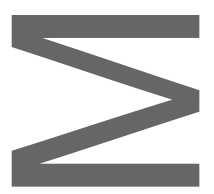

PANEL A. Loss Firms and the Latent Components of Linguistic Complexity

\begin{tabular}{|c|c|c|c|c|c|c|}
\hline \multirow{2}{*}{ Sample partition: } & \multicolumn{2}{|c|}{ Profit Firms } & \multicolumn{2}{|c|}{ Loss Firms } & $\begin{array}{l}p \text {-value: test } \\
\text { of difference }\end{array}$ & \multirow{2}{*}{$\begin{array}{l}p \text {-value: test } \\
\text { of difference in medians }\end{array}$} \\
\hline & mean & median & mean & median & in means & \\
\hline Fog(Pre & 15.754 & 15.794 & 16.396 & 16.426 & {$[<0.001]$} & {$[<0.001]$} \\
\hline Obfu(Pres & -0.049 & -0.023 & 0.244 & 0.288 & {$[<0.001]$} & {$[<0.001]$} \\
\hline Info(Prese & 15.803 & 15.812 & 16.152 & 16.184 & {$[<0.001]$} & {$[<0.001]$} \\
\hline Fog(Respon & 11.906 & 11.788 & 12.201 & 12.093 & {$[<0.001]$} & {$[<0.001]$} \\
\hline Obfu(R & -0.038 & -0.160 & 0.189 & 0.066 & {$[<0.001]$} & {$[<0.001]$} \\
\hline Info(Respor & 11.944 & 12.023 & 12.012 & 12.109 & {$[<0.001]$} & {$[<0.001]$} \\
\hline
\end{tabular}

This article is protected by copyright. All rights reserved. 
PANEL B. Loss Firms and the Relation between Latent Components of Linguistic Complexity and Information Asymmetry

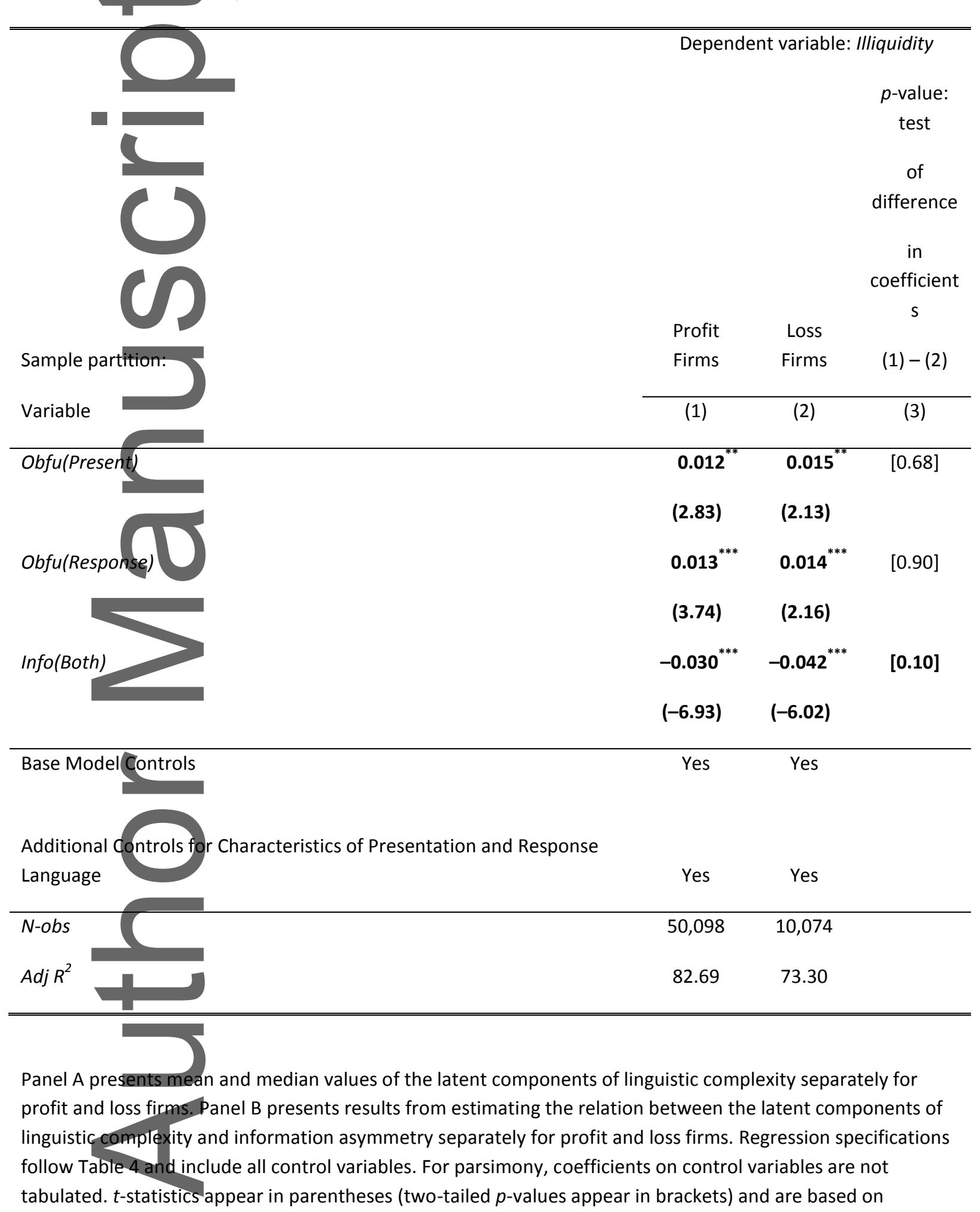

This article is protected by copyright. All rights reserved. 
standard errors clustered by firm and date. ${ }^{* * *},{ }^{* *}$, and ${ }^{*}$ denote statistical significance at the $0.01,0.05$, and 0.10 levels (two-tail), respectively.

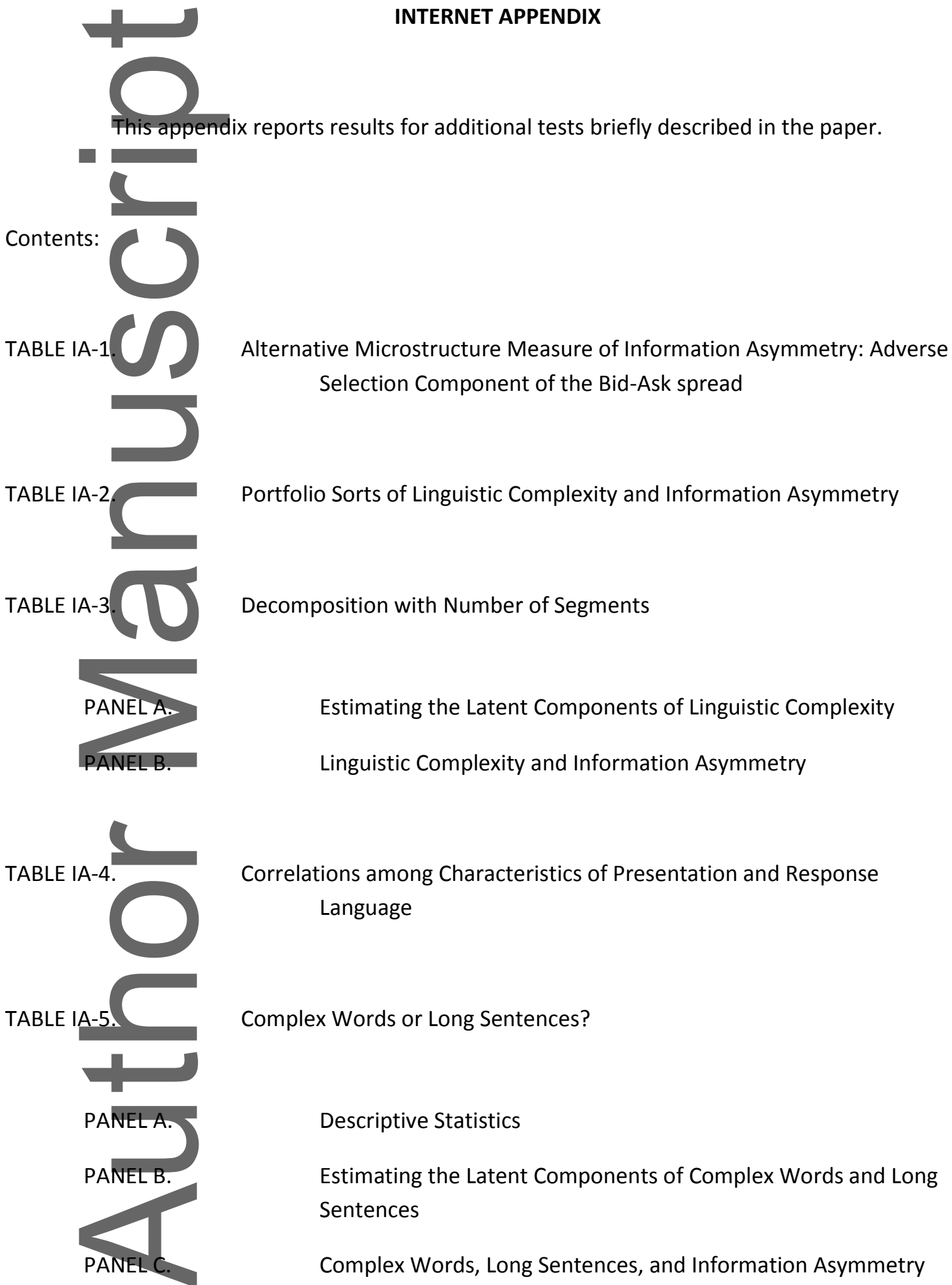

Portfolio Sorts of Linguistic Complexity and Information Asymmetry

Decomposition with Number of Segments

Estimating the Latent Components of Linguistic Complexity

Linguistic Complexity and Information Asymmetry

Correlations among Characteristics of Presentation and Response Language

\author{
Descriptive Statistics \\ Estimating the Latent Components of Complex Words and Long \\ Sentences \\ Complex Words, Long Sentences, and Information Asymmetry
}

This article is protected by copyright. All rights reserved. 


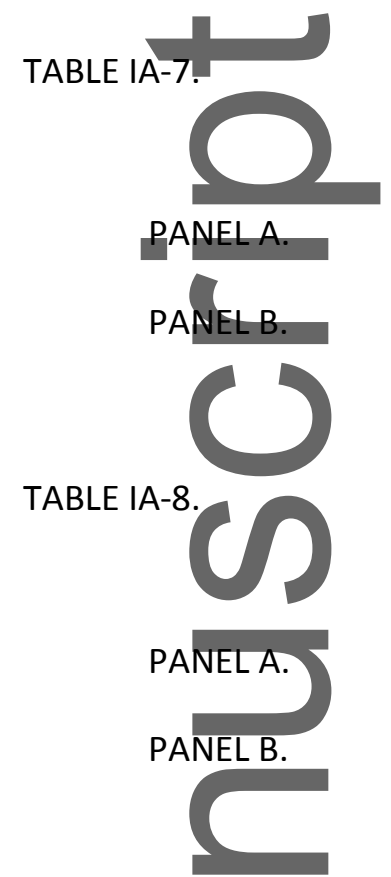

Decomposition of Early versus Late Portion of the Response

Estimating the Latent Components of Linguistic Complexity

Linguistic Complexity and Information Asymmetry

Decomposition of FOG calculated as in Li[2008]

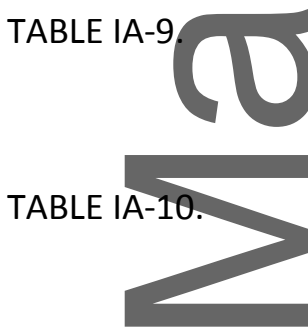

Alternative Ways to Control for Outliers in Illiquidity

TABLE IA-1. Alternative Microstructure Measure of Information Asymmetry:

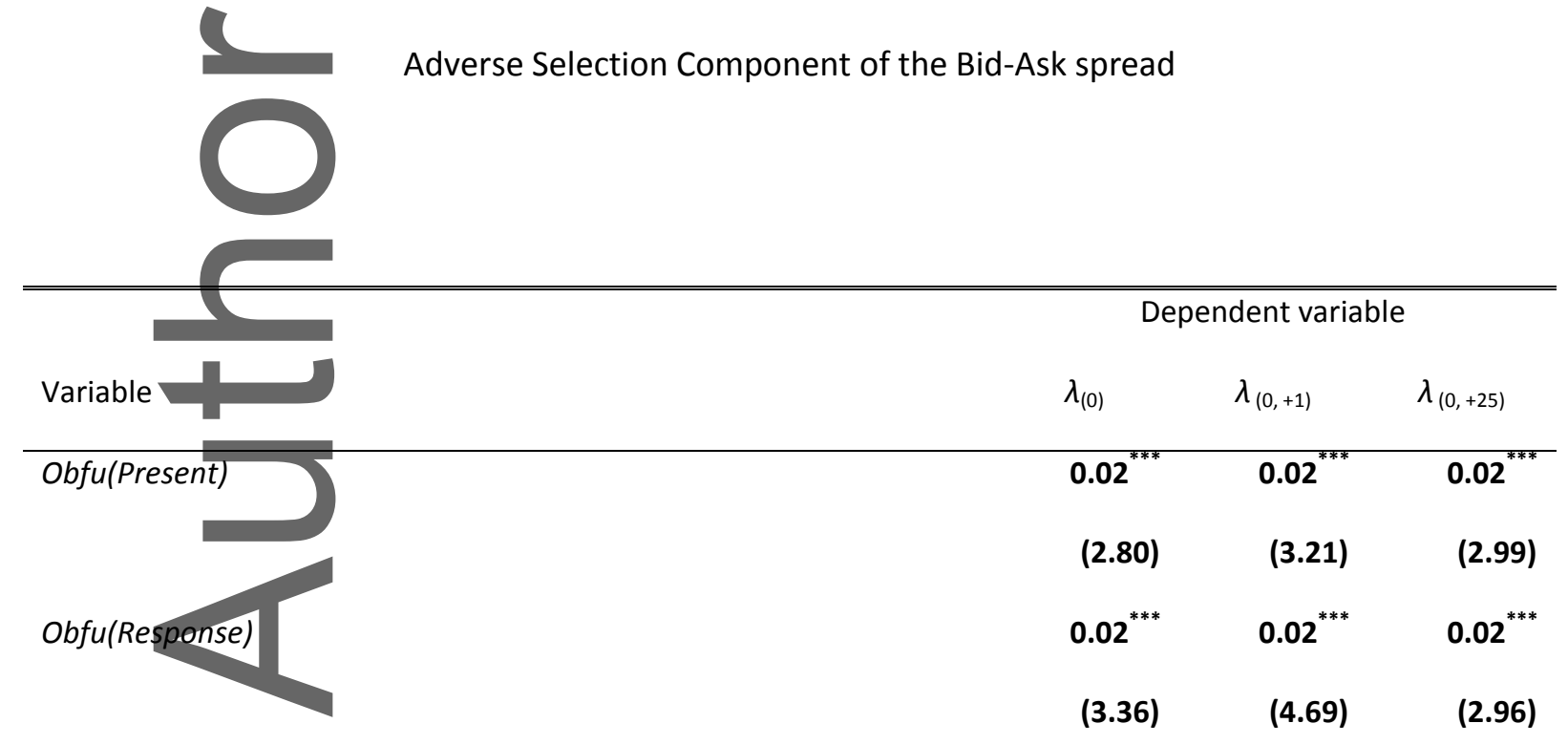

This article is protected by copyright. All rights reserved. 
Additional Controls for Characteristics of Presentation and Response

\begin{tabular}{|c|c|c|c|}
\hline Language & Yes & Yes & Yes \\
\hline$N$-obs & 45,341 & 45,341 & 45,341 \\
\hline $\operatorname{Adj} R^{2}$ & 49.57 & 56.77 & 40.55 \\
\hline
\end{tabular}

This table presents results from estimating the relation between information asymmetry and the latent components of linguistic complexity, using the adverse selection component of the bid-ask spread, or $\lambda$, to measure information asymmetry. $\lambda$ measures the extent to which unexpected order flow affects prices (i.e., the price impact of a trade) and is increasing in information asymmetry. We calculate $\lambda$ at the daily level and then take the average value of the respective period, either $(0),(0,+1)$, or $(0, \ldots,+25)$, where day 0 is the day of the call. We then follow Balakrishnan, Core, and Verdi [2014] and use the percentile ranks of $\lambda$ in our regression tests. Details on the estimation procedure appear below. Because this measures requires intra-day data from TAQ, it is available for only approximately $75 \%$ of our sample. For this reason, we use it as an alternative measure. Regression specifications follow column 3 of Table 4. $t$-statistics appear in parentheses and are based on standard errors clustered by firm and date. ${ }^{* * *},{ }^{* *}$, and ${ }^{*}$ denote statistical significance at the $0.01,0.05$, and 0.10 levels (two-tail), respectively.

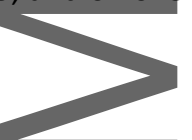

Estimation of $\lambda$. Following Madhavan, Richardson, and Roomans [1997] and Armstrong, Core, Taylor, and Verrecchia [2011], we clean intraday trade and quote data from TAQ and estimate the following firm-day regression:

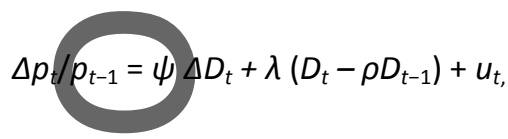

where $p_{t}$ is the transaction price, $D_{t}$ is the sign of trade ( +1 if buy and -1 if sell), and $\rho$ is the $\operatorname{AR}(1)$ coefficient for $D_{t}$. We require at least ten trades for each firm-day to estimate the regression. We deflate the dependent variable by lagged price to allow for cross-sectional comparability. Estimates are winsorized at the $1 \%$ and $99 \%$ levels. The fitted $\lambda$ in the above, represents our estimate of $\lambda$.

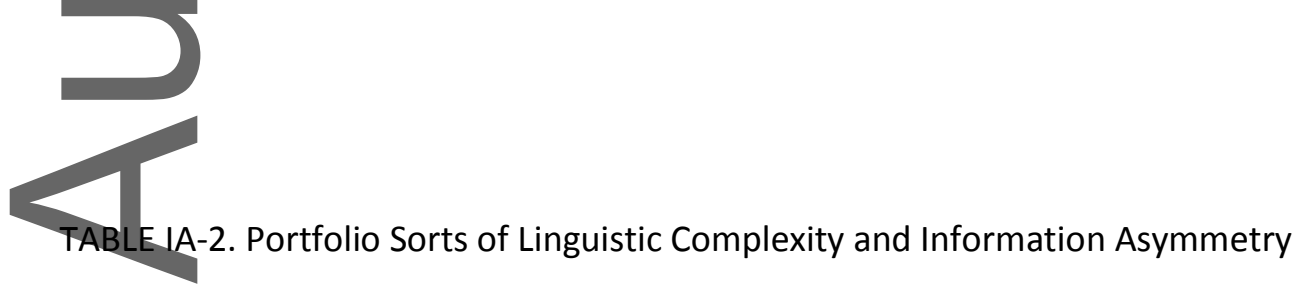

This article is protected by copyright. All rights reserved. 
PANEL A. Linguistic Complexity of the Presentation

\begin{tabular}{|c|c|c|c|c|c|c|}
\hline \multirow{3}{*}{ Sort variable } & \multicolumn{5}{|c|}{ Abnormal Illiquidity by Quintile of Sort } & \multirow[b]{2}{*}{ Diff } \\
\hline & & & Variable & & & \\
\hline & Q1 & Q2 & Q3 & Q4 & Q5 & Q5-Q1 \\
\hline \multirow{9}{*}{$\begin{array}{l}\text { Linguistic Corr } \\
\text { Fog(Present) }\end{array}$} & -0.003 & -0.002 & -0.002 & 0.003 & 0.004 & 0.007 \\
\hline & $1-$ & $1-$ & $1-$ & & & $(5,03)$ \\
\hline & $3.08)$ & 2.05) & $1.58)$ & $(2.36)$ & $(4.00)$ & \\
\hline & -0.006 & -0.004 & -0.001 & 0.004 & 0.008 & 0.014 \\
\hline & $1-$ & $1-$ & $1-$ & & & (9.16) \\
\hline & $6.09)$ & $3.96)$ & 1.08) & (3.96) & $(6.85)$ & \\
\hline & 0.007 & 0.004 & 0.006 & -0.000 & -0.017 & -0.024 \\
\hline & & & & $1-$ & $(-$ & $1-$ \\
\hline & (6.81) & $(4.18)$ & $(5.50)$ & $0.09)$ & 14.70) & 15.62) \\
\hline
\end{tabular}

PANEL B. Linguistic Complexity of the Presentation

\begin{tabular}{|c|c|c|c|c|c|c|}
\hline \multirow{4}{*}{ Sort variable } & \multicolumn{6}{|c|}{ Abnormal Illiquidity by Quintile of Sort } \\
\hline & \multicolumn{5}{|c|}{ Variable } & \multirow{2}{*}{$\begin{array}{c}\text { Diff } \\
\text { Q5-Q1 }\end{array}$} \\
\hline & Q1 & Q2 & Q3 & Q4 & Q5 & \\
\hline & 0.004 & -0.000 & -0.001 & -0.002 & -0.000 & -0.004 \\
\hline Linguistic Complexity of Response, Fog(Response) & (3.42) & $\begin{array}{c}(- \\
0.26)\end{array}$ & $\begin{array}{c}(- \\
1.07)\end{array}$ & $\begin{array}{c}(- \\
1.68)\end{array}$ & $(-0.39)$ & $(-2.67)$ \\
\hline & -0.003 & -0.003 & -0.000 & 0.003 & 0.003 & 0.006 \\
\hline Obfu(Response) & $\begin{array}{c}(- \\
2.76)\end{array}$ & $\begin{array}{c}(- \\
3.06)\end{array}$ & $\begin{array}{c}(- \\
0.05)\end{array}$ & $(2.72)$ & $(2.96)$ & $(4.04)$ \\
\hline Information Component, & 0.011 & 0.007 & 0.001 & -0.005 & -0.014 & -0.025 \\
\hline
\end{tabular}

This article is protected by copyright. All rights reserved. 
This table presents average abnormal illiquidity by quintile of linguistic complexity and its latent components. Abnormallilliquidity is the residual from a regression of Illiquidity on control variables specified in Section 3.3. In Panel A firm-quarters are ranked into quintiles based on linguistic complexity of the presentation section of the call, Fog(Present), and its latent obfuscation and information components, Obfu(Present) and Info(Present) respectively. In Panel B firm-quarters are ranked into quintiles based on linguistic complexity of the response section of the call, Fog (Response), and its latent obfuscation and information components, Obfu(Response) and Info(Response) respectively. $t$-statistics appear in parentheses and test whether the average abnormal illiquidity is different from zero. See Appendix $\mathrm{C}$ for variable definitions.

TABLE IA-3. Decomposition with Number of Segments

PANEL A. Estimating the Latent Components of Linguistic Complexity
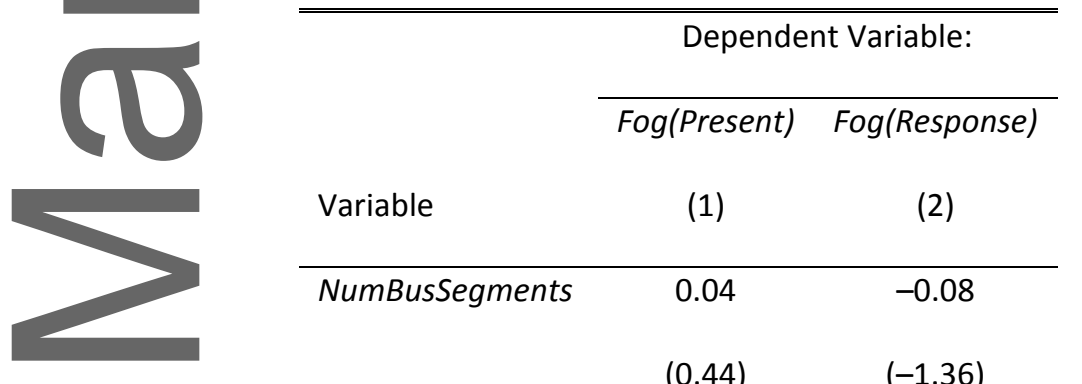

\begin{tabular}{lcc} 
Variable & $(1)$ & $(2)$ \\
\hline NumBusSegments & 0.04 & -0.08 \\
& $(0.44)$ & $(-1.36)$ \\
NumGeoSegments & $-\mathbf{0 . 6 4 ^ { * * * }}$ & $-\mathbf{0 . 2 6} 6^{* * *}$ \\
& $(\mathbf{- 7 . 0 3 )}$ & $\mathbf{( - 3 . 4 8 )}$
\end{tabular}

Base Model

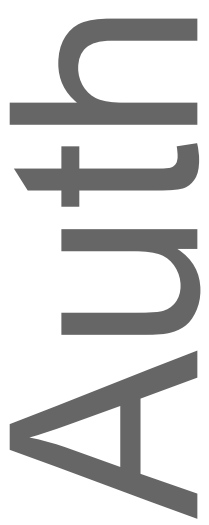

Fog(Analysts)

$0.09^{* * *}$

$0.21^{* * *}$

(20.42)

(31.37)

Size

$-0.48^{* * *}$

$0.33^{* * *}$

$(-5.52)$

(4.85)

Leverage

$0.20^{* * *}$

0.09

(2.61)

This article is protected by copyright. All rights reserved. 


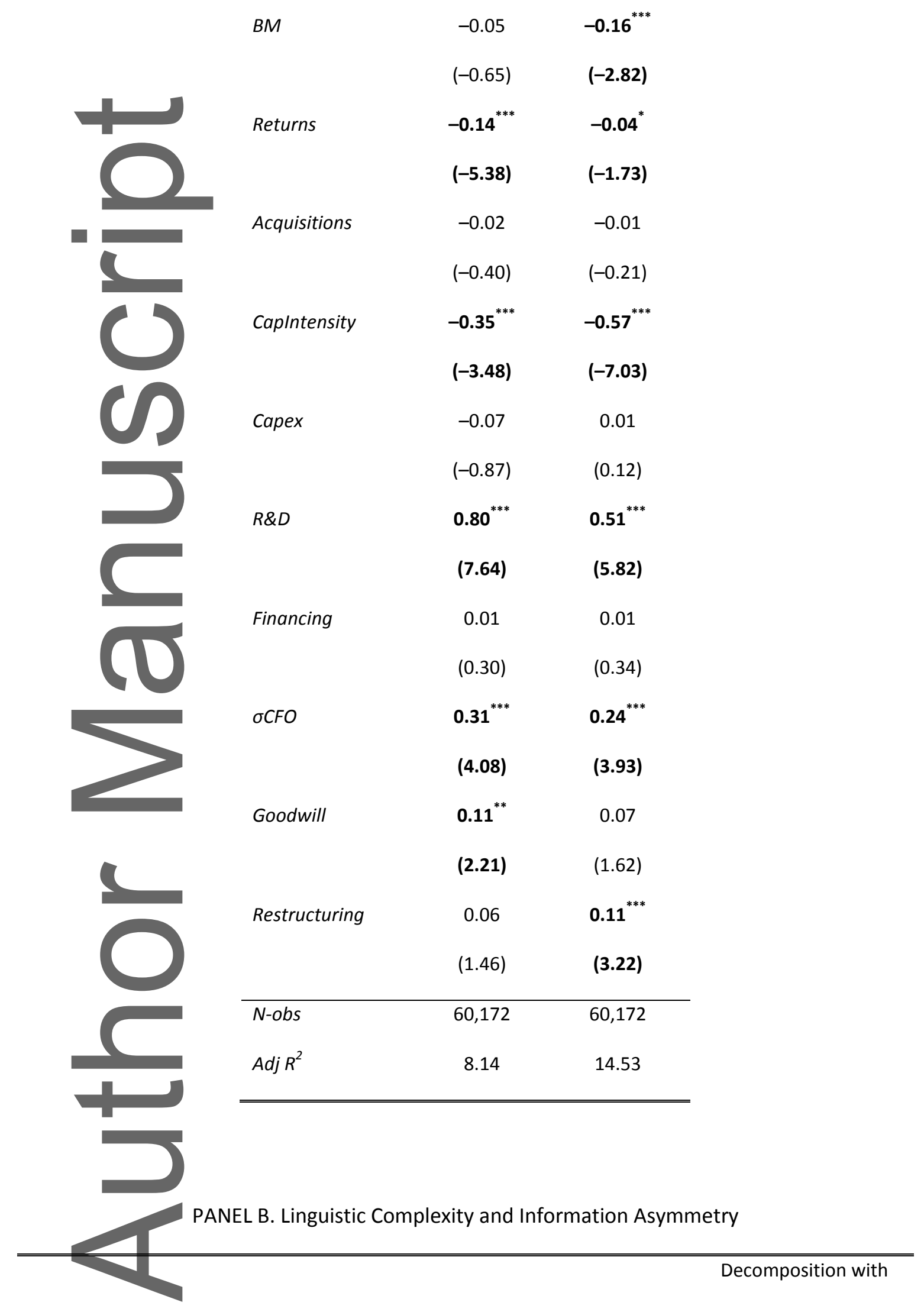

This article is protected by copyright. All rights reserved. 
Segment Data

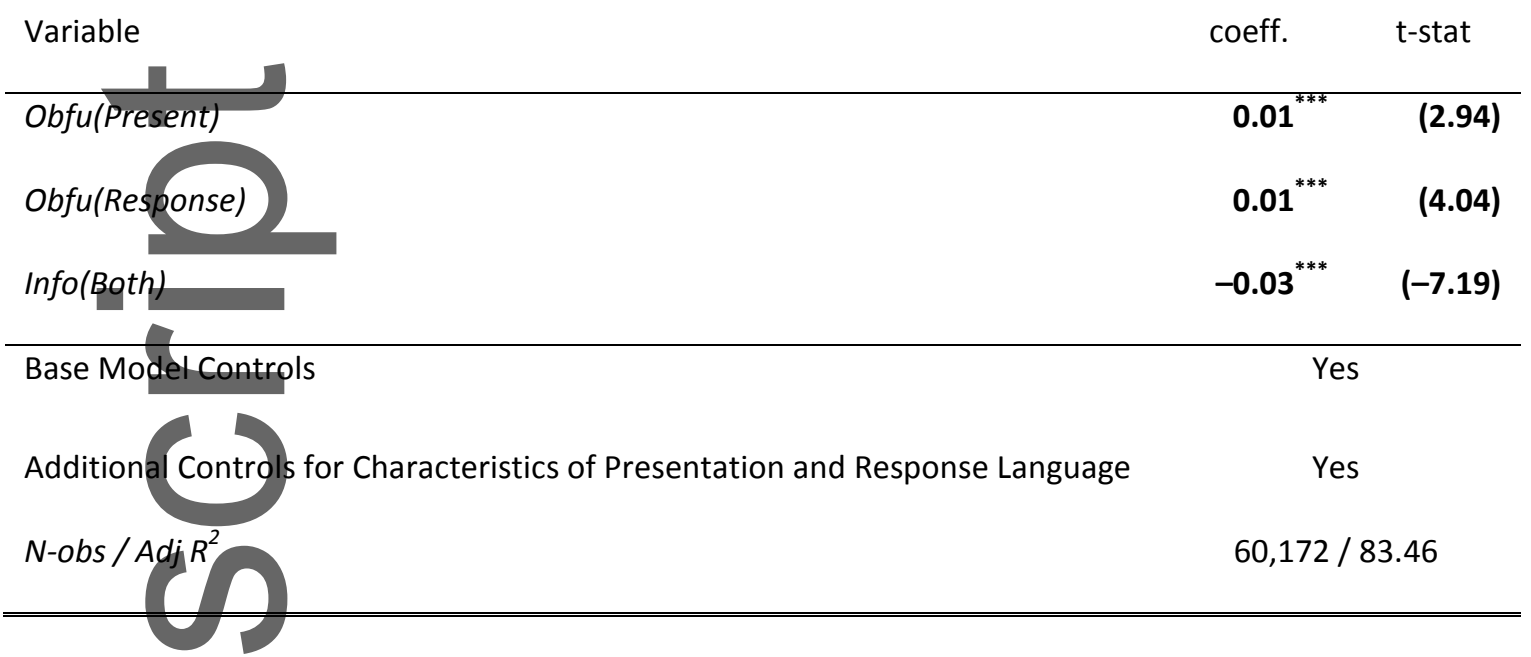

This table presents results from repeating our primary analysis using the number of business segments (NumBusSegments) and number of geographic segments (NumGeoSegments) as additional controls for complexity not associated with obfuscation. Panel A presents results from estimating the specification in Table 2 including these additional variables. Panel B presents results from estimating the specification in Table 4 based on the decomposition of linguistic complexity given in Panel $A$ that employs the additional segment variables. All variables are as previously defined. $t$-statistics appear in parentheses and are based on standard errors clustered by firm and date. ${ }^{* * *},{ }^{* *}$, and ${ }^{*}$ denote statistical significance at the $0.01,0.05$, and 0.10 levels (two-tail), respectively.

TABLE IA-4. Correlations Among Characteristics of Presentation and Response Language

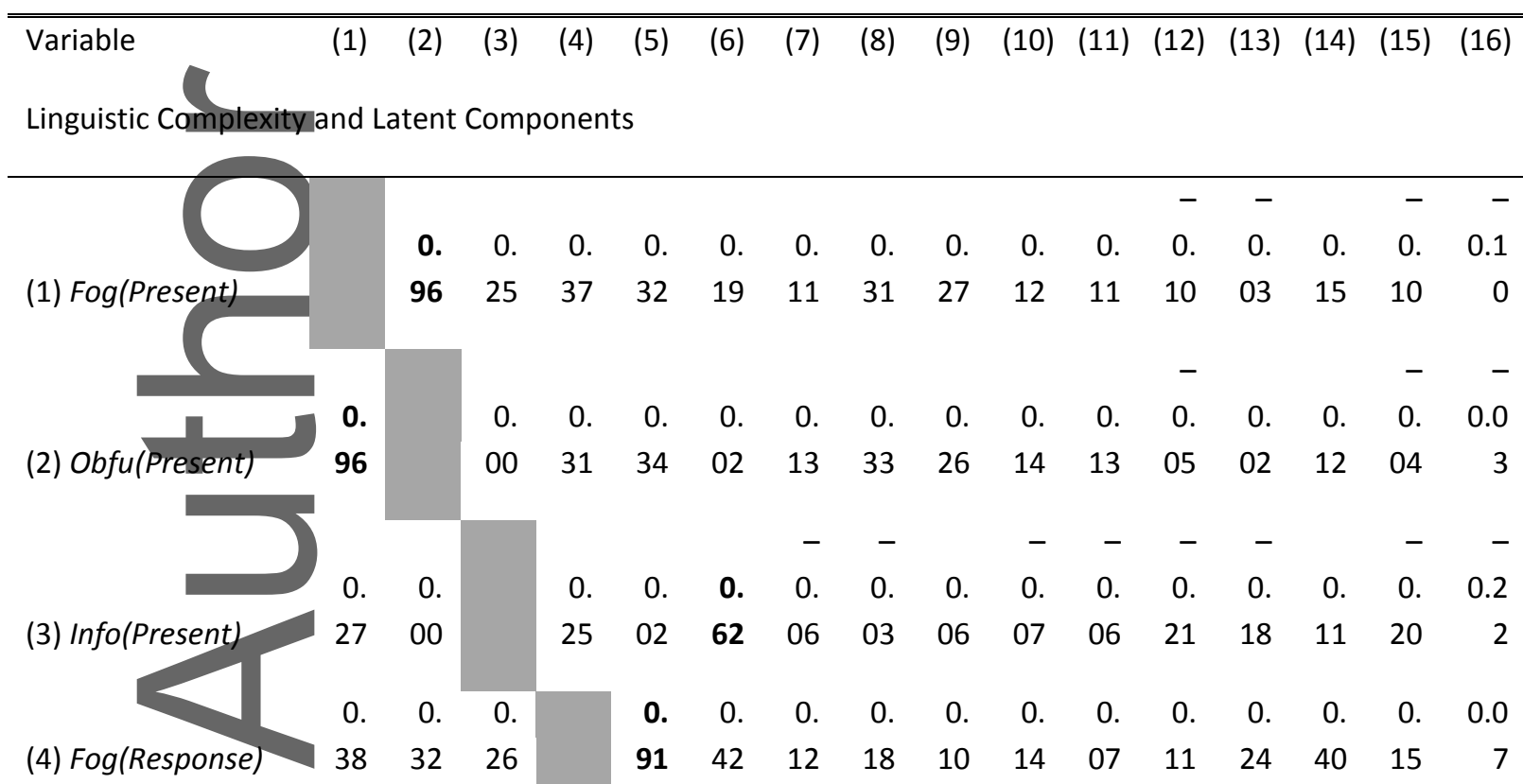

This article is protected by copyright. All rights reserved. 


$\begin{array}{rrrrrrrrrrrrrrrrr} & 0 . & 0 . & 0 . & \mathbf{0 .} & & 0 . & 0 . & 0 . & 0 . & 0 . & 0 . & 0 . & 0 . & 0 . & 0 . & 0.1 \\ \text { (5) Obfu(Response) } & 34 & 35 & 00 & \mathbf{9 3} & & 09 & 09 & 14 & 09 & 10 & 06 & 13 & 25 & 37 & 15 & 0 \\ & & & & & & & & & & & & & & & & \\ & 0 . & 0 . & \mathbf{0 .} & 0 . & 0 . & & 0 . & 0 . & 0 . & 0 . & 0 . & 0 . & 0 . & 0 . & 0 . & 0.0 \\ \text { (6) Info(Response) } & 19 & 00 & \mathbf{7 0} & \mathbf{3 8} & 00 & & 13 & 14 & 04 & 15 & 06 & 09 & 12 & 16 & 10 & 6\end{array}$

Characteristics of Presentation and Response Language

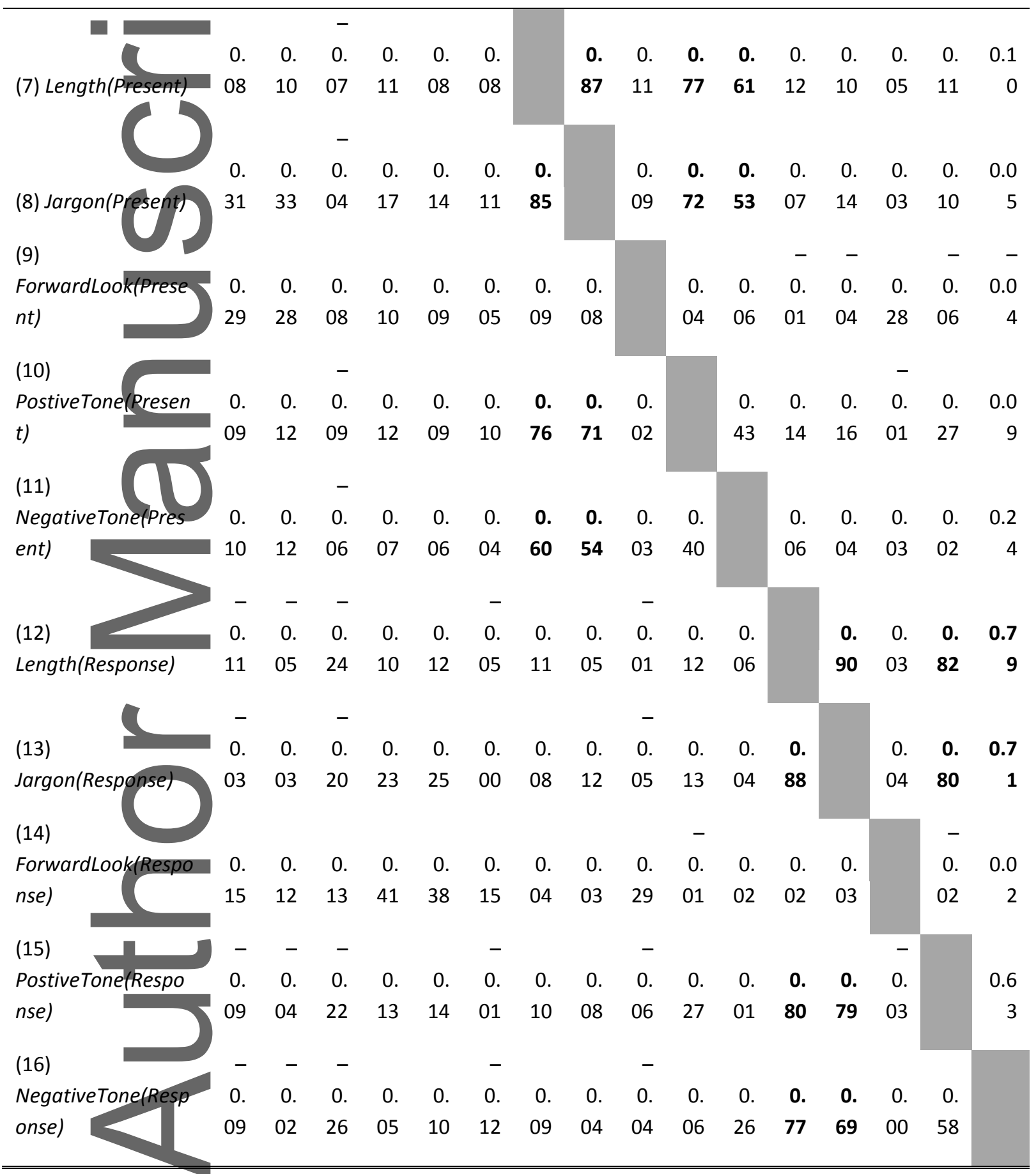

This article is protected by copyright. All rights reserved. 
This table presents correlations among the latent components of linguistic complexity and characteristics of presentations and response language. Fog(.) is the Fog index of the respective portion of the conference call. $O b f u($.$) is the latent obfuscation component during the respective section of the call. Info(.) is the latent$ information component during the respective section of the call. Pearson correlations between $O b f u()$ and Info() are zero by construction. Length(.) is the number of words in the respective portion of the call. Jargon(.) is the number of words with more than two-syllables in the respective portion of the call that are industry jargon, where industry jargon is defined as the 100 most common words with more than two-syllables among firms in the same two-digit SIC code. ForwardLook(.) is the proportion of sentences containing forward-looking statements (ti [2010]). PositiveTone(.) (NegativeTone(.)) is the number of positive (negative) tone words in the respective portion of the call (Loughran and McDonald [2011]). Spearman (Pearson) correlations appear above (below) the diagonal and bold denotes correlations in excess of 0.5 .

TABLE IA-5. Complex Words or Long Sentences?

\begin{tabular}{|c|c|c|c|c|c|}
\hline \multicolumn{6}{|c|}{ PANEL A. Descriptive Statistics } \\
\hline Variable & Mean & Std. Dev. & P25 & Median & P75 \\
\hline PctComplex(Anal) & 0.096 & 0.028 & 0.090 & 0.100 & 0.110 \\
\hline htLength(Anal) & 12.598 & 4.035 & 11.257 & 12.925 & 14.724 \\
\hline PctComplex(Present) & 0.192 & 0.028 & 0.175 & 0.194 & 0.211 \\
\hline entLength(Present) & 20.433 & 2.592 & 18.738 & 20.307 & 21.991 \\
\hline PctComplex(Response) & 0.117 & 0.018 & 0.105 & 0.116 & 0.128 \\
\hline SentLength(Response) & 18.188 & 3.579 & 15.818 & 17.845 & 20.170 \\
\hline
\end{tabular}
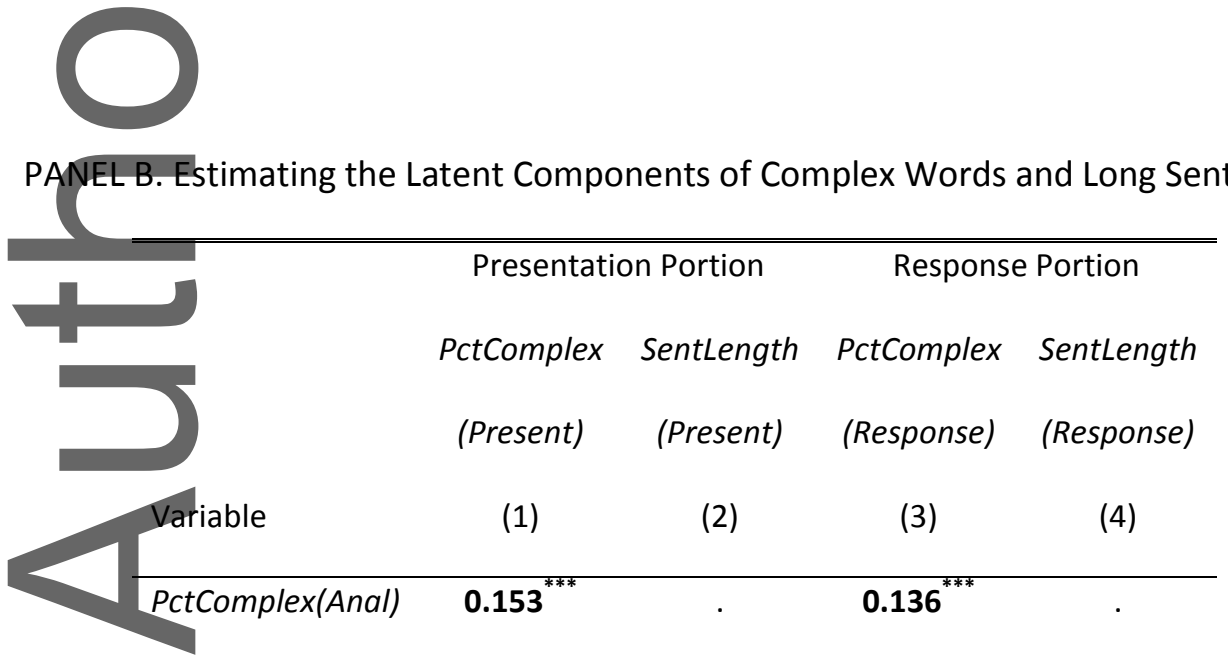

This article is protected by copyright. All rights reserved. 
(19.71)

(20.11)

\begin{tabular}{|c|c|c|c|c|}
\hline SentLength(Anal) & . & $0.077^{* * *}$ & . & $0.346^{* * *}$ \\
\hline & - & (17.46) & . & (37.22) \\
\hline & $-0.004^{* * *}$ & $-1.075^{* * *}$ & $-0.002^{* *}$ & $0.817^{* * *}$ \\
\hline & $(-2.65)$ & $(-8.28)$ & $(-2.40)$ & (6.34) \\
\hline erage & 0.001 & $0.467^{* * *}$ & $0.002^{* *}$ & 0.086 \\
\hline & $(1.02)$ & (3.92) & (2.12) & $(0.73)$ \\
\hline & 0.001 & $-0.324^{* * *}$ & -0.001 & $-0.370^{* * *}$ \\
\hline & (1.05) & $(-2.88)$ & $(-1.35)$ & $(-3.33)$ \\
\hline irns & $-0.002^{* * *}$ & $-0.160^{* * *}$ & $-0.001^{* * *}$ & -0.055 \\
\hline & $(-5.42)$ & $(-4.08)$ & $(-3.04)$ & $(-1.14)$ \\
\hline quisitions & 0.000 & $-0.226^{* * *}$ & 0.000 & -0.066 \\
\hline & $(-0.01)$ & $(-2.60)$ & $(-0.51)$ & $(-0.75)$ \\
\hline Intensity & $-0.009^{* * *}$ & -0.055 & $-0.007^{* * *}$ & $-0.756^{* * *}$ \\
\hline & $(-4.88)$ & $(-0.34)$ & $(-6.94)$ & $(-4.88)$ \\
\hline & -0.001 & -0.046 & $-0.003^{* * *}$ & $0.275^{* *}$ \\
\hline & $(-0.96)$ & $(-0.37)$ & $(-3.94)$ & (2.25) \\
\hline$Q D$ & $0.015^{* * *}$ & -0.098 & $0.009^{* * *}$ & 0.230 \\
\hline & (8.46) & $(-0.61)$ & (8.52) & (1.46) \\
\hline ancing & -0.001 & $0.137^{* *}$ & -0.001 & 0.108 \\
\hline & $(-1.00)$ & (1.99) & $(-1.29)$ & (1.51) \\
\hline & $0.003^{*}$ & $0.492^{* * *}$ & 0.000 & $0.573^{* * *}$ \\
\hline & (1.96) & (4.17) & (0.06) & (4.91) \\
\hline pdwill & $0.002^{* *}$ & 0.068 & 0.000 & $0.169^{*}$ \\
\hline & (2.26) & (0.91) & (0.37) & (1.84) \\
\hline Restructuring & $0.002^{* *}$ & $-0.241^{* * *}$ & 0.000 & $0.129^{*}$ \\
\hline & (2.43) & $(-3.79)$ & (0.57) & (1.91) \\
\hline
\end{tabular}

This article is protected by copyright. All rights reserved. 


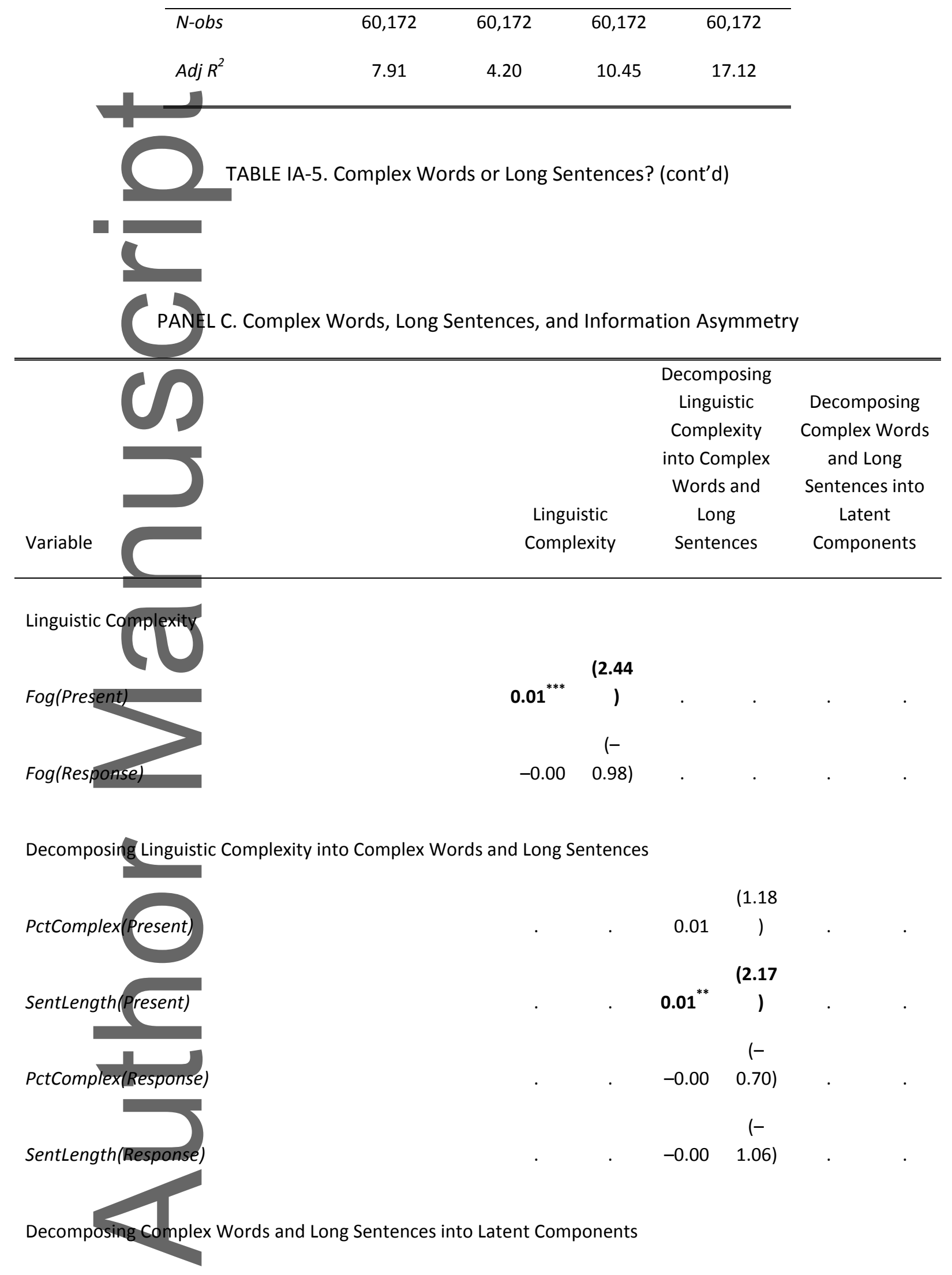

This article is protected by copyright. All rights reserved. 


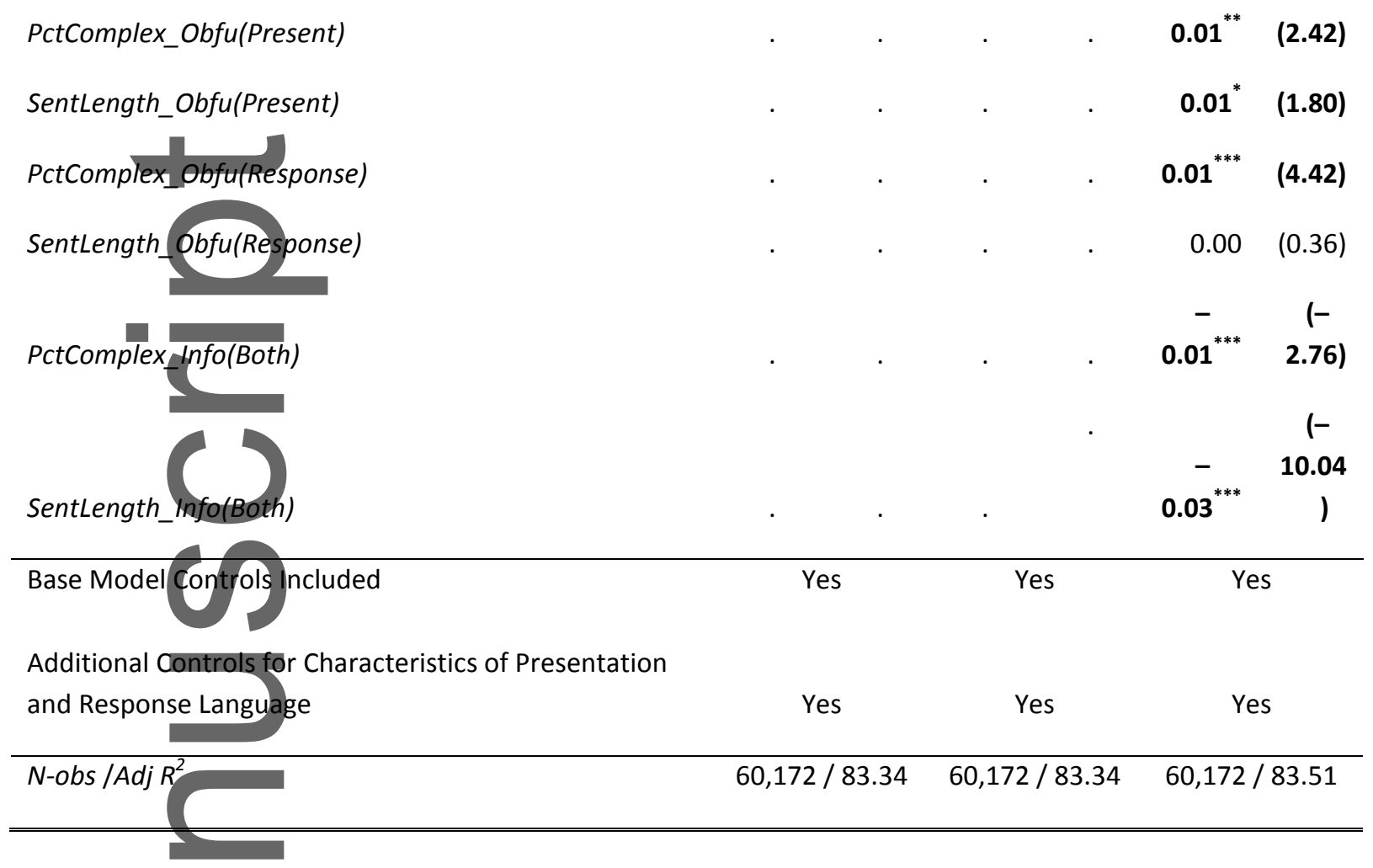

This table presents results from repeating our primary tests after decomposing our measures of linguistic complexity into percentage of complex words and words per sentence. PctComplex(.) is the percent of words that are complex, i.e., have more than two syllables, and SentLength(.) is the average number of words per sentence. Panel A presents descriptive statistics for these variables. Panel B presents results from repeating our analysis in Table 2 using PctComplex(.) and SentLength(.) to measures the linguistic complexity of the presentation and the response portions of the call. Panel $C$ presents results from repeating our analysis in Table 4 after decomposing Fog(.) into PctComplex(.) and SentLength(.), and further decomposing PctComplex(.) into obfuscation and information components, PctComplexObfu(.) and PctComplexInfo(.), and SentLength(.) into obfuscation and information components, SentLengthObfu(.) and SentLengthObfu(.). PctComplexInfo(.) and SentLengthInfo(.) are the fitted values from the regression models in Panel B and PctComplexObfu(.) and SentLengthObfu(.) are the residual values from the regression models in Panel B. Regression specifications in Panel B follow Table 2. Regression specifications in Panel C follow Table 4. $t$-statistics appear in parentheses and are based on standard errors clustered by firm and date. ${ }^{* * *},{ }^{* *}$, and ${ }^{*}$ denote statistical significance at the $0.01,0.05$, and 0.10 levels (two-tail), respectively.

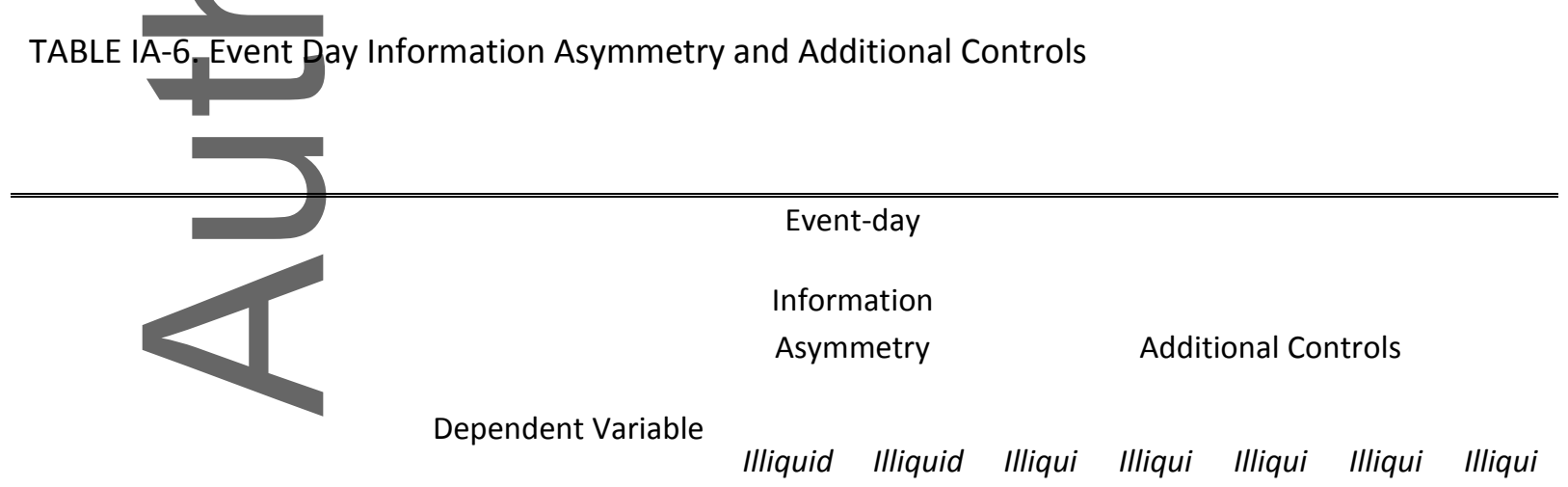

This article is protected by copyright. All rights reserved. 


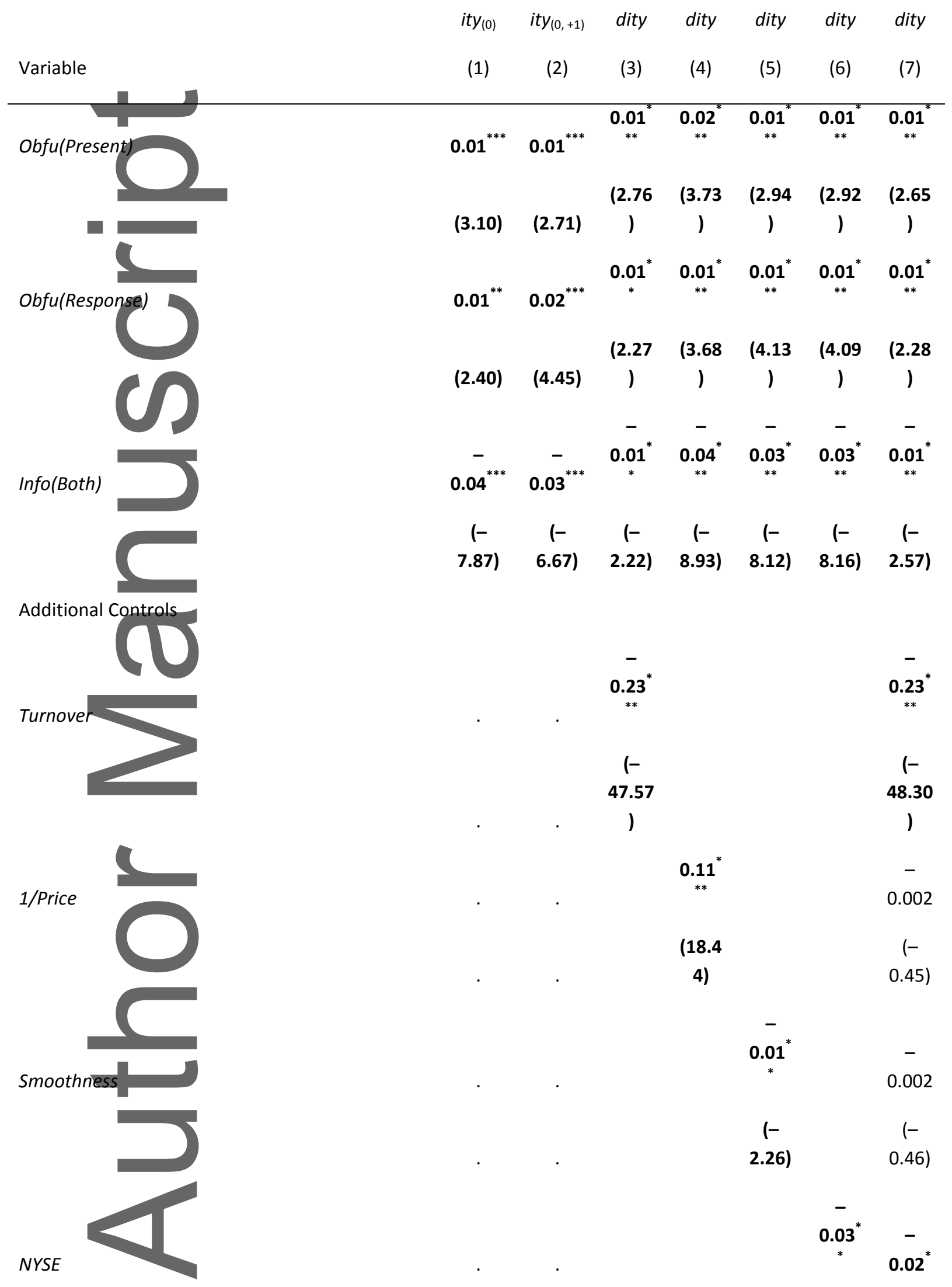

This article is protected by copyright. All rights reserved. 


\begin{tabular}{|c|c|c|c|c|c|c|c|}
\hline \multirow[t]{2}{*}{ NASDAQ } & . & . & & & \multicolumn{3}{|c|}{$\overline{-}^{-}{ }^{*}$} \\
\hline & & & & & & $\begin{array}{c}(- \\
2.08)\end{array}$ & $\begin{array}{c}(- \\
1.21)\end{array}$ \\
\hline Base Model Controls + & Yes & Yes & Yes & Yes & Yes & Yes & Yes \\
\hline Presentation and Response Language & Yes & Yes & Yes & Yes & Yes & Yes & Yes \\
\hline & & & 60,17 & 60,17 & 60,17 & 60,17 & 60,17 \\
\hline$N$-obs & 60,172 & 60,172 & 2 & 2 & 2 & 2 & 2 \\
\hline $\operatorname{Adj} R^{2}$ & 65.11 & 77.47 & 88.26 & 84.33 & 83.49 & 83.49 & 88.27 \\
\hline
\end{tabular}

This table presents results from repeating our tests relating linguistic complexity and information asymmetry using severalalternative specifications. Columns (1) and (2) present results after shortening the measurement window of information asymmetry to include only the day of and after the call. Illiquidity ${ }_{0}$ is the Amihud [2002] measure of illiquidity on the day of the conference call, and Illiquidity $y_{(0,+1)}$ is the average Amihud [2002] measure of illiquidity on the day of and day following the call. Column (3) through (7) present results after including several additional control variables. Turnover is the dollar volume over the prior quarter scaled by market value, 1/Price is the inverse of share price at the end of the prior quarter, Smoothness is the ratio of the standard deviation of earnings scaled by assets over the prior five years to the standard deviation of operating cash flows scaled by assets over the past five years, and NYSE and NASDAQ are indicator variables for exchange listing. Regression specifications follow column 3 of Table 4. $t$-statistics appear in parentheses and are based on standard errors clustered by firm and date. ${ }^{* * *},{ }^{* *}$, and ${ }^{*}$ denote statistical significance at the $0.01,0.05$, and 0.10 levels (two-tail), respectively.

TABLE IA-7. Decomposition of Early versus Late Portion of the Response

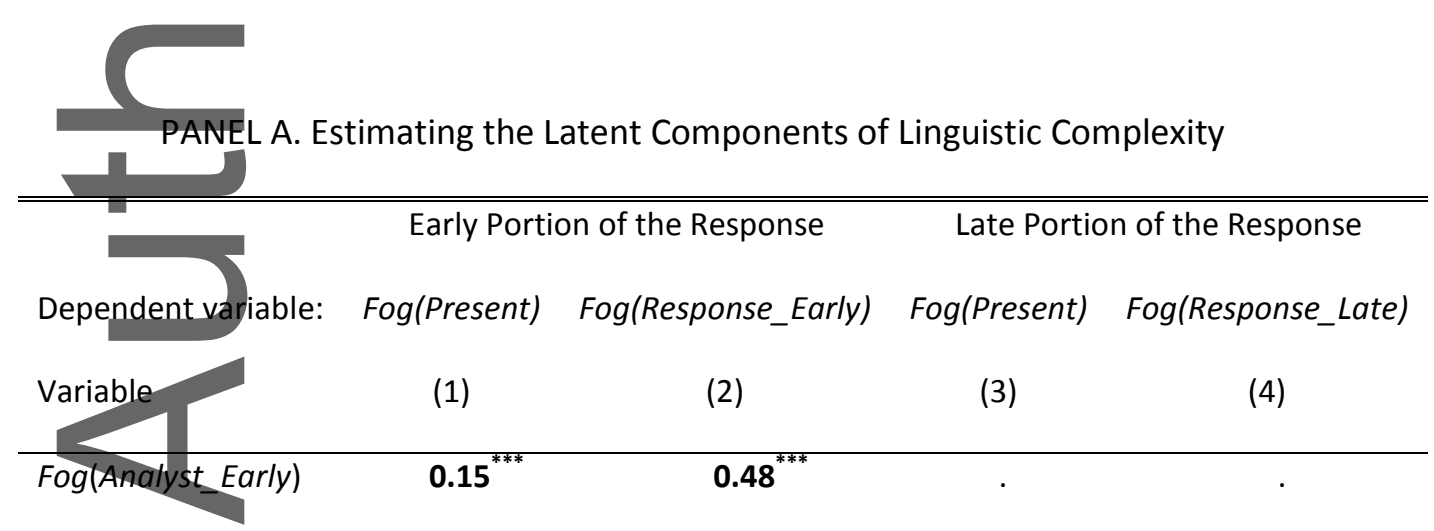

This article is protected by copyright. All rights reserved. 
(16.54)

(56.53)

\begin{tabular}{|c|c|c|c|c|}
\hline Fog(Analyst_Late) & . & . & $0.11^{* * *}$ & $0.42^{* * *}$ \\
\hline & . & & (13.86) & (61.88) \\
\hline & $-0.66^{* * *}$ & 0.09 & $-0.65^{* * *}$ & $0.14^{* *}$ \\
\hline & $(-7.38)$ & (1.33) & $(-7.24)$ & (2.03) \\
\hline & $0.27^{* * *}$ & 0.06 & $0.28^{* * *}$ & 0.06 \\
\hline & (3.40) & (0.96) & (3.52) & $(0.91)$ \\
\hline$B M$ & -0.06 & $-0.17^{* * *}$ & -0.06 & $-0.18^{* * *}$ \\
\hline & $(-0.78)$ & $(-2.75)$ & $(-0.81)$ & $(-3.03)$ \\
\hline & $-0.14^{* * *}$ & -0.01 & $-0.14^{* * *}$ & 0.02 \\
\hline & $(-5.12)$ & $(-0.38)$ & $(-5.21)$ & (1.01) \\
\hline & -0.08 & -0.05 & -0.08 & -0.06 \\
\hline & $(-1.28)$ & $(-0.93)$ & $(-1.25)$ & $(-1.33)$ \\
\hline & $-0.38^{* * *}$ & $-0.55^{* * *}$ & $-0.39^{* * *}$ & $-0.58^{* * *}$ \\
\hline & $(-3.64)$ & $(-6.40)$ & $(-3.68)$ & $(-7.19)$ \\
\hline & -0.06 & 0.06 & -0.07 & 0.09 \\
\hline & $(-0.71)$ & (0.87) & $(-0.90)$ & (1.44) \\
\hline$R \&$ & $0.59^{* * *}$ & $0.33^{* * *}$ & $0.59^{* * *}$ & $0.38^{* * *}$ \\
\hline & (5.63) & (3.74) & (5.60) & (4.49) \\
\hline & 0.02 & 0.02 & 0.02 & 0.02 \\
\hline & $(0.34)$ & (0.45) & $(0.44)$ & $(0.43)$ \\
\hline & 0.29 & $0.21^{* * *}$ & $0.29^{* * *}$ & $0.17^{* * *}$ \\
\hline & (3.60) & (3.30) & (3.67) & (2.87) \\
\hline Goodwill & $0.10^{*}$ & $0.09^{*}$ & $0.10^{*}$ & 0.06 \\
\hline & (1.83) & (1.83) & (1.79) & (1.35) \\
\hline turing & -0.03 & $0.07^{*}$ & -0.03 & 0.05 \\
\hline & $(-0.76)$ & (1.83) & $(-0.65)$ & (1.46) \\
\hline
\end{tabular}

This article is protected by copyright. All rights reserved. 


\begin{tabular}{ccccc}
\hline$N$-obs & 60,172 & 60,172 & 60,172 & 60,172 \\
Adj $R^{2}$ & 6.92 & 16.38 & 6.28 & 16.20 \\
\hline
\end{tabular}

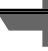
은

PANEL B. Linguistic Complexity and Information Asymmetry

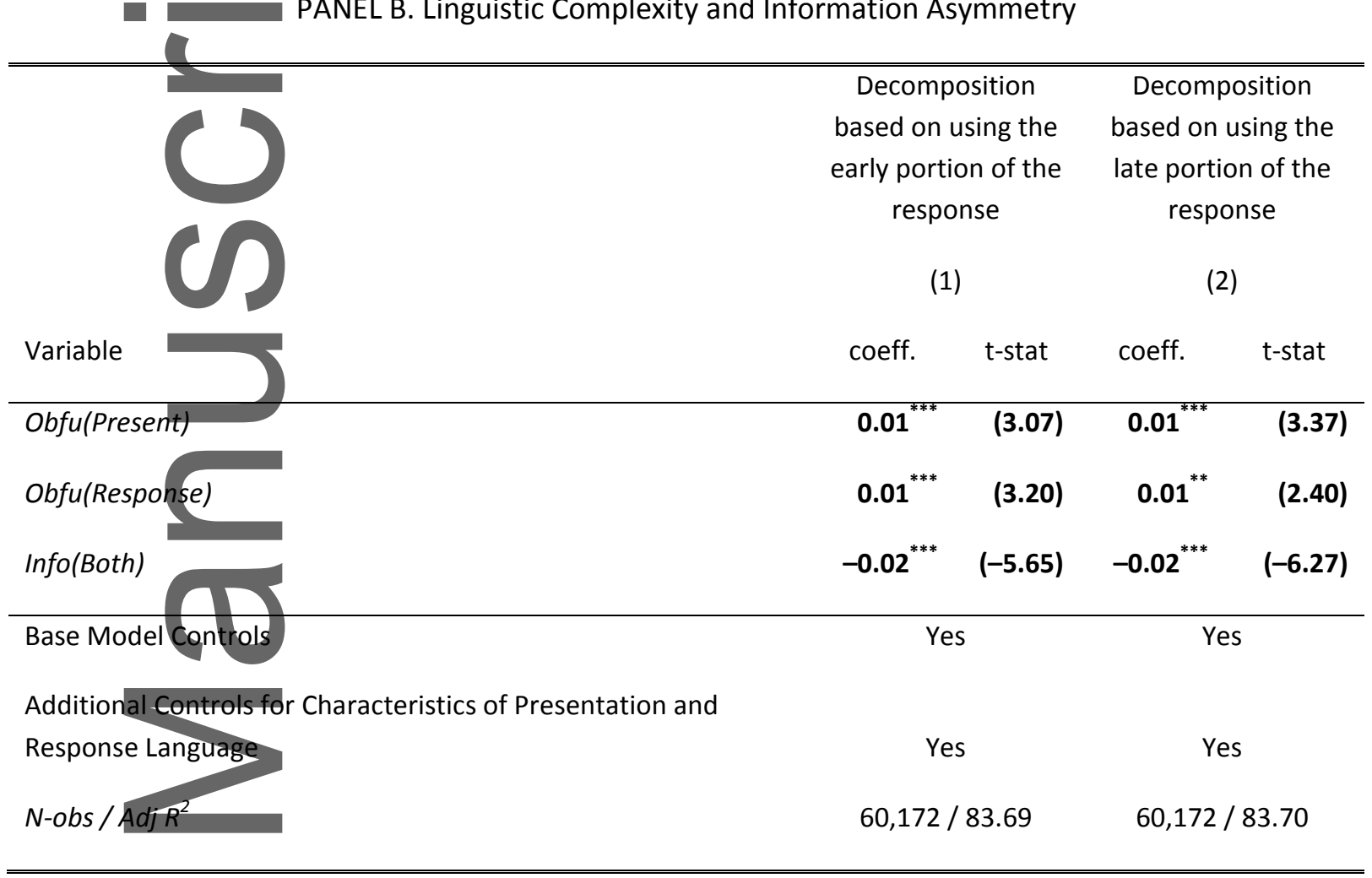

This table presents results from repeating our primary tests after dividing the response section of the call into "early" and "late" portions, and separately decomposing linguistic complexity of these two portions of the response section. The early portion of the response sections (late potion of the response section) is defined as the first (second) half of the response section of the call, based on number of speakers. Panel A, columns (1) and (2), show results from decomposing the linguistic complexity of managers during the presentation and early portion of the response section, as a function of the linguistic complexity of analysts during the first half of the call. Panel A, columns (3) and (4), show results from decomposing the linguistic complexity of managers during the presentation and late portion of the response section, as a function of the linguistic complexity of analysts during the second half of the call. Regression specification in Panel A, follow Table 2. Panel B, column (1), shows results from regressions of information asymmetry on the decomposition of the early portion of the response section. Panel $B$, column (2), shows results from regressions of information asymmetry on the decomposition of the late portion of the response section. Regression specification in Panel B follow Table 4. Fog (Response_Early) is the Fog index of managers during the first half of the response section of the call. Fog(Response_Late) is the Fog index of managers during the second half of the response section of the call. Fog(Analyst_Early) is the Fog index of analysts called on during the first half of the response section of the call.

This article is protected by copyright. All rights reserved. 
Fog(Analyst_Late) is the Fog index of analysts called on during the second half of the response section of the call. All other variables are as previously defined. $t$-statistics appear in parentheses and are based on standard errors clustered by firm and date. ${ }^{* * *},{ }^{* *}$, and ${ }^{*}$ denote statistical significance at the $0.01,0.05$, and 0.10 levels (two-tail), respectively.

TABLE IA-8. Decomposition of FOG calculated as in Li[2008]

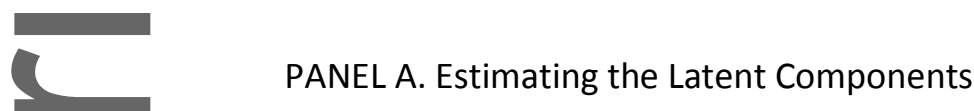

FathomFog(Present) $\quad$ FathomFog(Response)

Variable

(1)

(2)

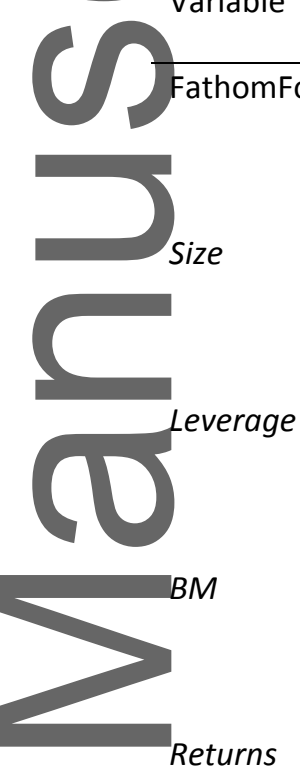

$\begin{array}{ll}0.20^{* * *} & 0.52^{* *} \\ (19.09) & (57.71)\end{array}$

$0.15^{*}$

0.06

(1.75)

$(0.90)$

$0.31^{* * *}$

0.05

(3.99)

$-0.07$

$-0.14^{* *}$

$(-0.99)$

$(-2.48)$

$-0.12^{* * *}$

0.00

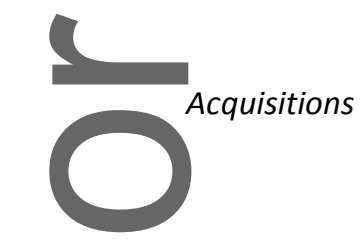

(-4.89)

(0.02)

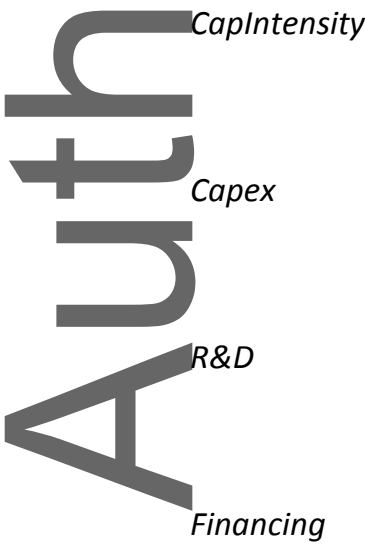

$-0.06$

$-0.07$

(-1.01)

$(-1.54)$

$-0.22^{* *}$

$-0.52^{* * *}$

$(-2.25)$

(-6.61)

$-0.09$

0.05

$(-1.17)$

(0.75)

$0.94^{* * *}$

$0.38^{* * *}$

(9.07)

(4.66)

Financing

$0.09^{* *}$

$-0.01$

This article is protected by copyright. All rights reserved. 


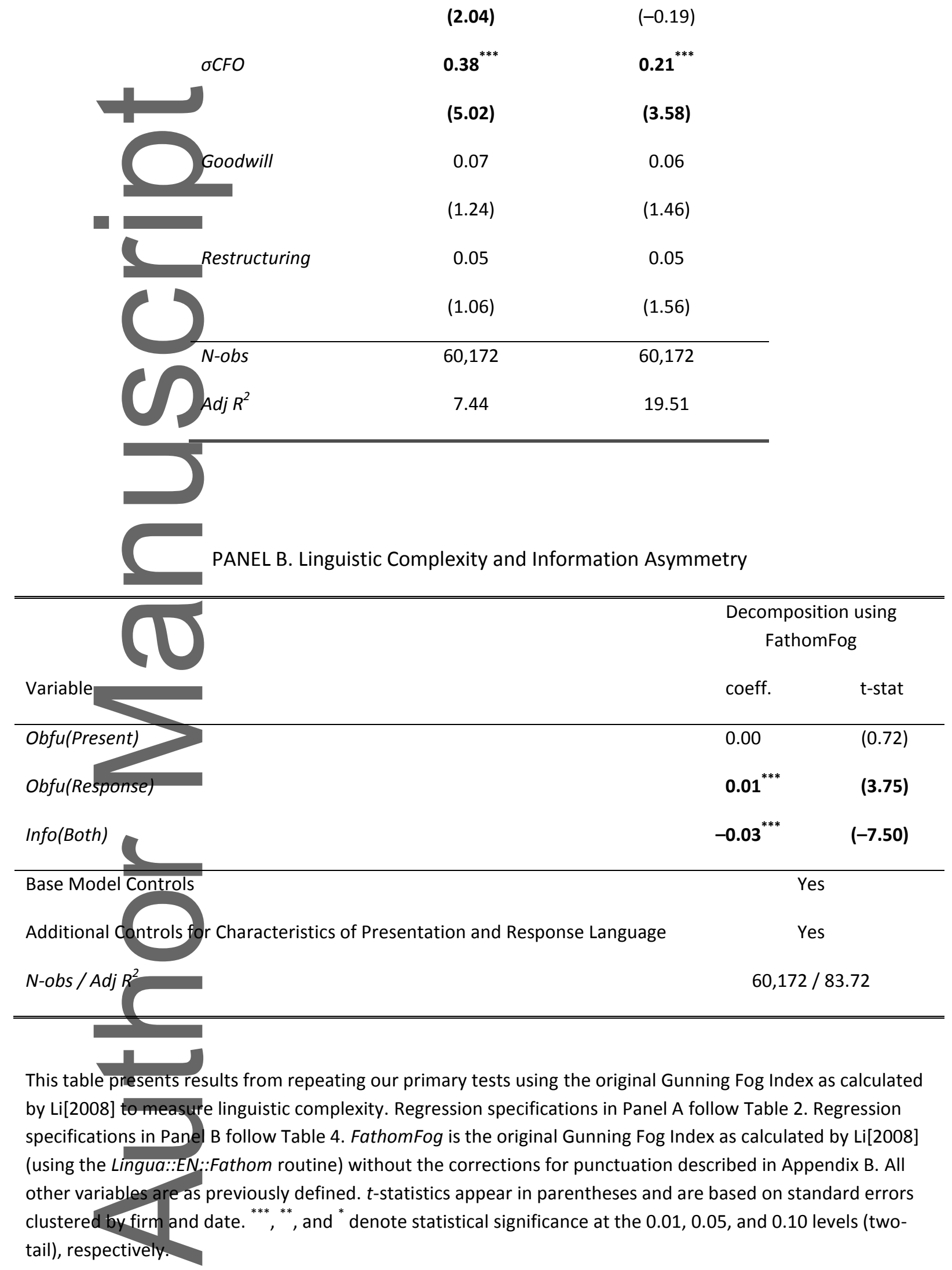

This article is protected by copyright. All rights reserved. 
TABLE IA-9. Alternative Ways to Control for Outliers in Illiquidity

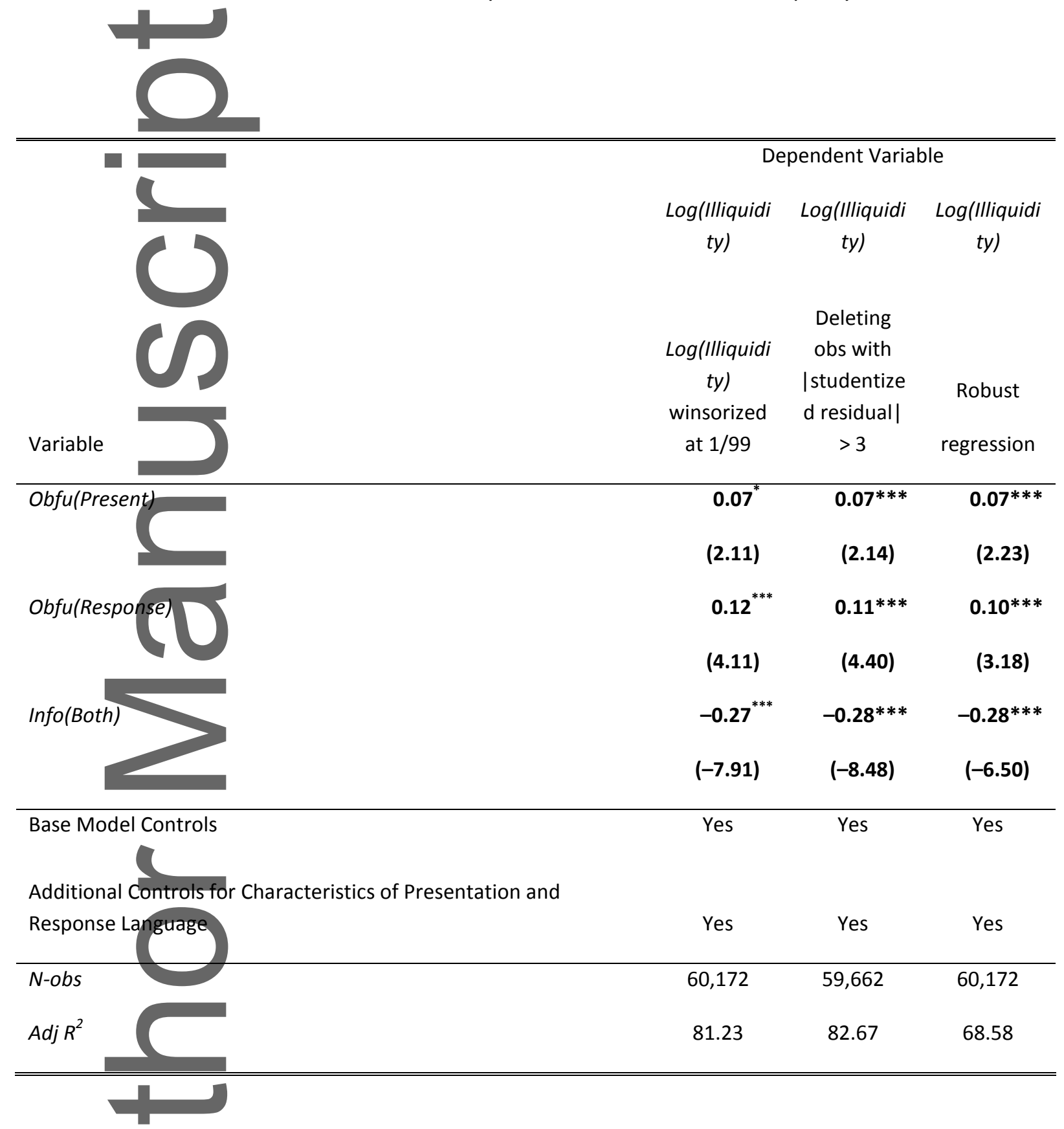

This table presents results from estimating our primary tests using the natural log of the Amihud [2002] illiquidity measure, Log(Illiquidity), to proxy for information asymmetry. Column (1) presents results using Log(Illiquidity) winsorized at the 1st/99th percentiles. Column (2) presents results using Log(Illiquidity) after winsorizing and removing observations with studentized residuals greater than three is absolute value. Column (3) presents results after winsorizing and using robust regression to estimate the regression rather than ordinary least squares. All regression specifications follow column 3 of Table 4. $t$-statistics appear in

This article is protected by copyright. All rights reserved. 
parentheses and are based on standard errors clustered by firm and date. ${ }^{* * *},{ }^{* *}$, and ${ }^{*}$ denote statistical significance at the $0.01,0.05$, and 0.10 levels (two-tail), respectively.

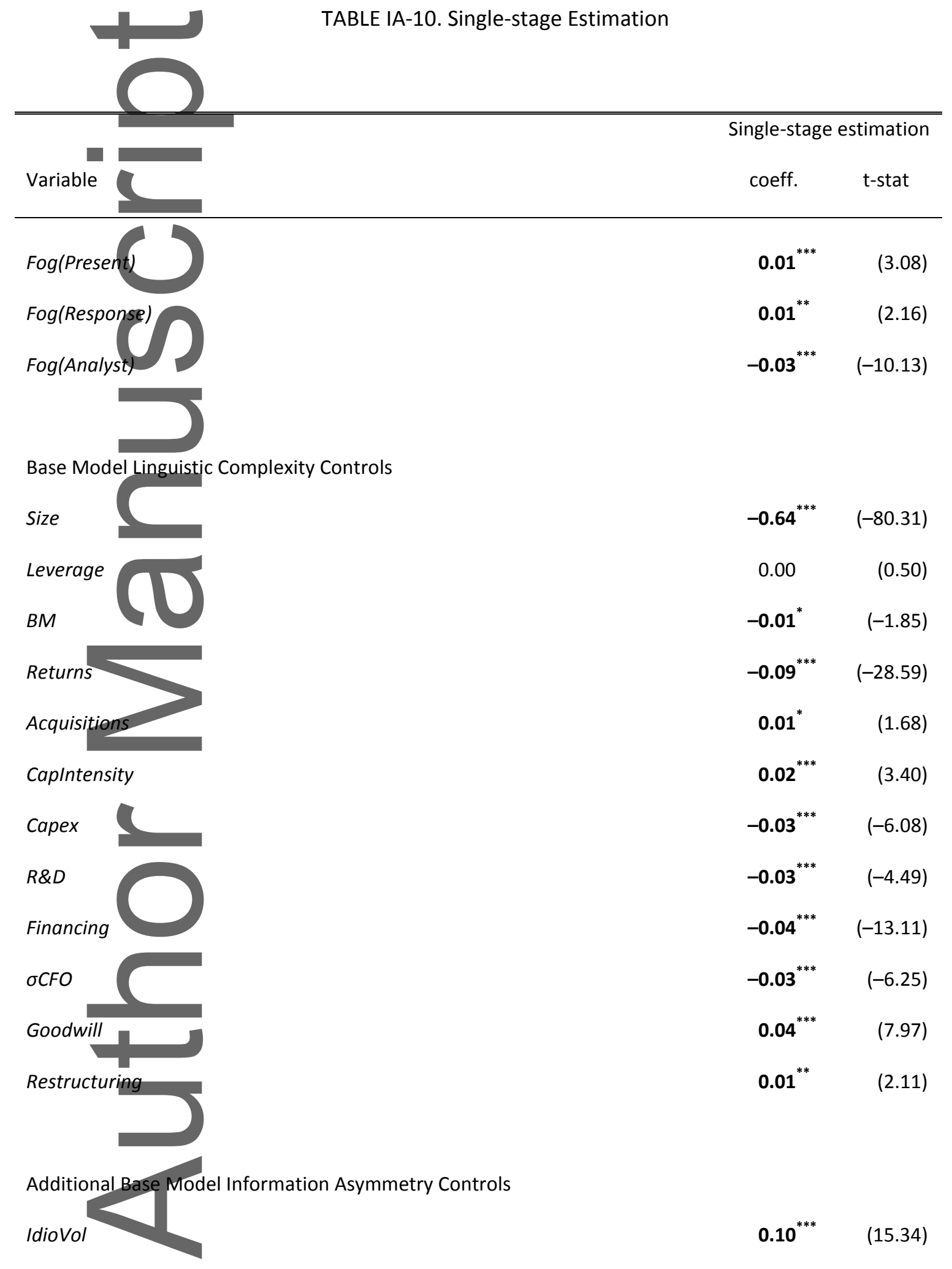

This article is protected by copyright. All rights reserved. 


\begin{tabular}{|c|c|c|}
\hline Coverage & $-0.16^{* * *}$ & $(-25.45)$ \\
\hline Dispersion & $-0.05^{* * *}$ & $(-11.44)$ \\
\hline MgmtFores & $-0.01^{* * *}$ & $(-3.30)$ \\
\hline Surprise & $-0.03^{* * *}$ & $(-14.15)$ \\
\hline Loss & $0.04^{* * *}$ & (13.77) \\
\hline Specltems & $0.01^{* *}$ & (2.37) \\
\hline SmallBe & $0.01^{* * *}$ & (7.64) \\
\hline Length $(P$ & $-0.05^{* * *}$ & $(-5.94)$ \\
\hline Jargon( $P$ & $0.02^{* * *}$ & (3.04) \\
\hline ForwardLo & $-0.01^{* * *}$ & $(-3.04)$ \\
\hline PostiveTon & $-0.03^{* * *}$ & $(-5.24)$ \\
\hline Negative & $0.05^{* * *}$ & (11.19) \\
\hline Length $(\mathrm{R}$ & $-0.06^{* * *}$ & $(-8.33)$ \\
\hline $\operatorname{Jargon}(R$ & $0.01^{* *}$ & (2.09) \\
\hline ForwardLo & -0.00 & $(-0.13)$ \\
\hline PostiveTon & -0.01 & $(-1.36)$ \\
\hline NegativeTo & $0.03^{* * *}$ & (7.01) \\
\hline$N$-obs / Ad & \multicolumn{2}{|c|}{$60,172 / 83.83$} \\
\hline
\end{tabular}

This table presents results from estimating the relation between information asymmetry and the latent components of linguistic complexity using a single-stage estimation that consolidates all control variables from Tables 2 and 4. Because all control variables are consolidated into a single model, the coefficient on Fog (Present) is an estimate of the relation between information asymmetry and Obfu(Present), the coefficient on Fog(Response) is an estimate of the relation between information asymmetry and Obfu(Response), and the coefficient on Fog(Analyst) is an estimate of the relation between information asymmetry and Info(Both) All variables are as defined in Appendix C. For ease of interpretation, all independent variables are ranked into deciles and scaled to range from 0 to 1 . $t$-statistics appear in parentheses and are based on standard errors clustered by firm and date. ${ }^{* * *},{ }^{* *}$, and ${ }^{*}$ denote statistical significance at the $0.01,0.05$, and 0.10 levels (twotail), respectively.

This article is protected by copyright. All rights reserved. 


\section{University Library}

\section{- M M I E R R A A gateway to Melbourne's research publications}

Minerva Access is the Institutional Repository of The University of Melbourne

Author/s:

Bushee, BJ;Gow, ID;Taylor, DJ

Title:

Linguistic Complexity in Firm Disclosures: Obfuscation or Information?

Date:

2018-03-01

Citation:

Bushee, B. J., Gow, I. D. \& Taylor, D. J. (2018). Linguistic Complexity in Firm Disclosures:

Obfuscation or Information?. JOURNAL OF ACCOUNTING RESEARCH, 56 (1), pp.85-121. https://doi.org/10.1111/1475-679X.12179.

Persistent Link:

http://hdl.handle.net/11343/293352 